\title{
Improving the Use of
}

Surgical Suction Pumps in Sierra Leone

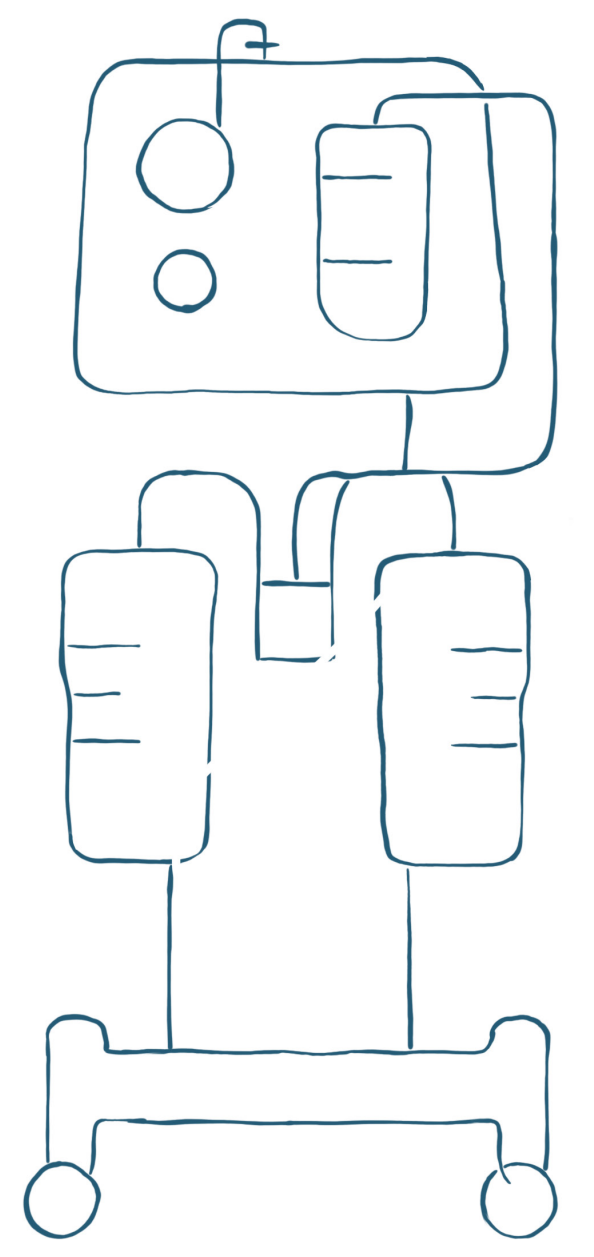

Master Thesis

\section{by}

Asja Mucha

Integrated Product Design

Delft University of Technology

November 2020 


\section{Acknowledgements}

This project concludes my two years as a Master student at TU Delft. These last six month have challenged me to break and build myself up again and discover who I am as a designer and as an individual and discover my passion. The journey was tough, but luckily, I had a great team of people to support me.

First and foremost, I would like to thank my chair Jan Carel for trusting me to do this project. Your drive and commitment have been my inspiration since we first met during AED. Thank you for always pushing me to do better and helping me stay on track.

Next I would like to thank Stefan, my mentor and second project supervisor. Apart from being my mentor you have been an incredible friend to me. Thank you for always being there for every little inconvenience and for teaching me how to trust myself.

This project would not have happened without the amazing team of my client Masanga Hospital.

Firstly I would like to thank dr. Jonathan Vas Nunes and Jesper Winter for introducing me to the problem with the suction pump and encouraging me to take action.

Then I would like to thank Frank van Raaij and Peter Bo Jorgensen for giving me the opportunity to work with Masanga Hospital. Your feedback and enthusiasm were always inspiring.

Most importantly, I would like to thank dr. Jan Henk Dubbink for being my eyes and ears at Masanga, the amazing feedback and for always being one Whatsapp text away. I would also like to thank the nursing staff at Masanga for their incredible devotion in testing the product and the first-hand feedback.

Lastly I would like to thank Titouan from Easy Solar, Sierra Leone for the first hand information on power at Masanga Hospital.

During the project a number of experts in differen fields were involved and helped the development and testing phases of the project.

Firstly, I would like to thank the team of the Applied Labs for providing feedback on my work and sharing their knowledge in the matter. I would mostly like to thank Mascha Slingerland for helping me execute the esting of the final design.

Thanks to the PMB team at the faculty for letting me spend endless hours there and for providing tips.

would also like to thank Julie Fleischer and Jan van Frankenuzen for sharing their knowledge and feedback on 3D printing of medical devices.

This project involved a lot of 3D printing. Thanks to Jordan and Jerry for lending their 3D printers and helping me prototype.

This project would not have been the same without my dear friends Girish Malage and Karl Heinz. Thank you for being my moral and design support and thank you for listening to me talk for hours about the project.

These two years at TU Delft were my first time living and studying abroad.

Therefore, I would like to thank Tara, Magdalena and Maarten for being my family away from home. Having you guys here means the world to me. I would like to thank my dear landlords Martijn and Esther for the home and for the support during the pandemic.

I want to thank Tina, Marek, Melek, Maaz, Atula, and Schao for being the most amazing friend anyone could ask for.

Thank you to all of my life-long friends and family in Macedonia for believing in me and supporting my success, especially my cousin Leni for being there for me every single day, even through Whatsapp.

None of this however would have been possible without the support of my parents and my brother. Thank you for making this experience possible for me, but also for teaching me the right values in life, pushing me do to better and for inspiring me to aim for the stars.

Lastly, I would like to thank you, the reader for taking an interest in this thesis.

Sincerely,

Asja Mucha 


\section{Executive Summary}

In Low-to-Middle-Income Countries more than 95\% of the medical equipment are devices donated by

NGOs, usually second hand, refurbished devices from

High Income Country Hospitals. However, the lack of consumables and spare parts and infrastructural limitations lead to $70 \%$ of that equipment not working, or working improperly shortly after being received.

The surgical suction pump at Masanga Hospital is such an example. The use of the suction pump is hindered

- Lack of consumables and appropriate tubing, leading to a mismatch between the different components

- Frequent power shortages

Therefore, the goals defined for the project together with the client were to

- Solve the dimensional mismatch between the medical consumables and

- power the device independently from the Hospital's solar grid

by leveraging locally available resources and manufacturing opportunities.

\section{Discover, Define, Freeze}

The project was started with a profound analysis of the principles of suction at a HIC hospital, followed by the use and function of suction at Masanga, to better understand the current challenge and Masanga and the envisioned use of the suction pump that the design solutions should achieve.

The research on suction was followed by an extensive contextual analysis. where the gathered insights helped understand the factors that influence the current situation, as well as limitations and opportunities were

The findings were transformed into a List of Requirements and principal design solutions.

\section{Develop}

Various iterations, more than 50 prototypes and an extensive testing protocol were made to achieve the following goals:

- To locally 3D print reusable medical tubing connectors, independently from Masanga's current supply chain and

- To make a conceptual plan for building a portable power-pack based on a $12 \mathrm{~V}$ car battery as the power source to power the suction pump during power shortages

Final Deliverables

- A tested method of 3D printing reusable medical tubing connectors using PETG filament

The connectors were developed through 1. Embodiment Design, 2. Design for Manufacturing and 3. Material choice. The final concept was validated on a TRL level 6.

- A detailed concept plan for building a portable power-pack based on a $12 \mathrm{~V}$ car battery with locally sourced components

Conclusion

The final validation phase and usability testing showed that the proposed solutions would improve the use of the suction pump, while promoting local manufacturing of spare parts and using common locally popular solutions. Both design solutions however still need to undergo testing in the context before applying them. 


\section{Table of Contents}

Acknowledgements

Executive Summary

Table of Contents

Glossary

1. Introduction

1.1 Introduction

1.2 The Client: Masanga Hospita

1.3 Approach

1.4 Remote Research and Stakeholder Analysis

2. Discover

2.1 Challenges of Frugal Innovation

2.2 Use of Suction in High Income Hospital

2.3 Suction at Masanga Hospital

2.4 The Users

2.5 Contextual Analysis

2.6 List of Insights

3 Define

3.1 Definition of subprojects

3.2 System Connect

3.3 System Power

4 Design Freeze

4.1 System Connect

4.1.1 How to Manufacture Them

4.1.2 Stiff or Flexible

4.1.3 Material Choice Considerations

4.1.4 Initial Embodiment Design

4.2 System Power

4.3 Failure Mode Element Analysis

5 Develop

5.1 System Connect

5.1.1 Method

5.1.2 Phase 1: Embodiment Design

5.1.3 Phase 2: Design for Manufacturing
5.1.4 Phase 3: Material Choice

5.2 System Power

6 Deliver

6.1 System Connect

6.1.1 Connector features

6.1.2 Final Design Evaluation

6.2 System Power

7 Conclusion, Evaluation \& Recommendations

7.1 Conclusion

7.2 Project Evaluation

7.3 Recommendation

Reflection

References

\section{Glossary}

LMIC - Low to Middle Income Country

HIC - High Income Country

FDM - Fused Deposition Manufacturing

PLA - Polylactic Acid

ABS - Acrylonitrile Butadiene Styrene

PETG - Polyethylene Terephthalate Glycol

TPU - Thermoplastic polyurethane

OR - Operation Room

BMET - Biomedical Technician

LM3D - Local Manufacturing 3D printing 


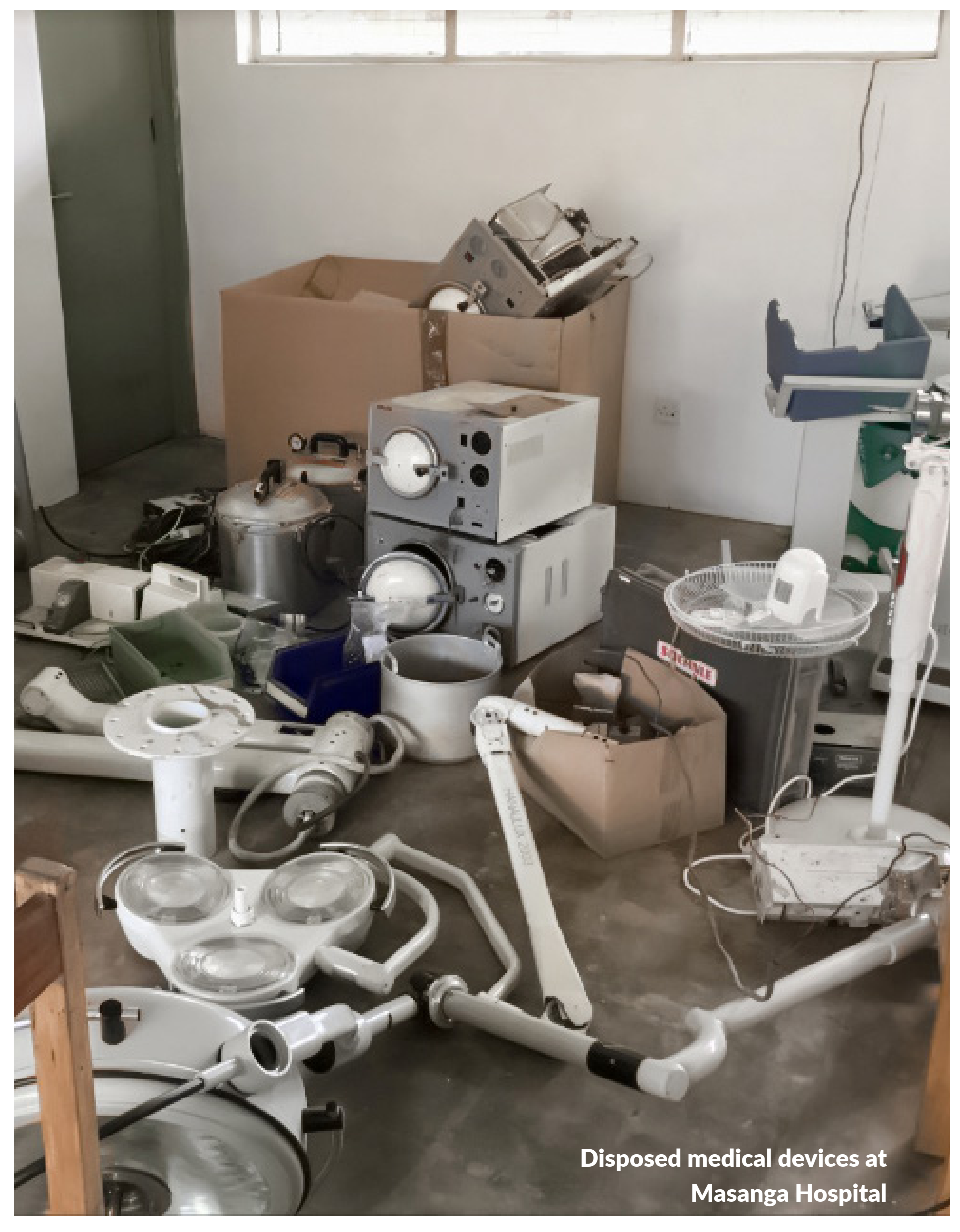

Chapter 1 INTRODUCTION

In this chapter the issues during use of the suction pump and the client are introduced. Following, the approach of the project and the involvement of stakeholders are described. 
In hospitals in Low-to-Middle-Income Countries more than $95 \%$ of the medical equipment is a donation imported from a High-Income country [1]. Non Governmental Organizations (NGOs) are usually the providers of the devices, either new or refurbished, second-hand devices. However, about $70 \%$ of this medical equipment does not work in LMIC hospitals due to lack of trained personnel, limitations with infrastructure, and the lack of spare parts or support for equipment [2] When the staff is not able to overcome these issues anymore, medical devices end up obsolete or discarded, although possibly still functional [3]

Unavailability or lack of medical consumables, together with high cost and lack of spare parts are the three principal limitations to accessible healthcare in LRS [4 5]. Consumables are the accompanying liquids or suplies that are required for use of medical equipment, usually meant for a single use [6]. Like the rest of the medical equipment, consumables are imported from HIC. Devices are usually received with some amount of consumables, but as soon as those are wasted it becomes hard for hospitals to locally obtain more as LRS rarely have medical device industries that locally produce these consumables [7].

Masanga hospital in Sierra Leone is one of the many hospitals facing this situation. Like most LRS hospitals, shortage of consumables is a continuous problem, with things missing almost every day [8]. Their surgical suction pump (Fig. 1) is one of the many devices targeted by this issue.

Suction is a necessary component of almost every surgical procedure, used for removal (aspiration) of blood, gas, tissue or other foreign materials and irrigating fluids that accumb the surgeon's view, by applying negative pressure to create movement of fluids and gases [8]. The use of their suction pump is often hindered by:

- Lack of consumables and appropriate tubing, leading to a mismatch between the different components

- Frequent power shortages

Partnering with Masanga happened after coming in touch with dr. Jonathan Vas Nunes, a tropical doctor from the Netherlands, working at Masanga. Their
METHOD

strong enthusiasm, their vision for constant improvement of healthcare and their facilities, as well as their entrepreneurial spirit inspired me to start this amazing partnership.

Together with the client we set a goal to improve the use of the existing suction pump by designing solutions that would help overcome the issues of mismatching consumables and power cuts and improve the use of the already existing device, instead of designing an entirely new, context appropriate design. This way a new life could be given to an old device, which could potentially become a practice for other devices as well and could contribute to the quality of healthcare provided by Masanga.

This will be done by performing a scrutinized analysis of the local context and resources (both human and material), map out their availability and strategically leverage them to deliver solutions that could improve the use of the suction pump for on the long run.

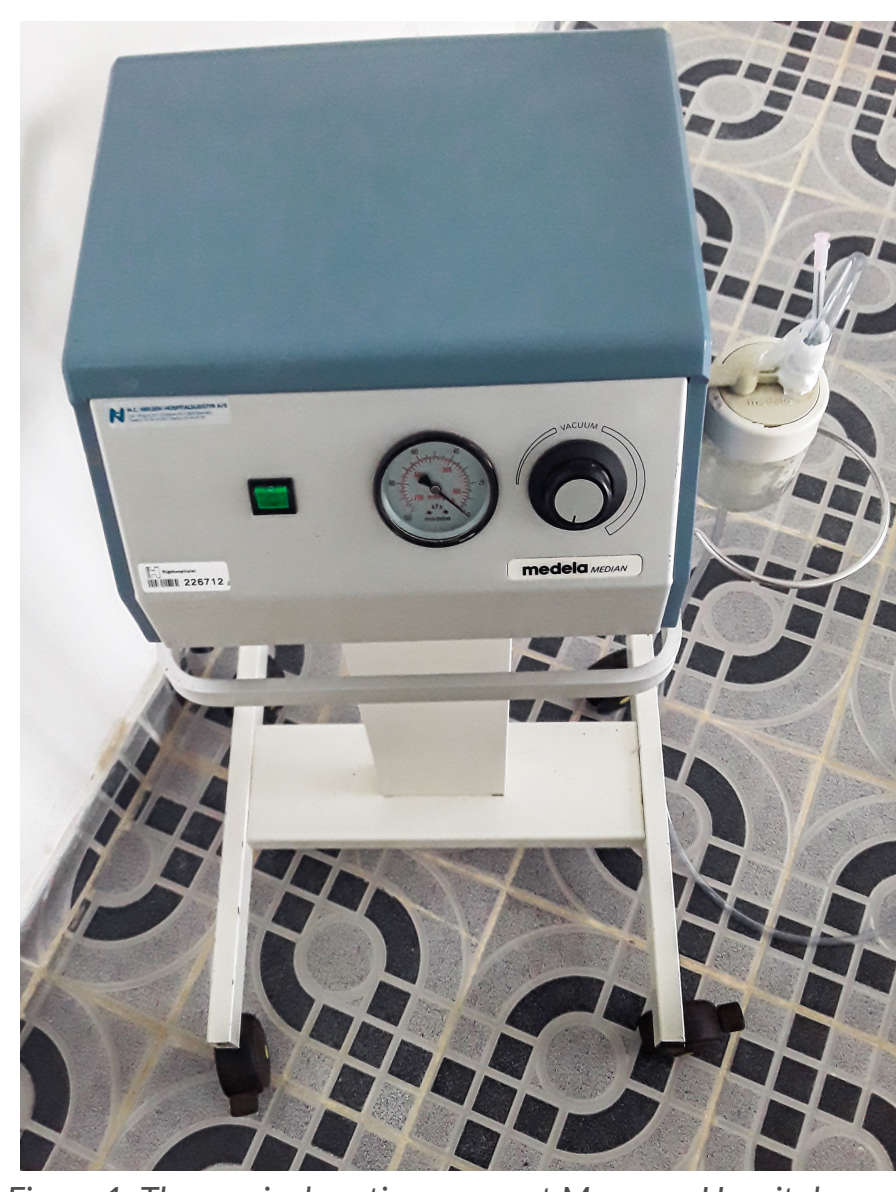

Figure 1: The surgical suction pump at Masanga Hospital
Information about Masanga was gathered through desktop research $[10,11,12,13,14,15]$, semi-structured interviews and informal communication with the staff:

- Jonathan Vas Nunes [16]: Dutch Tropical Doctors a Masanga Hospital

- Frank van Raai [17]: Head of Masanga Netherlands - Peter Bo Jorgensen [18]: Founder of Masanga H

- Jan Henk Dubbink [19]: Medical Officer at Masanga

- Jesper Winther [20]: Former Engineer at Masanga

- Melissa van Gaalen [21]: Clinical Technology Student at 3mE, TU Delft, Former 3D printing student at

Masanga

- Merel van der Stelt [22]: Clinical Technology Student at University of Twente, 3D printing researcher at

Masanga

\section{ABOUT MASANGA}

Masanga is a rural, jungle hospital located in the Tonkolili district in northern Sierra Leone (Fig. 2). The hospital was reopened in 2006 after being almost completely destroyed in the civil war. The reopening of the hospital started the ongoing recovery story. It is an NGO funded, government hospital, supported by NGOs from Denmark, the Netherlands, United Kingdom and Sweden. The recovery story of Masanga relies on three pillars: healthcare, education and entrepreneurship (Fig. 3 )
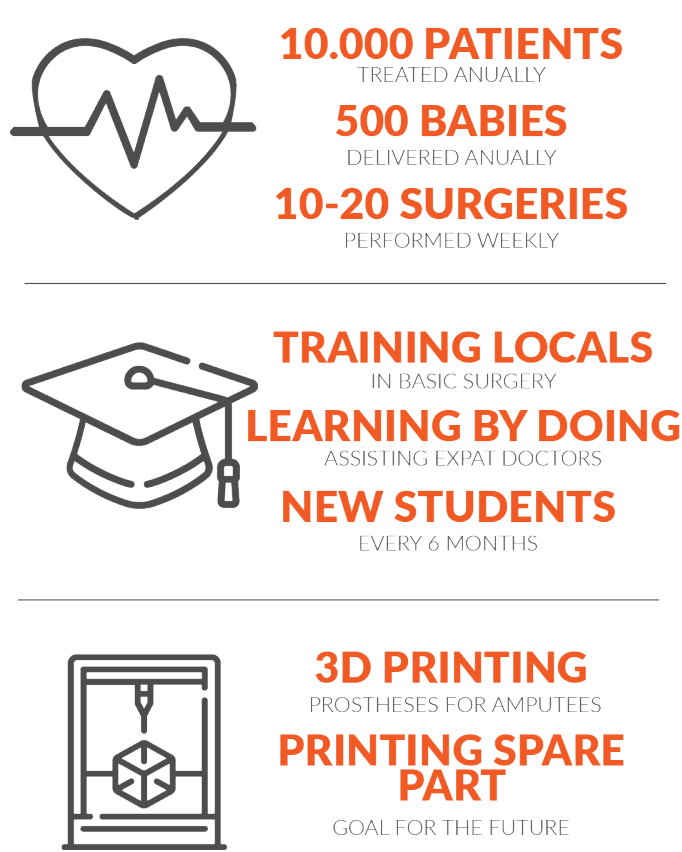

3D PRINTING PRINTING SPARE GART

Figure 3: Three pillars of recovery

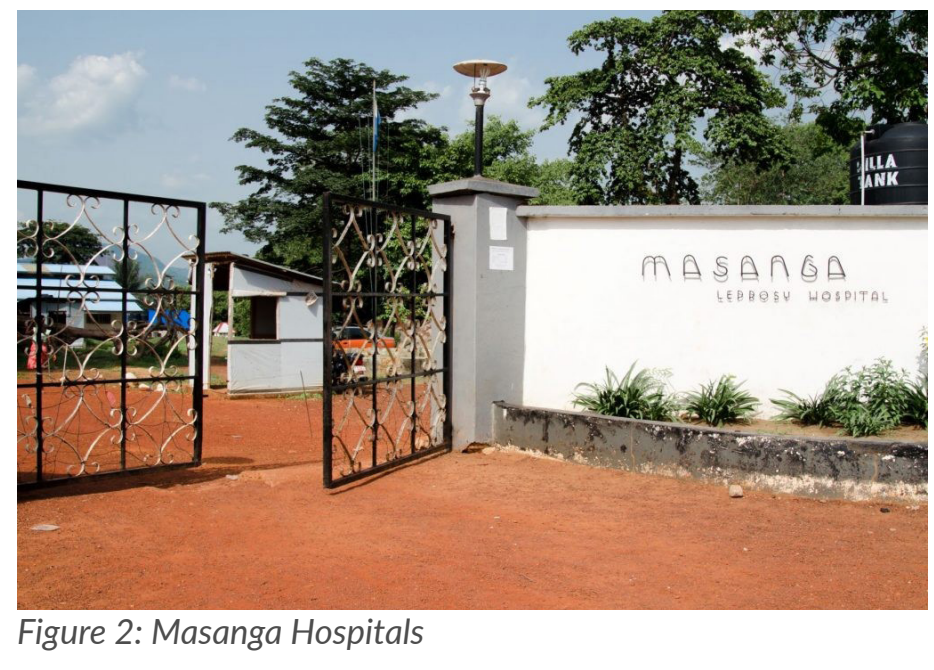

The medical staff at Masanga consists of local staff and expat doctors (Fig. 4). Every two years a new batch of tropical medicine doctors come to Masanga from the Netherlands. The local staff consists of community healthcare officers who are the right hands of the doctors. The clinical helpers are the students of which new batch comes every six months for surgical education and training. The nursing staff is divided among higher trained and lower trained nurses. ICU nurses are not available and the other nurses are overworked and understaffed and often one nurse is responsible for an entire ward by herself.
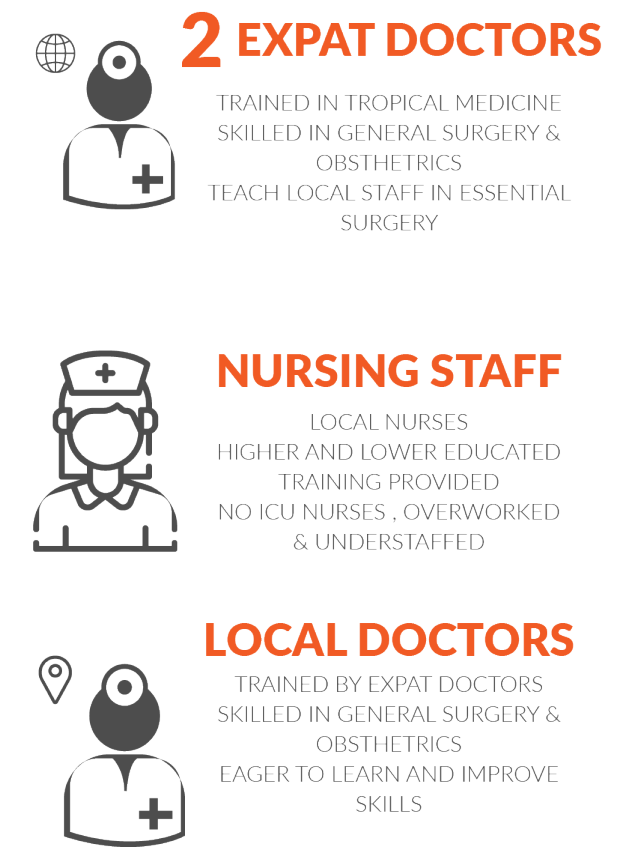

Figure 4: Medical staff at Masanga Hospital 


\subsection{APPROACH} bility of the existing surgical suction pump at Masanga Hospital in Sierra Leone.. The design process of the project was inspired by the Double Diamond approach. The emphasis of this approach is on divergent and convergent thinking, encouraging a deep exploration of the problem and then focusing the actions [9].

Although the process is depicted as linear, in reality the process was iterative and the phases were frequently revisited during the process.

The Discover phase is the start of the project and involves dwelling deep into the problem and understanding all of its aspects. In this project, the main focus is on understanding the device and its use, its components, what is necessary for the system to function properly and what are the issues experienced at Masaga, the
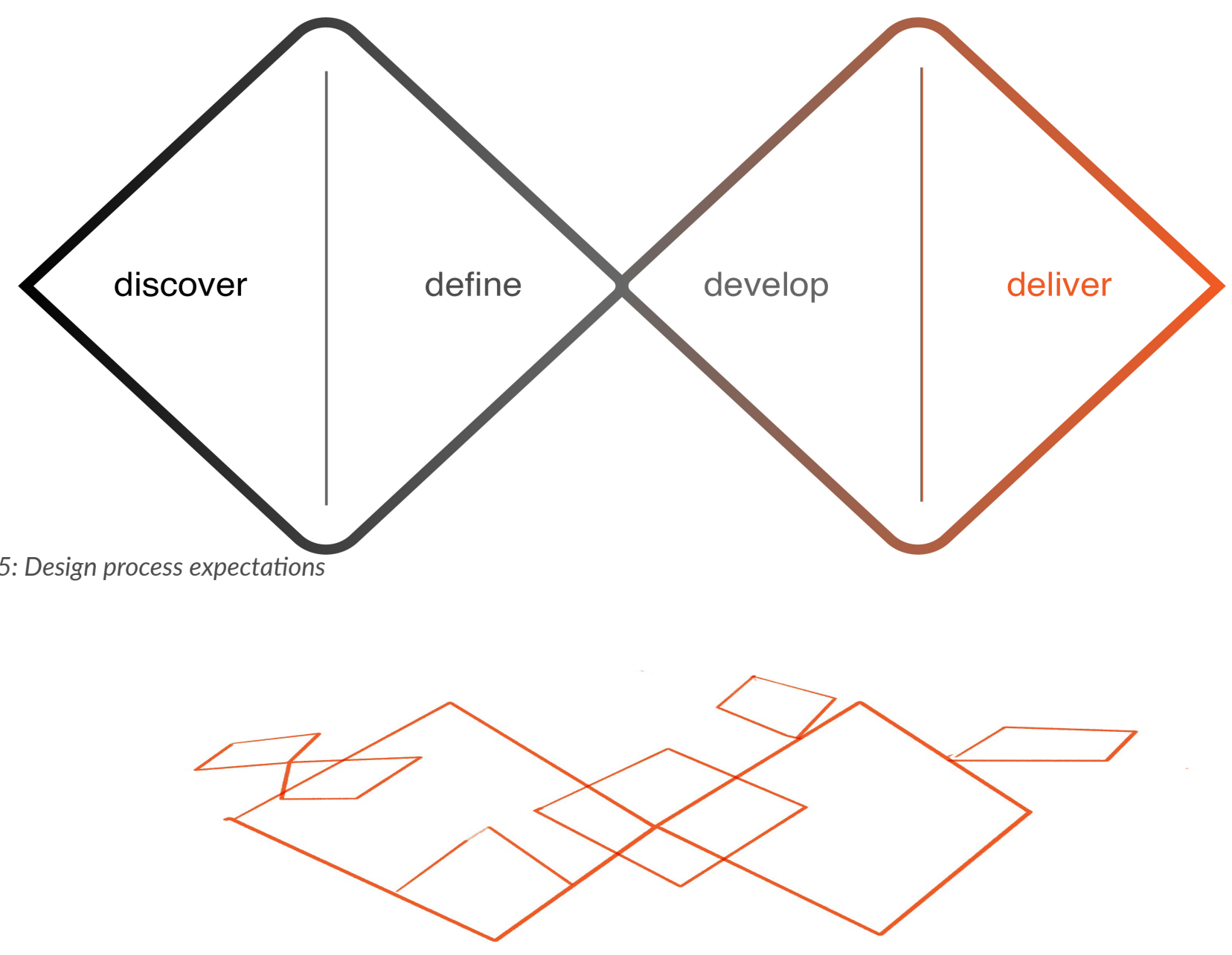

Figure 6: Design process reality (Diamonds everywhere)

Due to the global pandemic, this phase was restricted tal.

In the Define phase the insights gathered in the Discover phase come together to help define the clear problem statement, design vision for the project and the design drivers and requirements, as well as the conDefine phase diverge again to encourage the creation through co-design and seeking inspiration.

The final Deliver phase is where different solutions are tested and the promising ones are further improved. Figure 5: Design process expectations
This project focuses on improving the use and accessi- ties for the design solution and the users of the device. context and its implications, limitations and opportuni-

\subsection{REMOTE RESEARCH AND INVOLVEMENT OF STAKEHOLDERS}

The Develop phase is where the challenges from the of different possible solutions for the same problem

12 Improving the use of surgical suction pumps in Sierra Leone
The project was started during the first wave of the The main contact on the ground during this project was covid pandemic, which made it clear that visits of the raised the importa raised the importance of having a person on the ground who would be the main point of contact and main provider of relevant and correct information about $\mathrm{Ma}$ sanga. Through a stakeholder map (Fig. 4), where the stakeholders were mapped based on their power and interest in the project, it was decided that it is necessary to involve the expat doctors and the local staff in the design process.

\section{Stakeholder map}

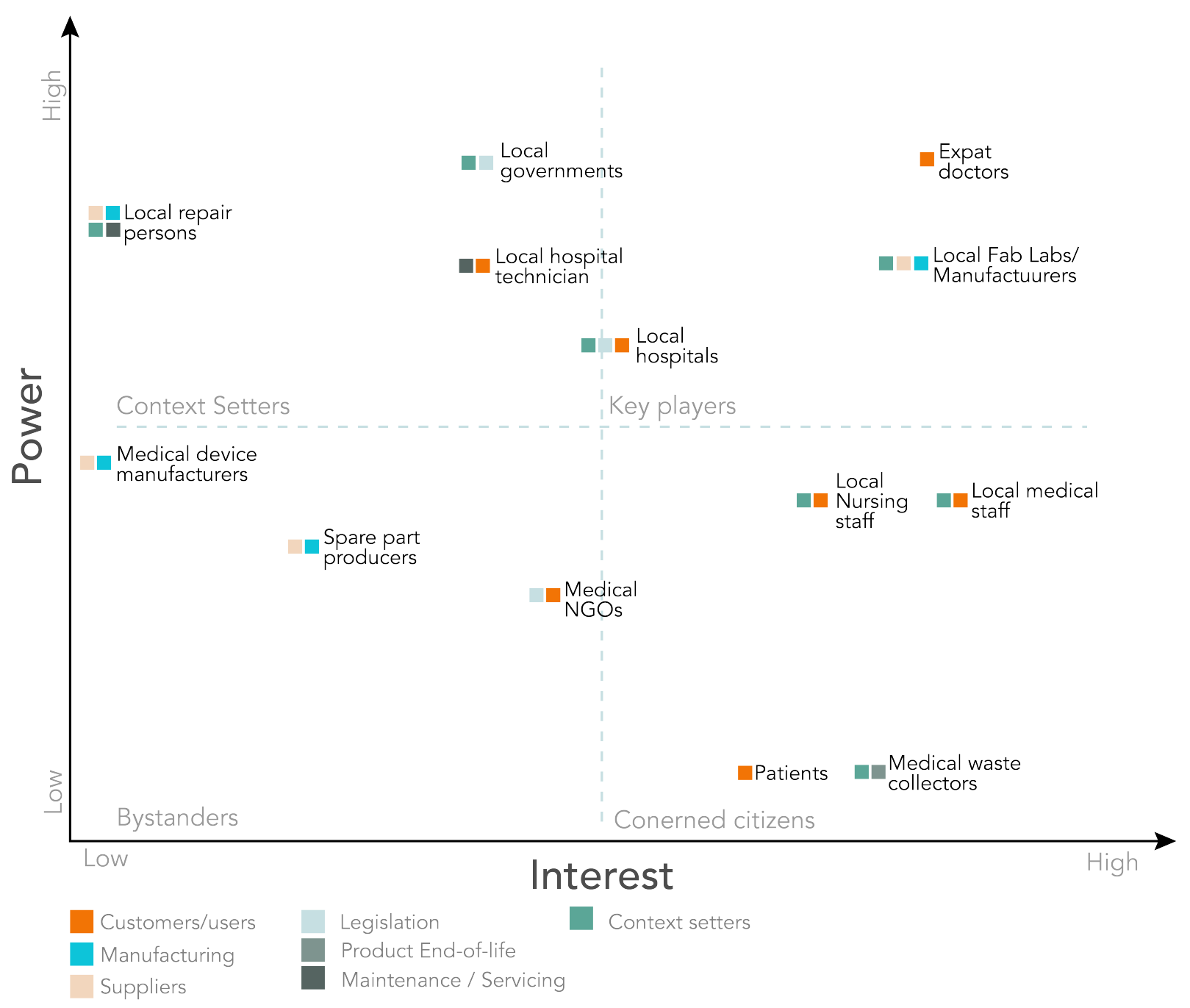

Figure 7: Stakeholder map
Dr. Jan Henk Dubbink a dutch Medical officer at Masanga In the later stages of the project, the local and expat nursing staff were involved in the project as the main players in the use of the suction pump.

The communication happened through video and voice calls, emails and frequent text messaging the updates. 
Chapter 2

\section{DISCOVER}

In the discover phase the research diverged into researching the three main elements regarding the use of the suction pump:

-The device and its use - The artefact's techno-physical system

-The users of the device - Human socio-cultural environment and

- The context of use of the device - Natural environment

Research was done on surgical suction at a HIC hospital for better understanding on the performance that the new design should achieve, followed by analysis of the current state of suction at Masanga.

User research was done to understand what are the implications that the users could have on the final design and how they can be involved in the design process.

The context of use was research to define contextual implications on the current use and limitation and opportunities for future improvement of the use of the suction pump.

This project revolves around the improvement of a medical device in Sierra Leone, therefore, literature research on Frugal Innovation and its principles was done to understand what are the most important factors to keep in mind when designing for healthcare for a LRS. 


\section{DISOCOER}

\subsection{CHALLENGES OF FRUGAL INNOVATION}

Medical innovations developed under resource scarci- whether it fits their current culture or give insights on ty come with a number of challenges. Along with dealing with a complex healthcare system, designing for medical devices is also a rather risk bearing task that comes with a number of precautionary elements [23] that could influence the wellbeing of the patient, the user and the environment of use [24]. The risk levels grow even higher in design for LRS, where resources are scarce and clinical validation is not always possible.

To avoid overlooking a certain factor that could influence the final outcome of the design solutions that are to be developed in this project, a summary was made of the most frequently mentioned challenges of Frugal Innovation encountered in literature.

\section{Method}

Several papers and articles [25, 26, 27, 28, 29, 30, 31] on healthcare in LRS, frugal innovation and contextual design were analyzed. The most commonly encountered factors are presented below.

Influencing factors of Frugal Innovation in Healthcare

\section{Safety Validation}

Primarily, frugal innovations can be developed based on mistaken beliefs and might cause more harm than good. To avoid such incidents, every design solution must be scientifically valued before utilization. What this means for this project is that the final design solution should undergo a lot of testing, remotely and in the field before it is applied for use at Masanga.

Acceptance by staff

Hospitals in both HIC and LMIC have their own individual behavioural cultures and a certain way or protocol in which things are done. Disrupting that culture with the introduction of a new product could lead to the staff disapproving of the product, regardless of how beneficial it might be. Involvement of the staff in the design process and taking their needs into consideration could result in better communication and more relevant feedback on how they perceive the new design solution and

\section{Clean water and power} though the new delivered product is supposed to be in mind environmental factors. Devices donated from

\section{Acceptance by patients}

Although effective and cheap, frugal innovations might not be accepted by the community due to cultural beliefs, stigmas or fear of the unknown. In this project however, the patients have no interaction with the device and most likely would not even be aware of the novelty Therefore the patient factc consideration.

Availability of power and clean water are challenges often mentioned that could influence frugal healthcare innovation Lack of the two could drastically influence the direction of designing if the designed product requires power or clean water in any of the stages of use. Unreliable power is already one of the challenges in this project, which confirms the fact that power availability should be closely monitored to see how it might influence the design.

\section{Maintenance}

Device failure in frugal innovation is common even inexpensive, effective and known. Devices require maintenance and maintenance requires a certain level of skill or knowledge in order to be properly executed. Determining the availability of maintenance staff or skilled personnel that would be in charge of maintenance of the design is important to define in the early stages of the design process to determine whether the proposed solution would last in the field.

\section{Effects on the environment}

Frugal innovation in healthcare is not just about delivering healthcare to those in need, but also about keeping HIC already generate a lot of waste in LMICs, therefore the novel design solution should be developed in a way that would not additionally harm the environment.

Repurposing locally available resources

In the four subtypes of Frugal Innovation by Tran, et. al, how it can be improved to fit them better.

a recurring pattern is the use of existing and available technologies, materials and resources to serve different purpose than intended or as a solution to non-related problems.

\section{Storage}

Storage facilities at LMIC hospitals do not have the same conditions as those in HIC hospitals. Exposure to humidity, dust and excessive heat should be taken into consideration when developing the final design solution. The human factor is also essential as literature, interviews [32] and knowledge from past projects show that the staff in LMIC hospitals is not always particularly mindful of how they treat devices and equipment. Storage conditions should be examined before proceeding with the design.

Disrupted Supply chains

Supply chains in LMIC hospitals are frequently dis rupted by financial limitations, dependence on NGOs

\section{TEST \& VALIDATE}

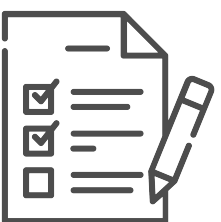

ENGAGE LOCAL STAFF

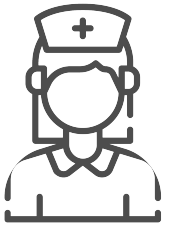

MAP AVAILABILITY OF MAINTENANCE

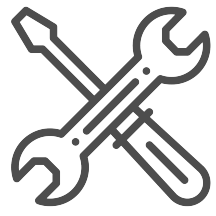

DEFINE SUPPLY CHAIN LIMITATIONS

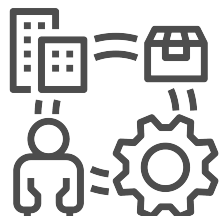

to provide equipment, infrastructural limitations and bureaucracy. These issues could affect: availability of medical equipment and also availability of manufacturing materials or machinery. Avoiding the dependence on these supply chains could aid the future of a design solution by creating a more local, small scale supply chain, with clearly defined actors.

\section{Insights}

Figure 8 shows the factors taken into consideration in this project:
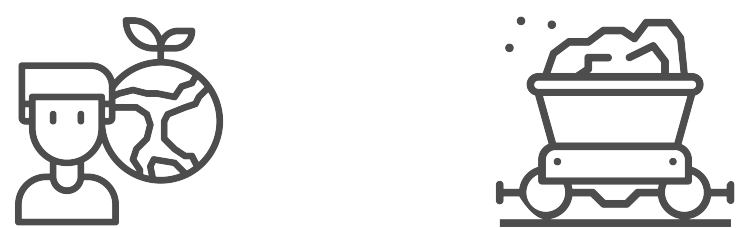


\subsection{USE OF SUCTION IN HIC HOSPITALS}

\section{Method}

Elements of Suction

Literature and desktop research $[33,34,35,36,37,38$, 39] was done on surgical suction pumps to understand how an efficient suction pump system functions at a HIC hospital and how the consumables are used and matched in dimensions.

From the findings a flow chart of the steps of use of the pump was created, (Appendix 1) which was presented to and discussed with surgeons from Leiden University Medical Clinic:

-Dr. Diederich Cornelisse [40]: Manager of OR Center at LUMC

-Dr. Elske Sitsen [41]: Anesthetist and Medical Manager at LUMC

In the interview, every step of the flow chart was analyzed and the doctors showed a demonstration with the components used at their OR. The insights from the interview and demonstrations were then transformed into a Journey Map (Appendix 2) of the use of surgical suction pumps. The Journey Map was used pump to perform (Fig. 9): lected gases and fluids within the system. nectors.
Medical Tubing Connectors

Medical tubing connectors (Fig. 10), also known as fittings are small plastic connectors designed to connect different medical components or consumables such as tubing, collection pots or syringes in various medical applications.

- A suction pump as a source of negative pressure

- A collection pot where the suctioned media is col-

A patient undergoing surgery as a source of biological

The main components are connected by medical tubing that transports the aspirated media from the patient to the pot and a second one that transmits the negative pressure from the suction pump to the collection pot, enabling the process of suction to happen and stay

\section{Use of consumables}

Consumables are disposed of after every surgery and are immediately replaced with new, sterile ones. The persons responsible for the installation and disposal of consumables are the Operating Room Technicians. The consumables are connected with medical tubing con-

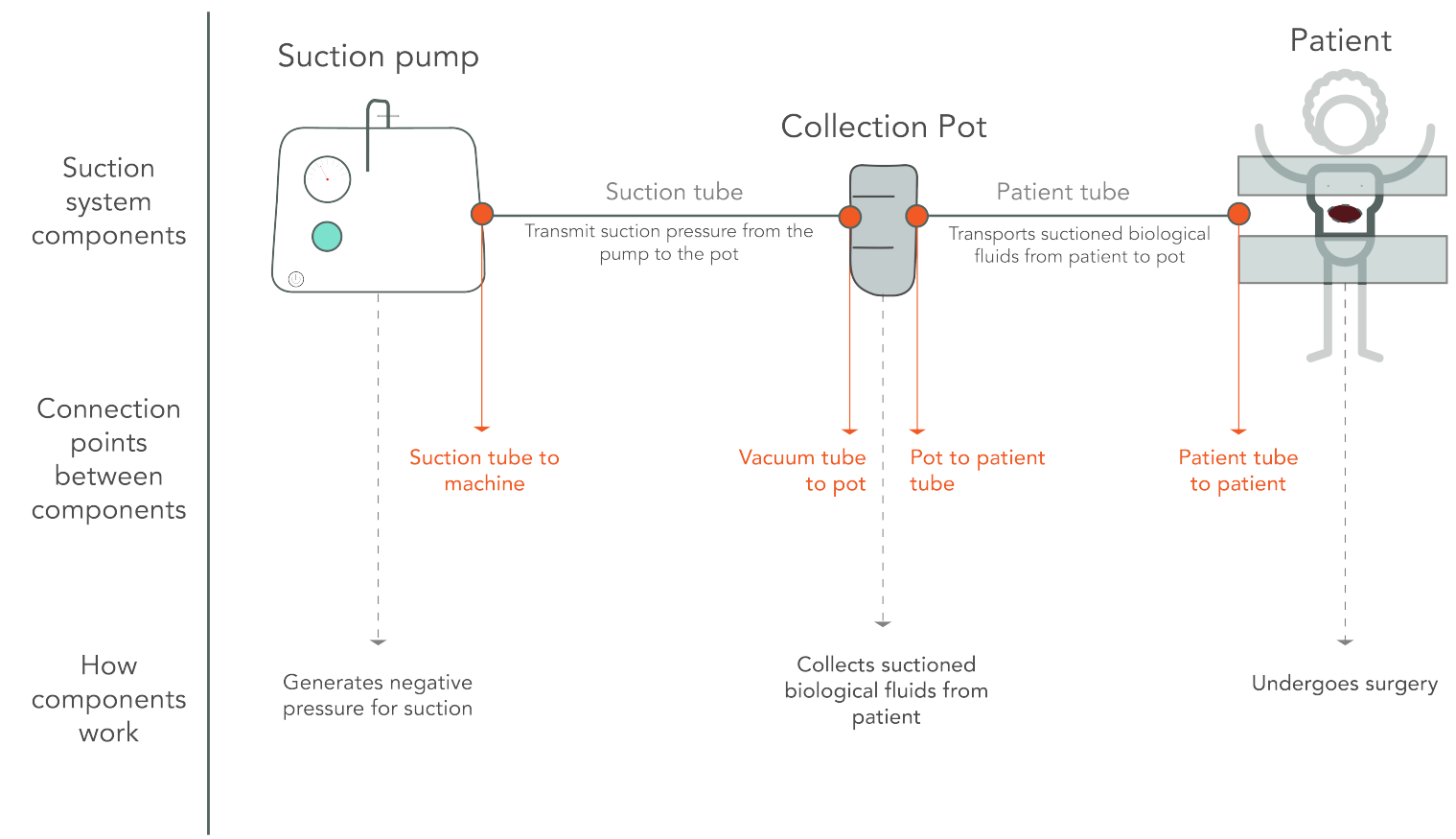

Figure 9: Overview of the suction pump system

Figure 10: Built-in flexible female connector (suction connector) Aside from connecting the consumables, they prevent disconnections, leaks or airflow through potential cracks (Fig. 11). In surgical suction, the connectors are exposed to suction pressure and have biological fluids and gases pass through them.

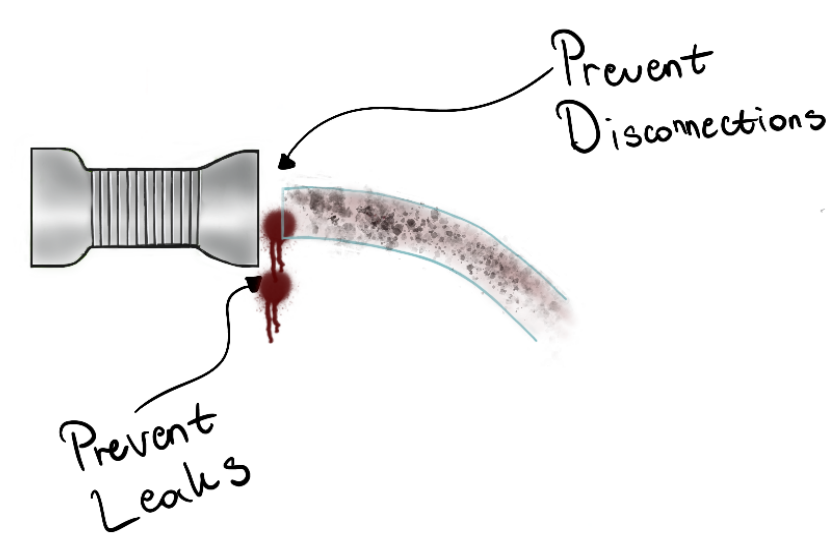

Figure 11: Funnel connector (flexible)

Various types of connectors are available for different applications (Appendix 3). In suction related consumables, barb, flare (Fig. 13) and suction connectors are used.

Connectors can be male or female and in addition to that they can be stiff (Fig. 12) (male connectors) or flexible (Fig. 11) (female connectors). A common practice is to produce the connectors from transparent materials for better observation of the suction flow, but many are also made out of coloured plastics.
The manufacturing method for connectors is injection molding and the most commonly used materials are Polyvinyl Chloride, Polypropylene, Nylon and Polyvinylidene fluoride and Silicones for flexible connectors.

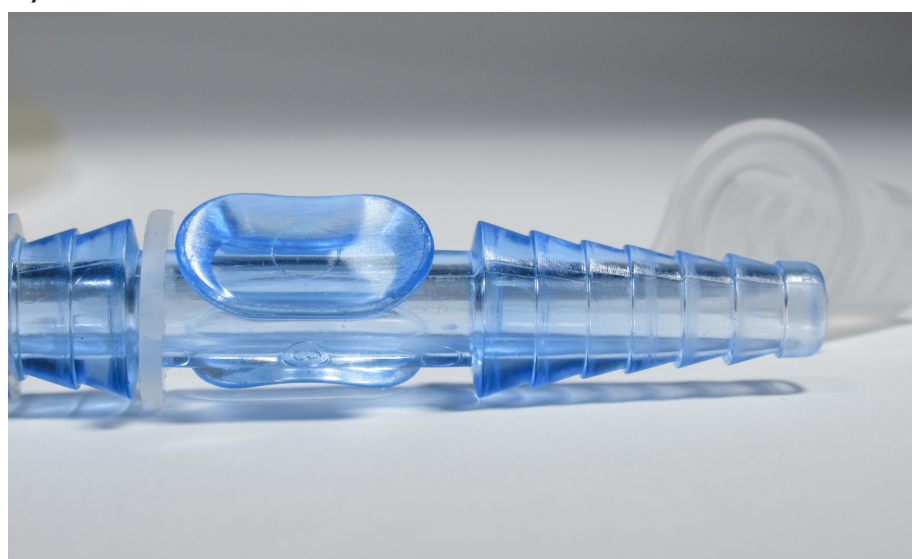

Figure 12: Built-in stiff male connector (barb connector)

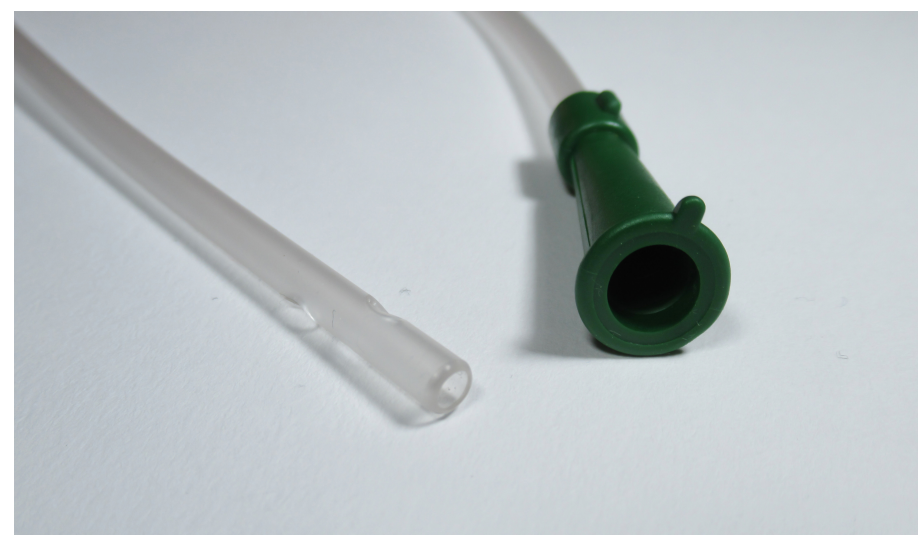

Figure 13: Flare connector (flexible)

\section{INSIGHTS}

- Consumables in HIC hospitals are always disposed after surgery

- Connectors can be stiff or flexible \& male or female

- Connectors must prevent leaks or disconnections to avoid risks 


\subsection{SUCTION AT MASANGA HOSPITAL}

The hospital has two portable electrical pumps available, but the focus of this project will be on their Medela Median pump only, as the second pump was discovered by the hospital staff at the end of the project.

\section{Method}

To understand in detail the use and performance of the pump, an extensive, structured interview was do with Dr. Jan Henk [42] on the use, main
use of consumables of the suction pump.

The gathered information from the interview was transformed into a device journey map (Appendix 4) in which every step taken in the use was identified. For each step (where applicable), pain points were identified as well. For every point, an envisioned performance requirement was defined.

The pain points were divided in: pain points regarding connection of consumables, pain points regarding power and general pain points.

To get a better visual understanding, Jan Henk shared photographs of every connection point, along with the dimensions of every inlet and outlet on the collection pot and the tube diameters of the most commonly used tubes to precisely identify the dimensional mismatch. The findings from the journey map, along with the dimensional specification were then visually mapped to get a more tangible preview of the problem.

Afterwards, the risks of the current use of the pump were defined. Because multiple parties are involved in the use of the device during a surgical procedure, the risks separated under Patient, Staff and Device risks.

To help the reader understand the components and connections in the system, Figure 16 shows an overview of all of the connection points present in $\mathrm{Ma}$ sanga's suction system. Figures 17, 18 and 19 show each connection point and the respective mismatch.

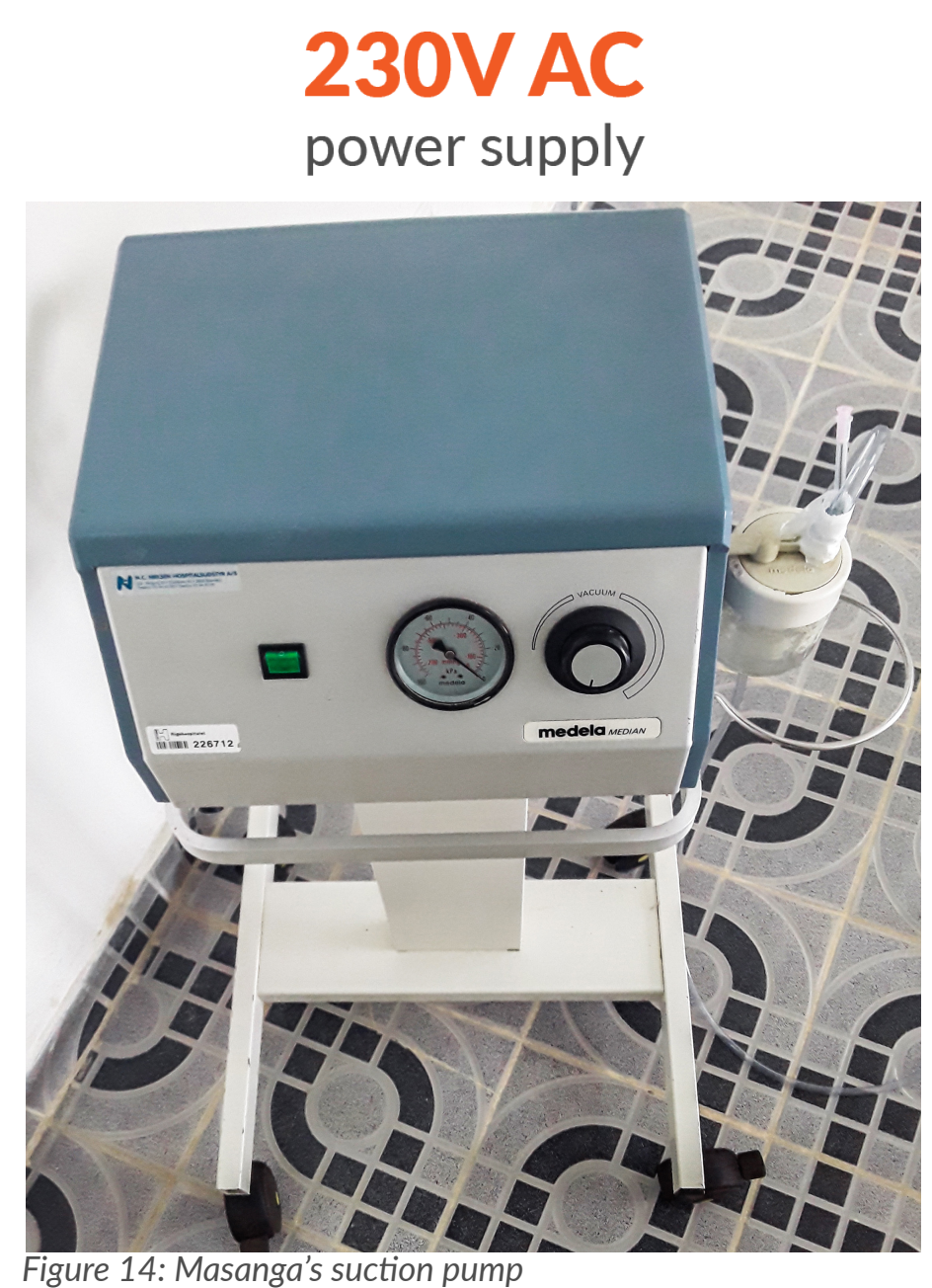

INTERVIEW $\longrightarrow$ JOURNEYMAP $\longrightarrow$ PAIN POINTS $\longrightarrow$ RISKS $\longrightarrow$ REQUIREMENTS Figure 15: Process flow

\section{$638 \mathrm{mmHG}$ negative pressure}

\section{$110 \mathrm{~W}$}

power consumption

\section{VAC}

$\mathbf{2 0}$ Improving the use of surgical suction pumps in Sierra Leone
Summary of pain points

Mismatching, outdated equipment

The pump comes with its custom overflow pot attached to the side of the pump, while for fluid aspiration the hospital has additional collection pots in two sizes: small pots of one liter and big pots of 3 liters. The pots are visibly old and outdated and only a few of them are available for use. The tubes they have are also quite old. According to Jan Henk, their suction tube has been there for a while. The diameter of the suction tube does not fit the outlets on the pots, so the connection is secured with glue tape to make them fit. Tubes are not long enough, so the staff has to connect more of them together to get the right length. Tubing from urine catheters is re purposed for the suction pump as an alternative for patient tubes.
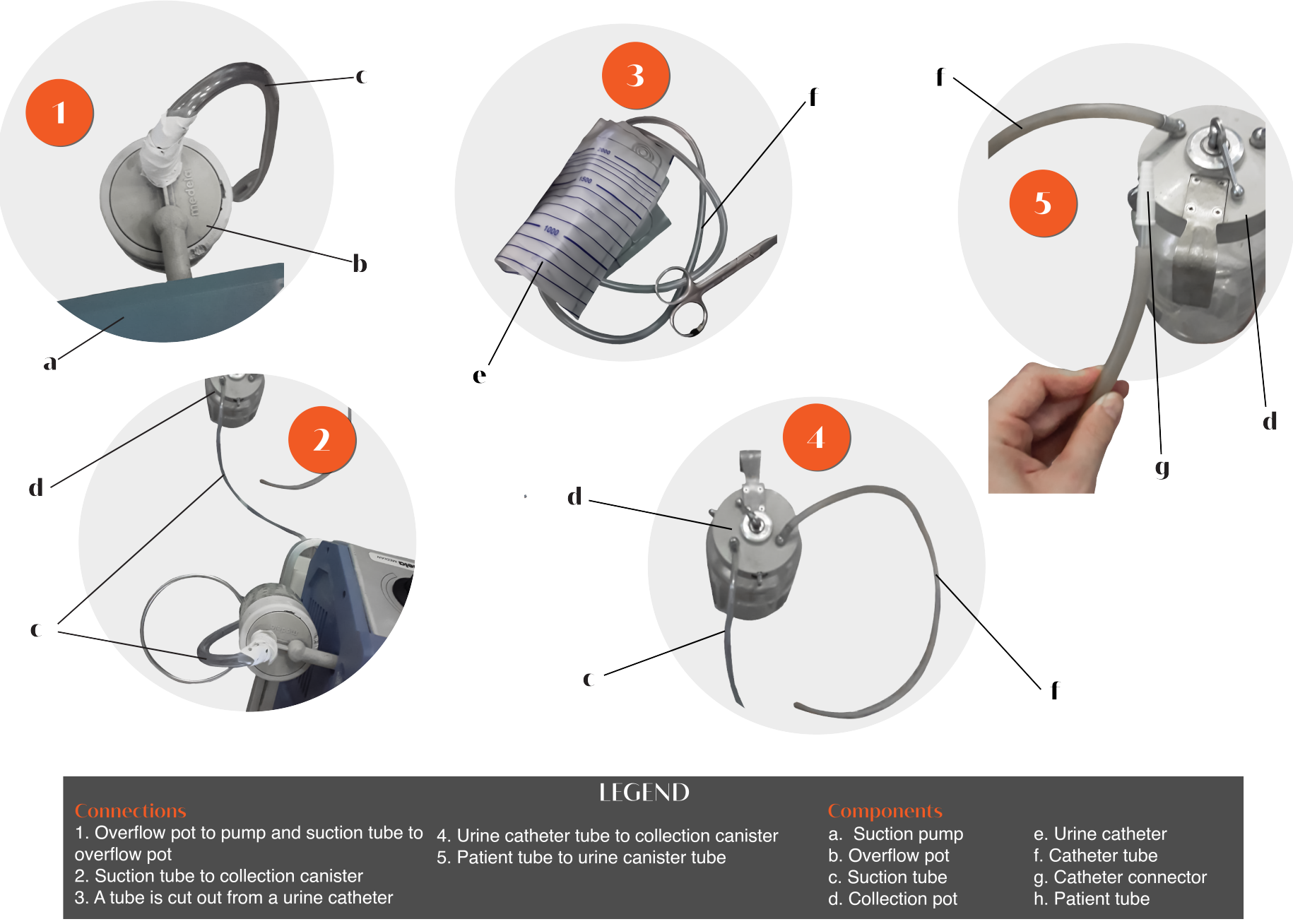

Figure 16: Components and connection points of Masanga's suction pump
Reused consumables

Unlike in HIC hospitals where consumables are immediately disposed of after, at Masanga components are reused. The standard cleaning method is soaking in

\section{Power Shortages}

In cases of power shortages, which could last from a few minutes to a few hours at a time, the pump goes out of function, along with the other devices at the OR. During periods when the generator is at function it would pick up the power after a few seconds. If the generator is out of function, the pump goes out of function as well. 
Point 1:

\section{Suction tube to machine}

¿) contact with patient

(C) Contact with aspirate

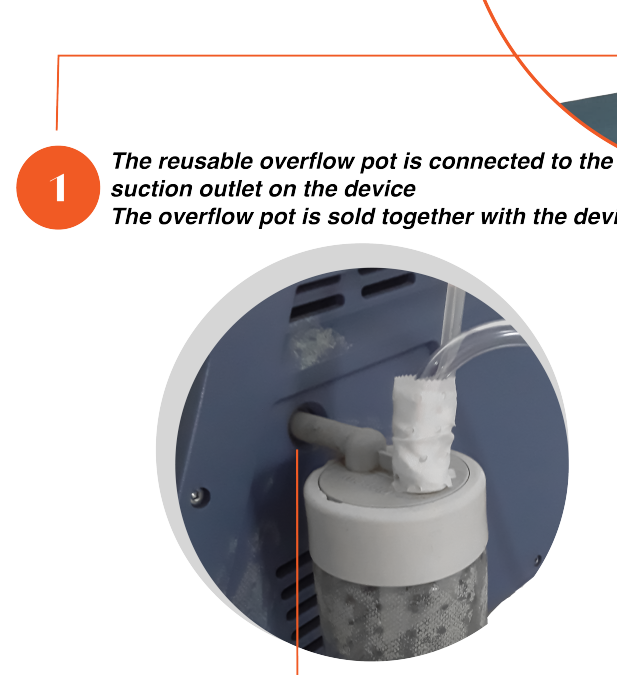

no issues in this

Figure 17: Connection suction tube to machine

\section{Point 2:}

Suction tube to collection pot
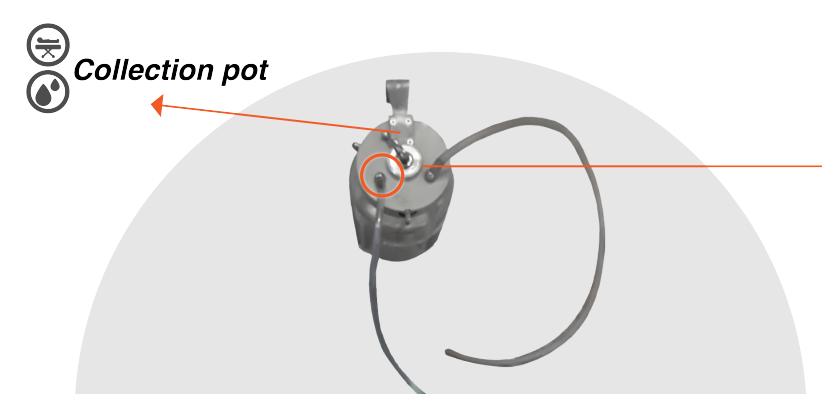

Figure 17: Connection suction tube to machine

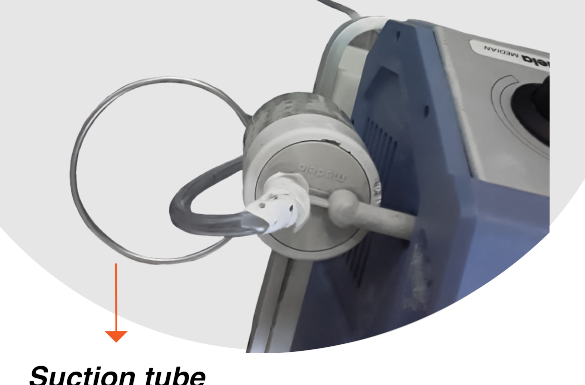

Suction tube

$\varnothing 8 \mathrm{~mm}$
$1=1.5 \mathrm{~m}$

$$
\text { (6) Contact with patient }
$$

DISCONNECTION BETWEEN TUBE

AND CAN CAUSE SAFETY HAZARDS

The reusable suction tube is connected the
suction outtet on the overtlow pot
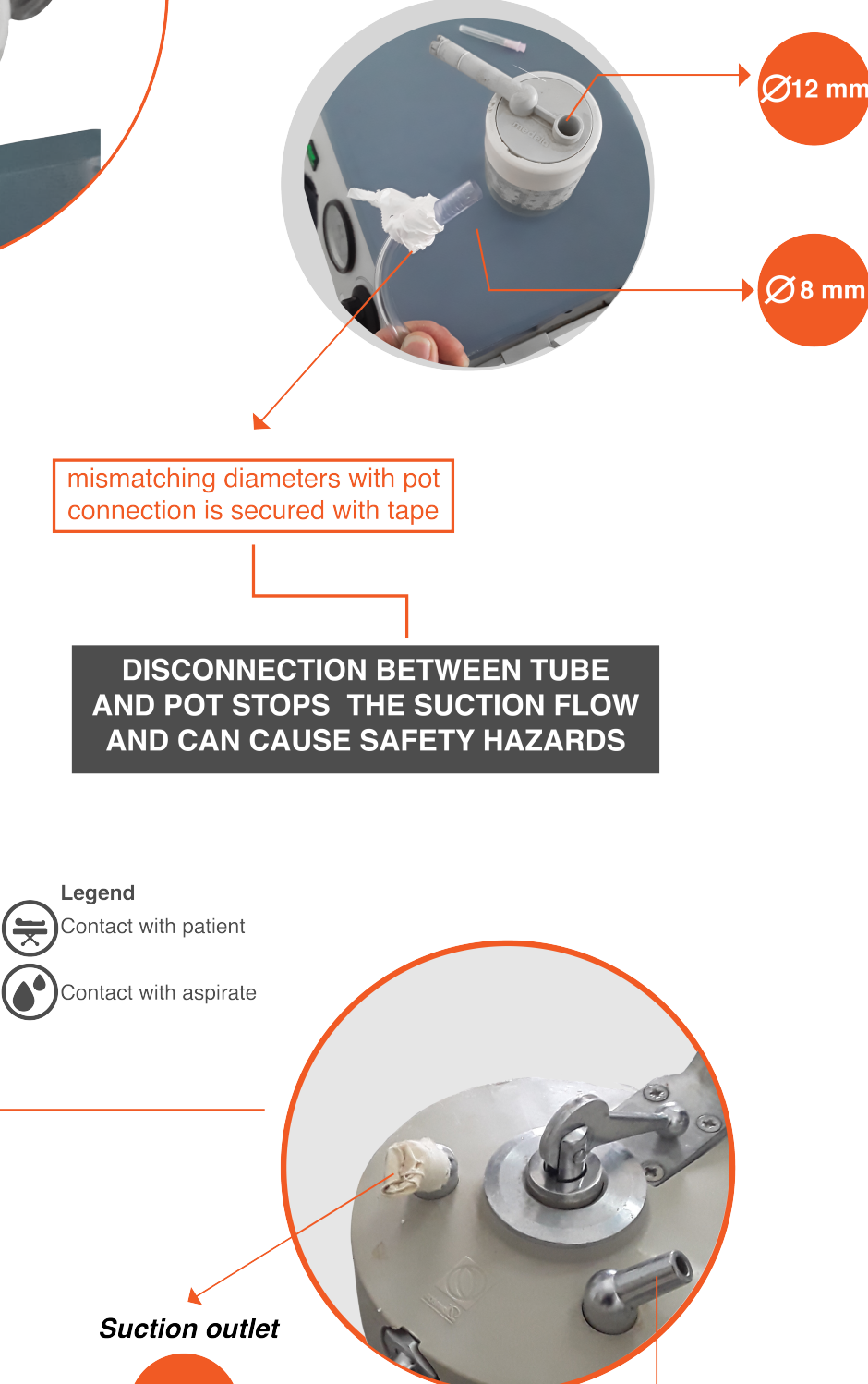

tube does not fit the pot outlet
connection is secured with tape

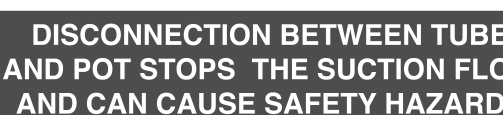

\section{Point 3: Patient tube to collection pot}

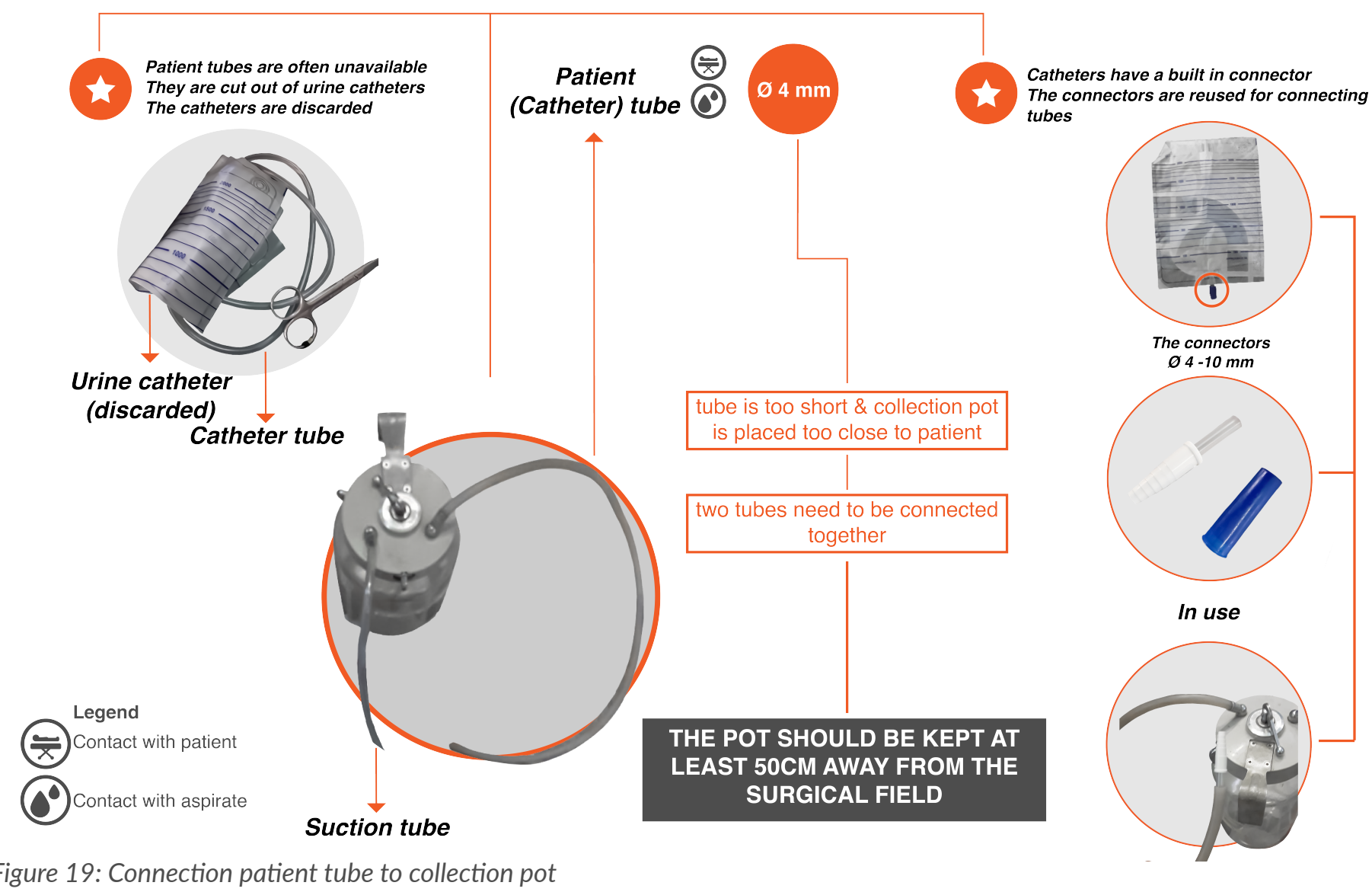

Maintenance

The pump also has not undergone enough maintenance which resulted in lowering of the negative pressure and the flow of the device.

Summary of connection points

As can be seen on the visuals, the use of tape to secure the components has become an imperative at Masanga. This short-term solution is a typical, but not always effective. In a video provided by Jan Henk, he showed an example of an abdominal, postpartum surgery where in the middle of the surgery the suction pump stopped suctioning because the taped connection between the suction tube and the suction pump was loose. A member of the OR staff immediately jumped on fixing the connection, but in between there was a short gap of time during which the suction pump was not operational. 
Patient risks:

A disconnection of one of the tubes can terminate the suction flow, which can lead to an overfilling of the surgical field and obstruction of the view of the surgeon. If the surgical field view is obstructed, the surgeon could do an operative error by not being able to see where they are operating.

In some cases the pump is used to remove fluids or tissue that could potentially harm the patient. If the pump is unavailable, the removal of this media might not be as successful, which could lead to life-threatening health complications for the patient [43].

Reuse of medical consumables that have not been cleaned properly could result in cross-contamination between patients. According to Jan Henk, this is extremely rare as in suction procedures the aspirated media travels in a one-way traffic, meaning that media is only removed from the body, but never injected into the body using the same tubing.

A power outage will terminate the suction flow, with repercussions same as the one identified in the first point.

Staff risks:

A disconnection of one of the tubes can cause leaking or spraying of aspirated fluid in the OR environment. These fluids could be carriers of life-harming pathogens from the patient, which could potentially infect the staff if they come in contact with them.

Leaked fluids on the floor of the OR can also be a cause of accidental injury for the staff.

Device risks:

A sudden power outage could potentially harm the electronics of the suction pump, leaving the hospital without a usable pump

Having these risks identified helps understand the initial safety requirements for the project and helps in understanding what is the intended performance of the pump that should be achieved.

\section{INSIGHTS}

General

- All consumables at Masanga are cleaned by soaking in a chlorine bath and reused after every surgery

- Availability of suitable tubing is limited.

Tubes are repurposed according to need and availability

- The pump does not undergo frequent maintenance which has lowered the power and suction strength

- During power outages, the pump operations stops and cannot be continued

- Collection pots are outdated with outlets that are incompatible compared to the ones on the tubes resulting in leaks and disconnections

- The tubes are not long enough which requires unsterilized components to be placed close to the sterile operative field and can pose a hazard. This is again a result of the unpredictable availability of the right com

- A loose connection could lower the suction flow and the performance of the pump
Risks

- Lowered or terminated suction flow puts the patient's wellbeing at risk

- Disconnections between components could cause contamination from the patient to the staff

- Leaks in the system could put the staff and the patient at risk

- Power cuts could harm the patient and the device itself

\subsection{THE USERS}

The nursing staff is in charge of preparing the device for use and taking care of it after use. They aredivided among higher trained and lower trained nurses. ICU nurses are not available and the other nurses are overworked and understaffed and often one nurse is responsible for an entire ward by herself.

As stated in chapter 2.1, research showed that the user level of LRS design is much more complex compared to the technical and economic aspects, which is suspected to be a result of difficulty of collecting meaningful quantitative data on what the users want or expect from the design. Many examples exist of a lack of acceptance of medical products or solutions due to social stigmas or fear, despite their obvious healthcarebenefits.

According to Jan Henk they all have a sufficient skil level of operating surgical devices and are always eager to learn new things that they do not know and become better. Additionally, during medical procedures there is always a surgeon present in the OR to monitor the lower levels of staff and make sure that everything is under

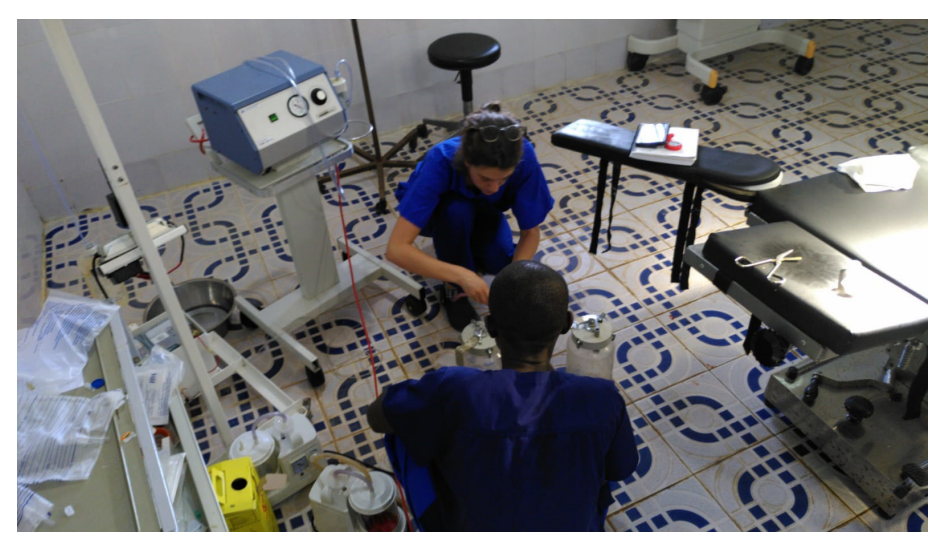

Figure 20: Nurses Emily and Aliue helping develop a solution control and safe. Therefore, even though the training of staff in LRS is perceived as challenging, the many educational examples from Masanga allow for

assumption that training the staff to use the device should not be perceived as a setback. Most important$y$, the designed solution should help the staff be more efficient and lower the time needed to install the suction pump system. 


\subsection{CONTEXTUAL ANALYSIS}

\section{Method}

Context is defined as the "aggregate of factors that influence the use of medical devices" [44] taking into consideration the organizational structure of the healthcare facility, the supplying of devices and the expectations for a device by the healthcare staff [45]. When designing for LRS it is essential to look at the broader context of the target country and the conditions for future implementation of the device (standards and policies, intellectual property, export/import) [46] to avoid neglecting crucial, defining factors.

Because the project is situated at a specific hospital, and the product is used at a particular location within the hospital, a more detailed establishment of the context was necessary. Therefore, I further defined the context on three geo-spatial levels:

- Sierra Leone, the country context of the project - Masanga Hospital, the device's operational environment

- Operation Room, the device's immediate environment

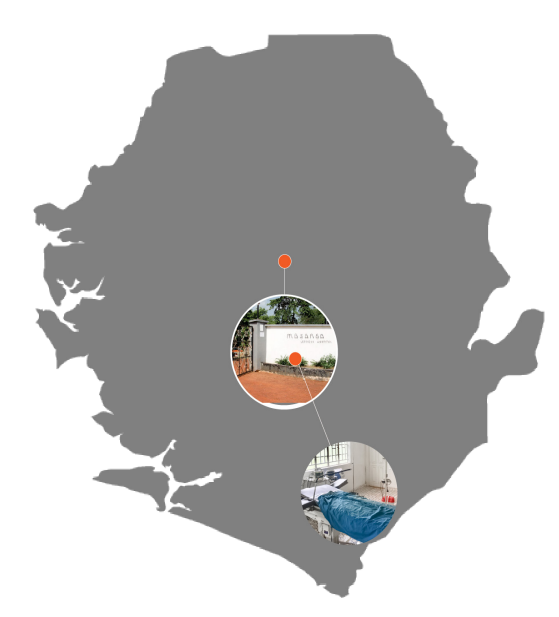

This was necessary as another hospital in Sierra Leone (same country) might not have the same capacity as Masanga. Similarly, another room or wing of the hospital might also not have the same environment as the OR.

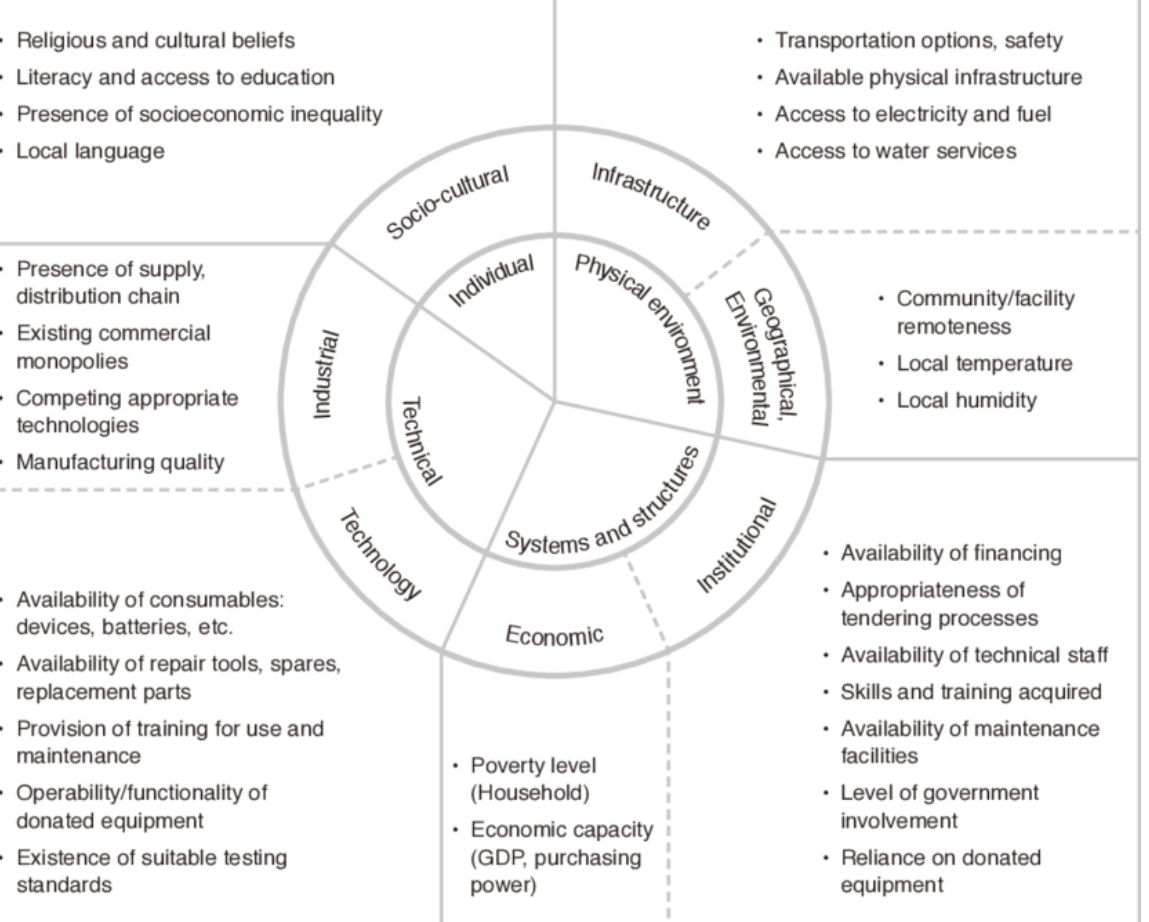

Figure 21: Framework for Hollistic Contextual Design
Socio-cultural

To avoid overlooking any important contextual factor, the contextual research was structured using the Framework for Holistic Contextual Design for Low Resource Settings by Aranda-Jan et al. (2016) (Fig. 21).

The context of Sierra Leone was researched through desktop and literature research $[47,48,49,50,51]$. Because of the inability to visit the context, for clarity, the findings were confirmed with the client as they have spend time there and know the context well.

The context of Masanga and the OR were researched through detailed, semi-structured interviews with the staff of Masanga (See Chapter 1.2). The engagement of staff members with different roles was beneficial because as mentioned earlier, hospital environments have a complex organizational structure, where every actor has different expectations of a product, which should all be fulfilled for the product to be a success.

The findings of the contextual research were combined together. Separate sub heading indicate information specific to Masanga hospital or the OR.

31.5\%

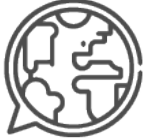

English
Sierra Leone is ocated on the coast of west Africa, with an area of $71,740 \mathrm{~km} 2$ and a population of $7,092,113$ as of the 2015 census, neighboring are Liberia to the Southeast and Guinea to the northeast. Freetown is the capital and largest city of the country.

Sopulation 7.4 milion $58 \%$ rural

\section{$170 \%$ in poverty}

83 LITERACY RATE

LANGUAGES SPOKEN

Creole (Variation of English) Various african lanuages

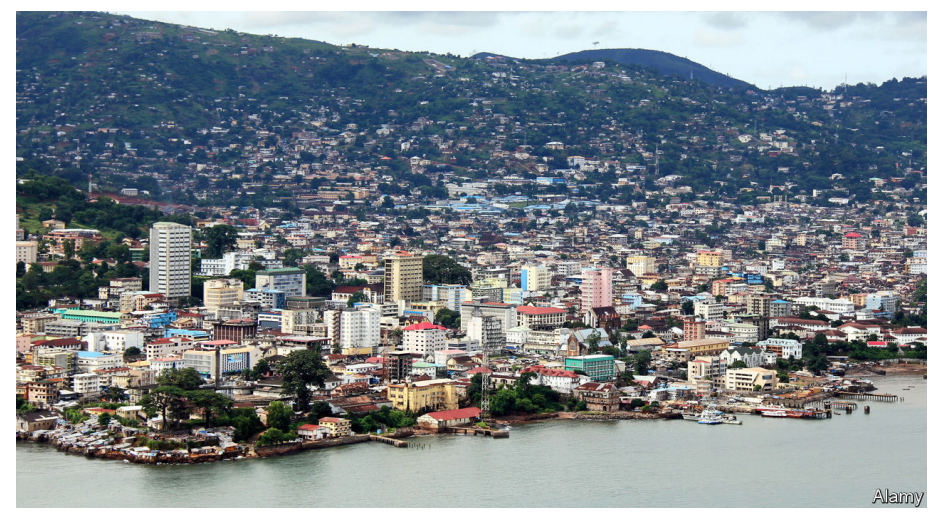

Figure 22: Freetown, Sierra Leone

\section{Devastated by war}

Sierra Leone suffered an 11 year long civil war from 1991 until 2002, which severely destroyed the country's infrastructure, homes and lands, leaving almost two thirds of the population living in poverty and a tragedy that they are still recovering from.

12000 schools were completely destroyed, leading to a current literacy rate of $43.21 \%$, an increase of $10.78 \%$ since 2013. Schools are overcrowded with students and have an unsatisfying number of teaching staff ratio against the student. Discrepancies on a gender, social status and urbanism level are present in the educationla system. Since the end of the war in 2002 the government has been promoting growth in education by offering free primary education and making primary and 3 years of secondary school compulsory for all.

Sierra Leonean education relies deeply on donor funding, which was recognized as a success by UNESCO in opinion is that the improvement of education can contribute to peace in the long run. Entrepreneurship education has also become a trend in the last years, as a way of battling poverty

\section{Education at Masanga Hospital}

Masanga's medical training programme results with a new batch of students every six months. They have recognized the educational issues in the system and the overall lack of medical staff in the country. The expat doctors share their knowledge and train the locals to ensure a future where Sierra Leone has skilled doctors that could improve the healthcare system.

\section{INSIGHTS}

- The war has severely influenced the quality of life and access to education of the population

- The entrepreneurial spirit is high among the population

- English is commonly spoken

- Masanga's educational programme ensures a high level of preparedness for the hospital staff

Infrastructure

Post-war renovations and restorations have been made, yet currently only $60 \%$ of the urban roads and $52 \%$ of the rural roads are in a good condition, which makes transport of people and goods a challenge. The main airport and amain port are both located in Free- 
:I ROAD INFRASTRUCTURE Classified road network: $119 \mathrm{~km} / 1000 \mathrm{~km} 2$ Total road network density: $126 \mathrm{~km} / 1000 \mathrm{~km} 2$ Main road network in good condition

\section{Rural road network in good condition $52 \%$}

D. Major

Export: Sherbro \& Pepe

AIRPORTS

Main airport in Freetown

smaller $<750$ passengers per Annum

town, which are not easily accessible to the population residing in the rural areas. Travelling from Masanga to Freetown takes around 3.5 hours by car [52], meaning that supplying things that can only be found at the cap ital takes a full day for the Masanga staff.

Power

Sierra Leone has no power grid and is one of the countries with the lowest power access in Africa, with only $26.10 \%$ of the population having access to electricity, with $10-12 \%$ of the urban population having access and only $2 \%$ of the rural population. The current installed capacity is not enough to satisfy the needs of the entire country. A common domestic alternative power source are car batteries, which are used for powering mobile phones or some smaller devices.

Between 2017 and 2020 the Rural Renewable Energy Project took place, which involved the installation of a total of 50 smaller solar mini grids and 40 bigger grids, located at healthcare facilities.

Power at Masanga

Masanga Hospital is powered by a stand-alone or of ten known as Remote Area Power Supply (RAPS) sola power grid, meaning that it is not connected to a local power grid. Recently the hospital received thirty six new solar panels with seven $48 \mathrm{~V}$ solar batteries, used to store the generated power that is not used during the day. The system has a capacity of $47 \mathrm{kWp}$ [53]. The hospital also has a diesel generator that is used as an alternative power source in case of a power shortage The high prices of fuel in Sierra Leone and the geographic positioning of the hospital make procurement

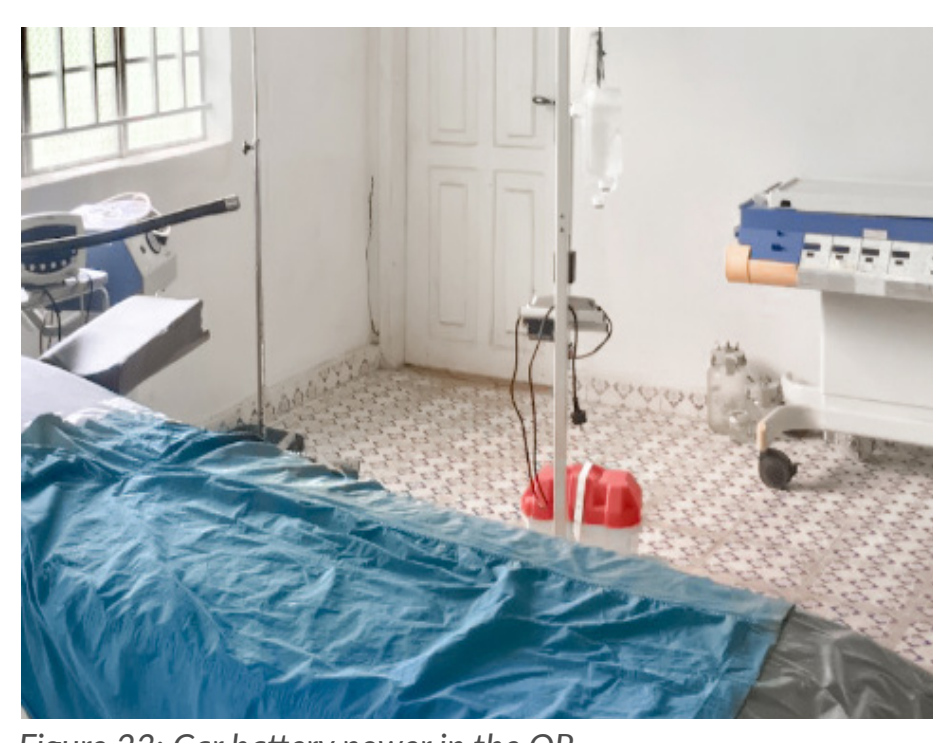

Figure 23: Car battery power in the $O R$
of fuel challenging, since a staff member is required to travel on a motorbike and bring fuel reserves, which have to be carefully used and distributed to last as long as possible.

However now with the new panels they hope to save the generated power on the solar batteries and use that stored power as an alternative source, including powering the OR electrical equipment.

\section{Power in the OR}

Power in the OR comes from the hospital's solar grid through a regular power line. Devices are plugged-in on an extension cord. The surgical lights are connected to a car battery (Fig. 23). The car battery however does not have enough capacity to power any other devices.

\section{INSIGHTS}

- Transport and import of medical goods is a challenged due to the poor road network and distance of airport and port from Masanga

- The high prices of fuel very often leave Masanga without a back-up power supply

- If the solar panels or the wiring of the hospital fails, the whole hospital is left without power

\section{Geographical/Environmental}

The climate of Sierra Leone is tropical all year round, with a dry season during the winter period and con- stant high temperatures averaging between $30-35^{\circ} \mathrm{C}$. Between May and November is when then the rainy season takes place as a result of the African monsoons, with an annual rainfall of between 2000-3000 millimeters, highest in the coastal areas. Humidity levels are always around $80 \%$ and above, making the country extremely humid.

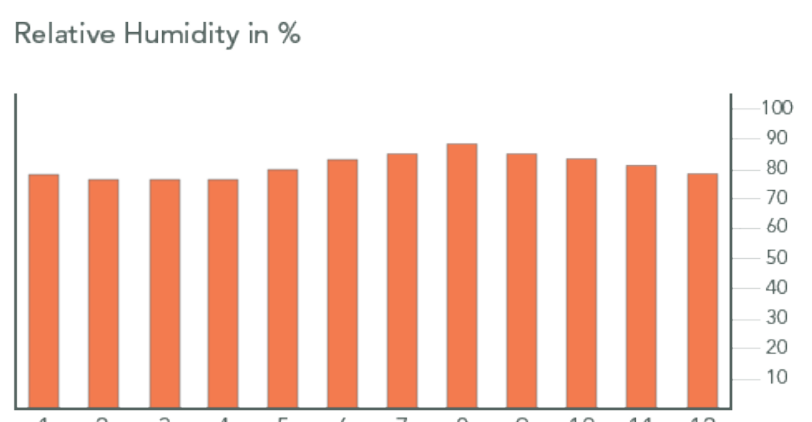

Average daytime \& nighttime temperatures at alt. $25 \mathrm{~m}$

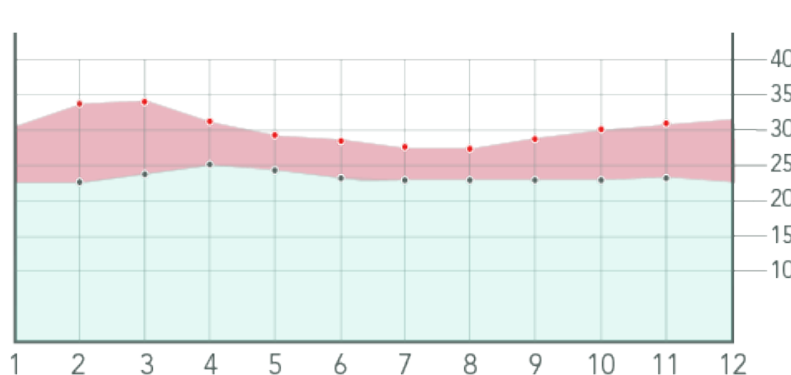

Temperature at Masanga is regulated by air conditioning. Most rooms, including the OR have an AC, but humidity levels are not regulated in any way.

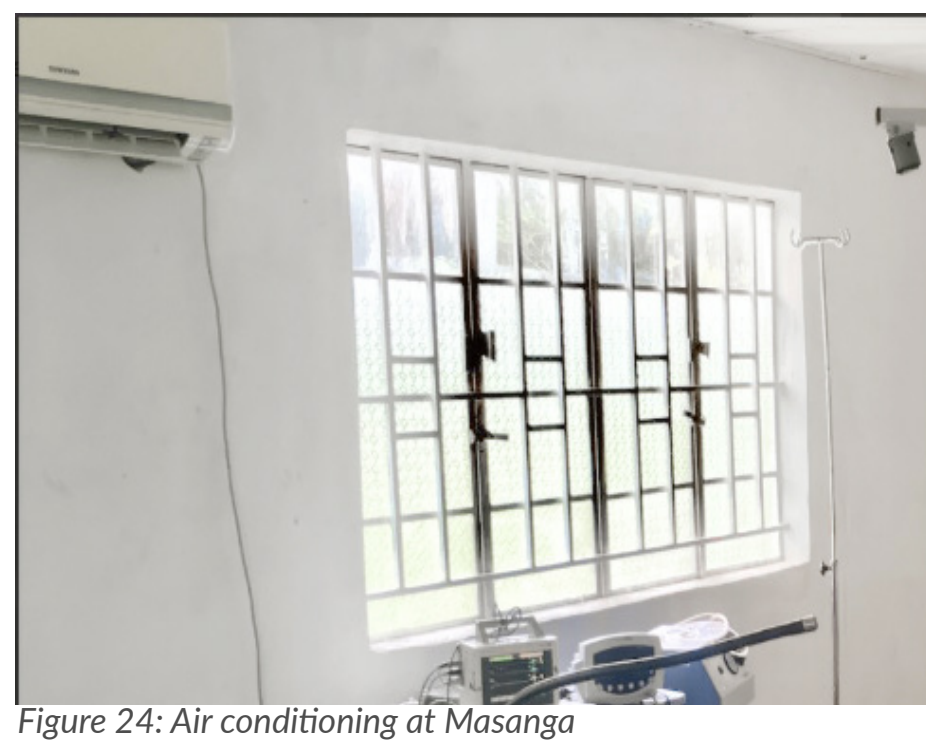

INSIGHTS

- Two thirds of the population live in poverty, which commonly results with poorer health and wellbeing

Public Health

Most hospitals and medical equipment were destroyed. during the war. The effects can still be felt today, with Sierra Leone being the country with the highest maternal mortality rate in the world with around 1200 per 100000 deaths, followed by one of the highest under five mortality rates with 105 per 1000 live births. The average life expectancy at birth is 52 years, which is 20 
- 200 DOCTORS (mainly in capital) $30 \%$ EXPAT DOCTORS

50 PERIPHERAL HEALTH UNITS (PHU) Community

Community health centre

- Maternal and Child Health posts

7 HEALTHCARE EXPENDITURE \% OF GDP \$ $11.4 \%$

(2) 100 NGOs operating in the

NGO health care sector

FREE HEALTH CARE MEDICAL INSURANCE for pregnant and breast-feeding women and children under five

years lower than the world average. The government is aiming towards improvement of the healthcare system and facilities, but only $11.4 \%$ of the GDP are going into healthcare expenditure, a significantly low percentage. Healthcare is most often inaccessible, partly due to financial reasons and partly due to the infrastructure. Patients often take an extended period of time before going to a medical facility to seek help and by the time they reach the hospital often there is not much that can be done to reverse the damage. The government has set in place an insurance system providing free healthcare to pregnant and breast-feeding women.

The ruptures in the education system consequently leave consequences on healthcare as the whole country has approximately 200 doctors, residing mainly in the capital, for a population of 7000000 . Annually around 30 expat doctors work at Sierra Leone and during their time of stay a large quantity of their time is devoted towards teaching locals basic nursing and surgery skills. All healthcare services provided highly depend on the help of NGOs, with around 100 NGOs operating in the healthcare sector.

Healthcare at Masanga

The lack of trained local staff requires the need for high skilled staff from other, HIC. The Masanga team consists of expat doctors and nurses who run the healthcare facility help train the local staff.

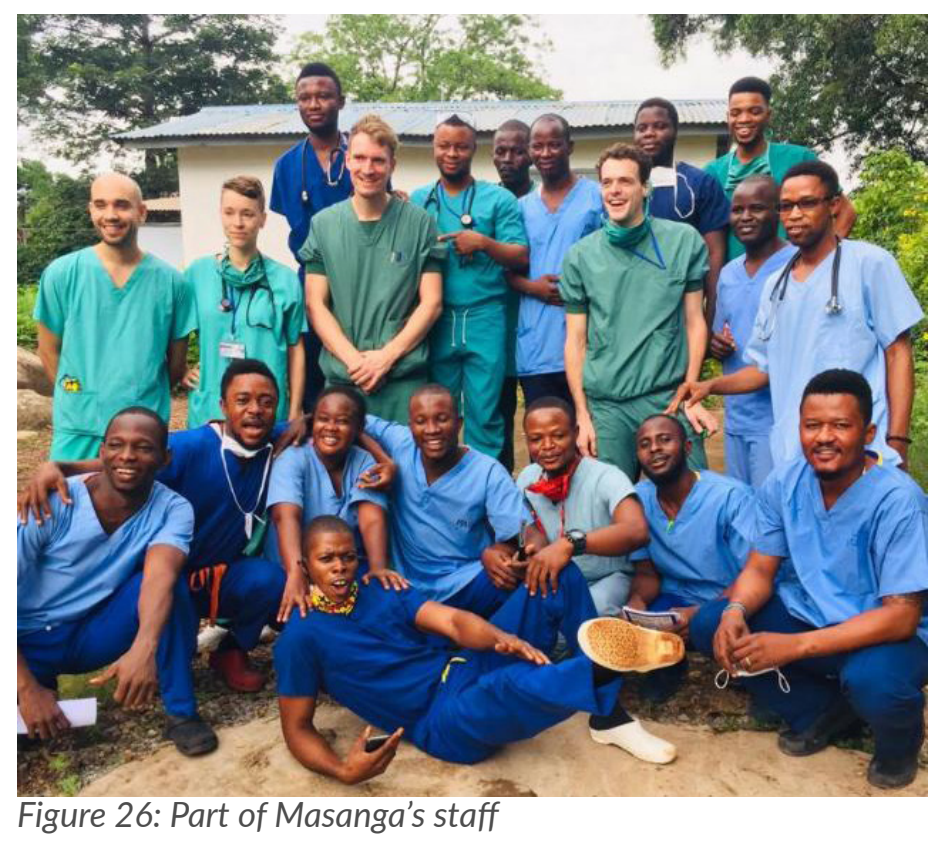

\section{INSIGHTS}

- The healthcare system of Sierra Leone and Masanga in particular relies on donations from NGOs

- The healthcare system is in dire need for improved accessibility and conditions

- Patients sometimes spend hour travelling to the nearest healthcare facility on foot Industrial

Even though the country is immensely rich on natural resources and precious metals, most of the mined goods end up being exported to the western world. Not a lot of manufacturing capacities are available, except for simple carpentry, welding, plumbing and electrical lining that can be done locally. There is no possibility of manufacturing any sort of medical devices or equipment in the country, therefore they are always imported from the west or from the neighbouring countries.

\section{D printing at Masanga Hospita}

The 3D fabrication lab is one of the most remarkable examples of the passion for improved healthcare by the Masanga Team. The lab was found in December 2017 when the first 3D printer was brought from the Netherlands. The lab was found in collaboration with RadboudUMC with the aim of $3 \mathrm{D}$ printing custom pros- thesis for amputees to reduce the social stigma that amputees face in Sierra Leone. The team consists of experts every few mo local staff on how to scan the patients and how to op erate the printers. The lab is a perfect representation of an Opportunistic Frugal Innovation solution, where a modern and accessible technology is used to tackle an old societal and healthcare problem.

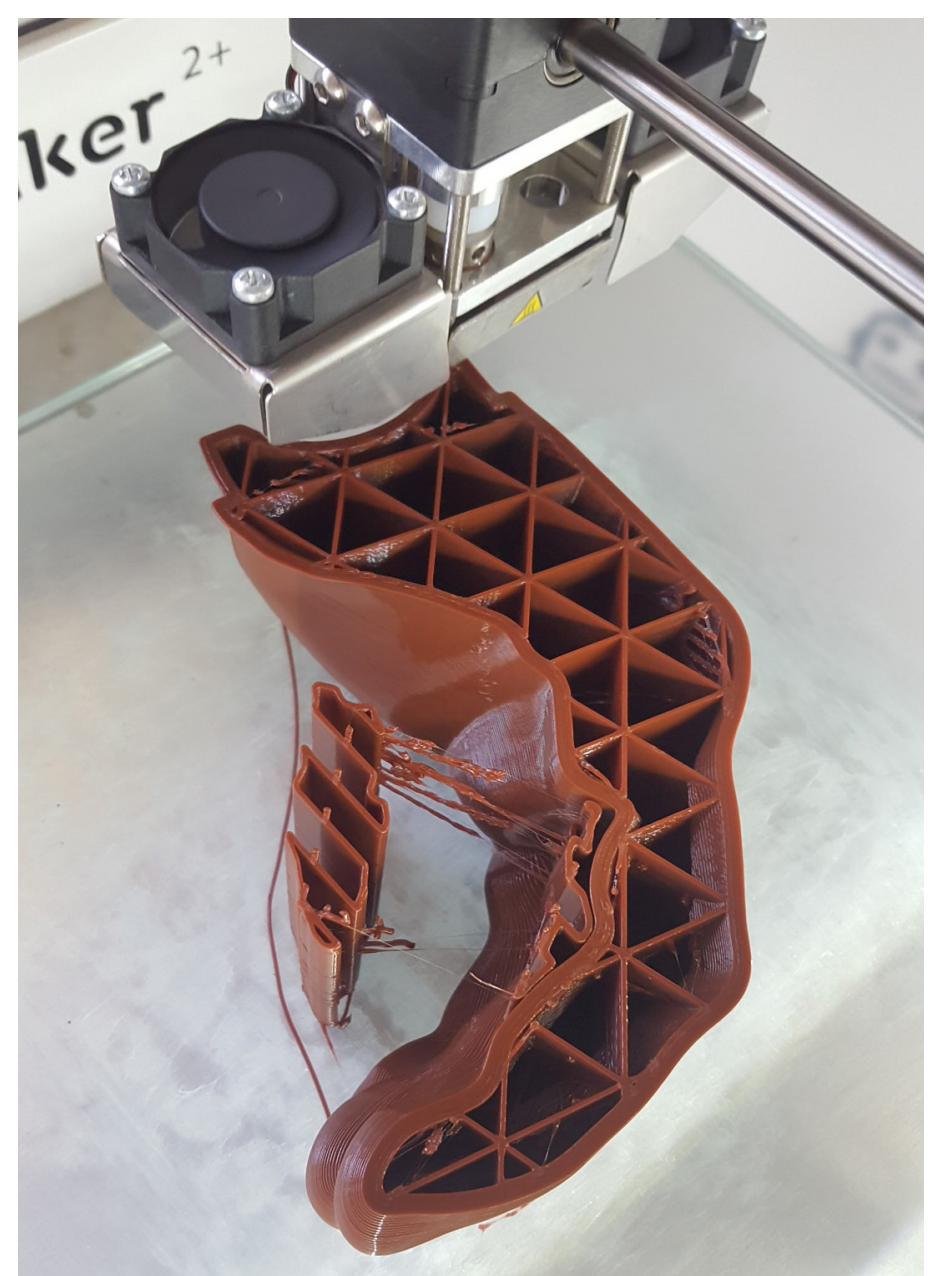

Figure 27: 3D printed prosthesis at Masanga's Lab

\section{INSIGHTS}

- Carpentry, welding and plumbing are the only industries available at Sierra leone

- There is no manufacturing of medical devices or consumables

- Masanga has a well-equipped 3D printing lab for printing of prostheses for amputees Institutional

The hospital has a capacity of 100 beds. Two days of the week are reserved for surgeries and the other days
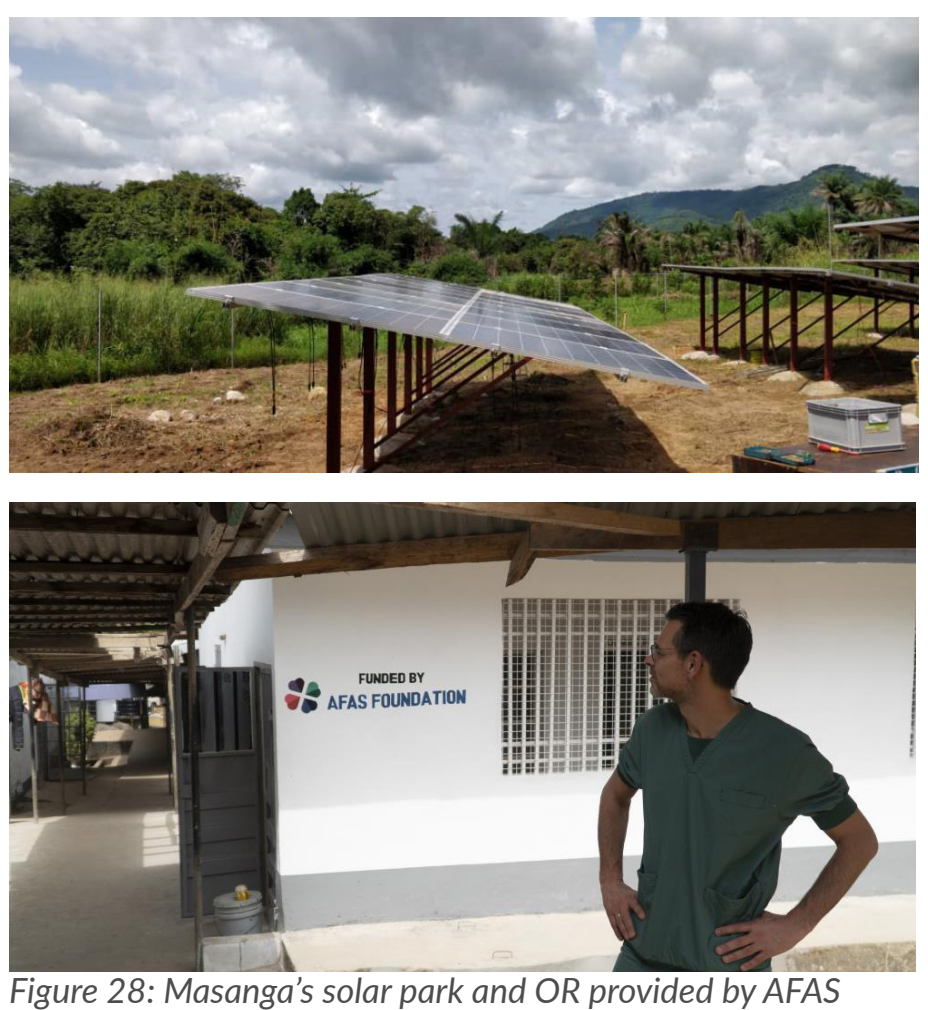

are devoted to non-surgical medical care, maintenance of the hospital and staff training.

The hospital has two ORs, one of which was recently renovated with the help of the dutch NGO AFAS. Basic equipment like surgical monitors, oxygen machines and ecgs are available, but a lot of other essentials such as anesthesia machines are not available. Surgical equipment and consumables are sterilized, washed and reused. Maintenance and cleaning of the OR is done by the cleaning staff and the OR staff.

The logistics officer keeps an overview of the hospital's inventory through an online system. Sadly, running out of stock is a daily occurrence, most common for antibiotics and disposable consumables. In these cases, if the need for a certain supply is inevitable, someone from the hospital goes by motorbike to the local pharmacy to restock, if they are also available there.

Medical Devices at Masanga

Most of the medical equipment is provided by NGOs. The devices are second hand, devices from european hospitals, collected and refurbished by Stichting Medic 
(the Netherlands) and then shipped to Masanga. Usually once a year a container is also shipped from the Netherlands with some extra supplies and consumables such as stethoscopes and blood pressure machines, but is quite inconsistent and reliant on availability. Smaller devices or equipment are often brought to Masanga by the doctors themselves in their suitcases. New devices are ordered by Masanga's logistics officer through a tendering process.

Maintenance of medical devices

In cases where a medical device breaks they lack locally available expertise to fix them and they usually end up stored in the storage unit or sent back to Stichting Medic in the Netherlands, a process that takes time and effort. According to Jesper Winther, there is a strong reluctance among the locals to even try to fix broken devices if the defect is something they cannot visibly see. If fixing the devices requires opening it up, they will give up and leave it broken. The hospital currently does not have a BMET in the staff.

\section{Hygiene and cleaning practices}

The OR has a lower hygiene level compared to Western hospitals. In Wester hospitals all medical consumables, including surgical bed covers etc are disposed of after every surgery, while at Masanga they are washed and reused as their availability is limited. The medical too in a chlorine bath, washed and then reused.

\section{INSIGHTS}

- Availability of medical equipment at

Masanga depends on NGO donations

- During shipping donated medical equipment can get stuck at customs for months and by the time it reaches Masanga some things might be damaged or expired

- Reuse of consumables is the common practice

- There is a strong reluctance towards fixing anything that is not visible without opening the device
- The hospital does not have a BMET

\section{Technology}

Standard electronic and electrical gadgets are available at local stores around Sierra Leone. Car batteries, which are a popular choice for domestic use as a power supply are also widely available at local car parts shops. Ordering from sites such as Aliexpress or Alibaba is extremely common for anything that cannot be found locally.

\section{D printing filament at Masanga}

3D printing filaments are not available to buy locally, therefore the staff supplies it by bringing it from the Netherlands in their luggage.

\section{INSIGHTS}

- Standard electronics can be sourced locally

- Car batteries are widely available

- 3D printing filament is brought in from the Netherlands

\subsection{LIST OF INSIGHTS}

In this sub-chapter all of the insights from the discover phase that could influence the final design solutions are gathered together

Suction at a HIC hospital

- Consumables in HIC hospitals are always disposed after surgery

- Connectors can be stiff or flexible \& male or female - Connectors must prevent leaks or disconnections to avoid risks

\section{Suction at Masanga}

- All consumables at Masanga are cleaned by soaking in a chlorine bath and reused after every surgery - Availability of suitable tubing is limited. Tubes are re purposed according to need and availability

- The pump does not undergo frequent maintenance which has lowered the power and suction strength

- During power outages, the pump operations stops and cannot be continued

- Collection pots are outdated with outlets that are incompatible compared to the ones on the tubes resulting in leaks and disconnections

-The tubes are not long enough which requires unsterile components to be placed close to the sterile operative field and can pose a hazard. This is again a result of the unpredictable availability of the right com

- A loose connection could lower the suction flow and the performance of the pump

Socio Cultural

- The war has severely influenced the quality of life and access to education of the population

- The entrepreneurial spirit is high among the population

- English is commonly spoken

- Masanga's educational programme ensures a high level of preparedness for the hospital staff

\section{Infrastructure}

- Transport and import of medical goods is a challenged due to the poor road network and distance of airport and port from Masanga

- The high prices of fuel very often leave Masanga without a back-up power supply

- If the solar panels or the wiring of the hospital fails, the whole hospital is left without power
Geographical/environmenta

- Humdity levels are extremely high at Sierra Leone - Temperature is stable at Masanga, but humidity is not controlled, which could be a problem for storage

\section{Economic}

- Two thirds of the population live in poverty, which commonly resuts with poorer health and wellbeing

Public health

- The healthcare system of Sierra Leone and Masanga in particular relies on donations from NGOs

- The healthcare system is in dire need for improved accessibility and conditions

- Patients sometimes spend hours traveling to the nearest healthcare facility on foot

Industrial

- Carpentry, welding and plumbing are the only industries available at Sierra leone

- There is no manufacturing of medical devices or consumables

- Masanga has a well-equipped 3D printing lab for printing of prostheses for amputees

\section{Institutional}

- Availability of medical equipment at Masanga depends on NGO donations

- During shipping donated medical equipment can get stuck at customs for months and by the time it reaches Masanga some things might be damaged or expired

- Reuse of consumables is the common practice - There is a strong reluctance towards fixing anything that is not visible without opening the device

- The hospital does not have a BME

\section{Technology}

- Standard electronics can be sourced locally

- Car batteries are widely available

- 3D printing filament is brought in from the Netherlands 
Risks of current suction method at

Masanga Hospital

- Lowered or terminated suction flow puts the patient's

wellbeing at risk

- Disconnections between components could cause

contamination from the patient to the staff

- Leaks in the system could put the staff and the pa-

- Leaks in the system could put the staff and the pa-
tient at risk

- Power cuts could harm the patient and the device

itself 


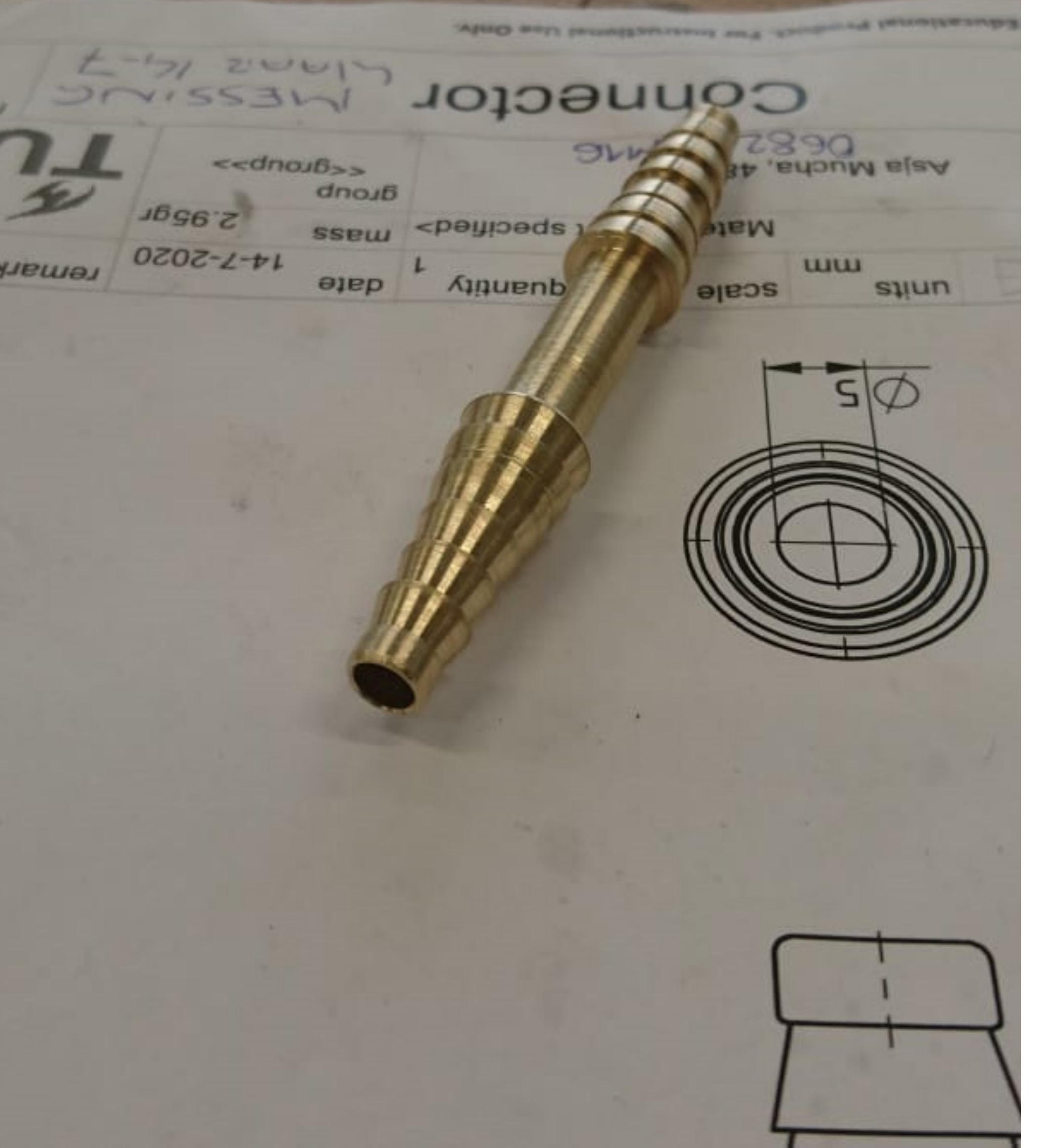

Chapter 3

\section{DEFINE}

In the Define Phase the insights gathered from the research come together to define the scope of the project, the design vision for the project and the list of requirements.

In this phase the two subprojects and their respective requirements are introduced. 


\section{$(3)$ ofwe}

\subsection{DEFINITION OF SUB PROJECTS}

In the previous chapter insights were gathered on the contex of use, suction at Masanga and suction at a HIC hospital and the users of the suction pump.

Due to the fact that both of the challenges introduced in the project were very different and independent from each other, a decision was made to ongoing separate them into two respective subprojects or subsystems. The subsystems were defined as:

System Connect: focused on local manufacturing of medical tubing connectors System Power: focused on a concept for a portable power pack built from locally sourced components.

For both subprojects, the insights were converted into a List of Requirements, taking into consideration Context Requirements and Product Requirements.

Note: The user research did not result in any specific insights in terms of user interaction, therefore the user-relat ed requirements were classified under contextual requirements.

The insights were converted into Product Requirements and Context Requirements, which were then combined in a final System List of Requirements.

From the lists of requirements, the design directions for both subsystems were defined. The design directions will serve for guidance in the Develop Phase.

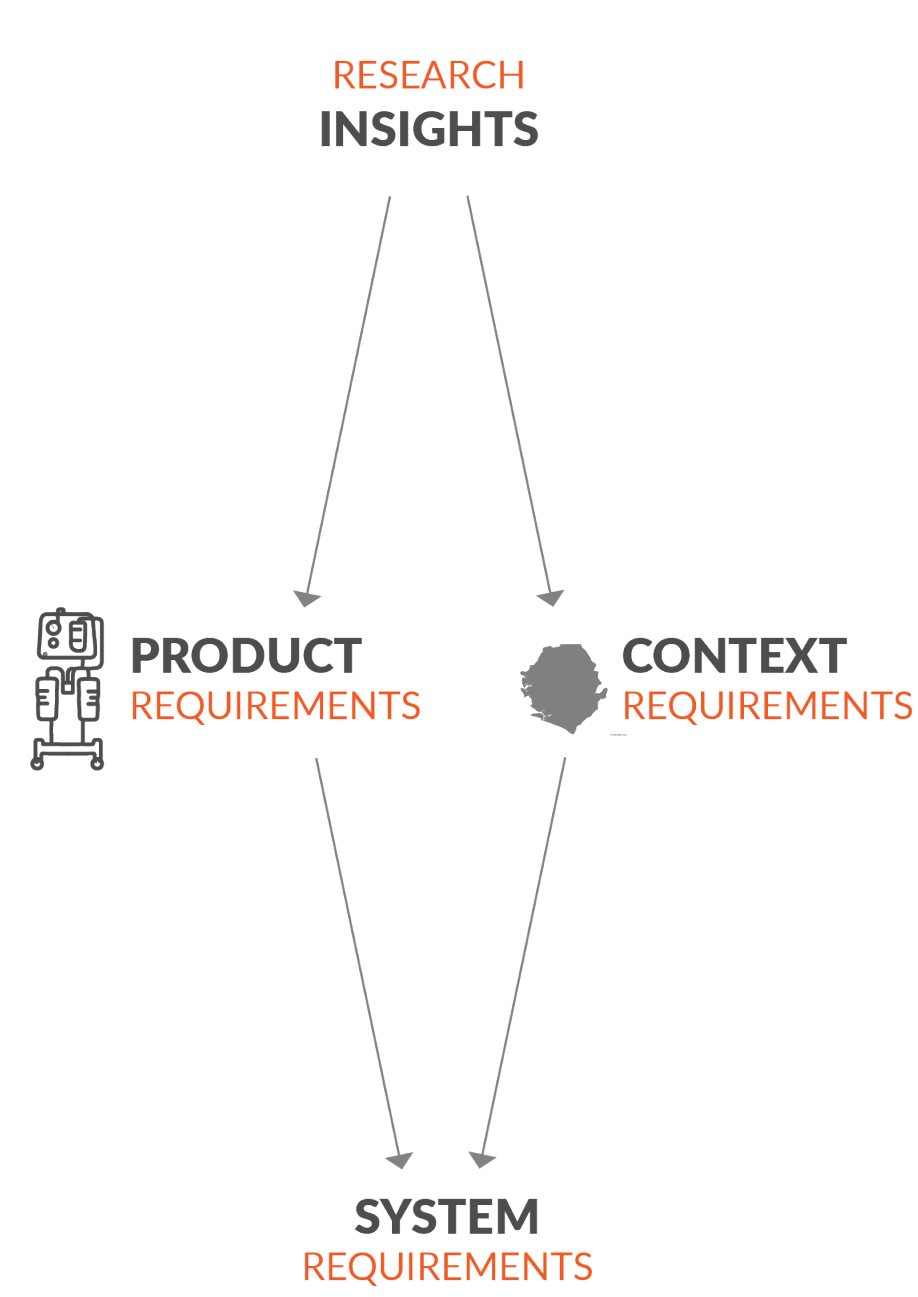

\subsection{SYSTEM CONNECT}

In chapter 2.2 it was shown that the connection of medical consumables can easily be done by using medical connectors. The availability of so many differen connectors on the market raises the questions: Why design new connectors instead of buying existing ones?

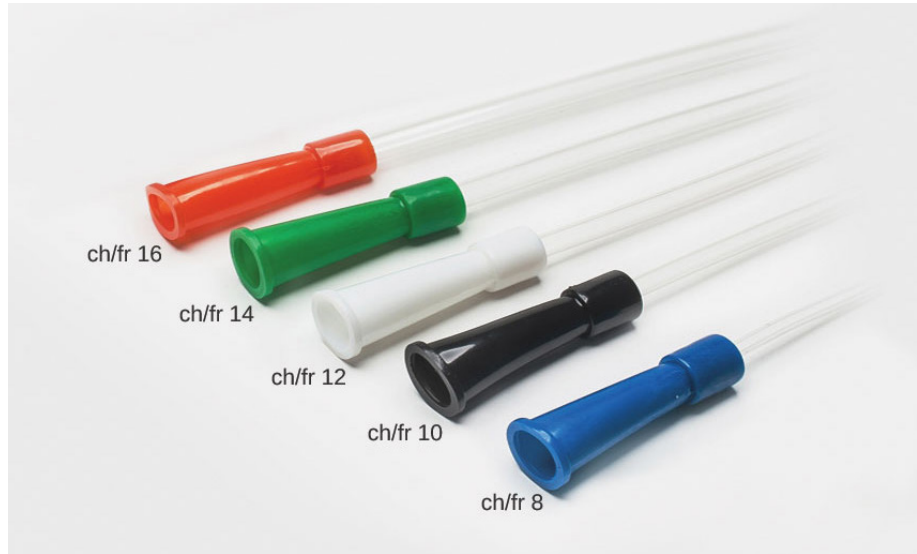

Figure 29: Flare tubing connectors on catheters

The reason is because in this case we are dealing with mismatching equipment, outdated and re purposed components and a supply chain that cannot ensure timely arrival of these connectors, but the focal need for a new design comes from the dimensional mismatch between old, outdated components.

BIG HOSPITALS WITH UP-TO-DATE EQUIPMENT CAN AFFORD TO BUY CONNECTORS. BUT FOR MASANGA, THE OUTDATED EQUIPMENT, UNPREDICTABLE DIMENSIONS OF CONSUMABLES, FINANCIAL CONSTRAINTS AND WEAK SUPPLY CHAIN REQUIRE A CUSTOMIZED DESIGNS AND A DIFFERENT SUPPLY CHAIN.

\section{List of requirements}

\section{Method}

The research from the Discover phase gave insights on what are the contextual and product requirements for the system.

Additional desktop $[54,55]$ research was done on the design of medical tubing connectors in relation to the safety requirements for medical tubing connectors .

Further, the requirements were expanded by taking into consideration the specific connector embodiment requirements based on Masanga's consumables.

\section{SYSTEM}

REQUIREMENTS

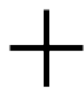

\section{EMBODIMENT}

REQUIREMENTS<smiles>[TeH]</smiles>

SAFETY

REQUIREMENTS 
System \& Safety Requirements

\begin{tabular}{|c|c|c|}
\hline Category & No. & Requirement \\
\hline \multirow{8}{*}{$\begin{array}{c}\text { SYSTEM } \\
\text { REQUIREMENTS }\end{array}$} & 1 & The connectors should be locally manufactured \\
\hline & 2 & The connectors should be reusable \\
\hline & 3 & The connector dimensions should be customizable \\
\hline & 4 & The connectors should improve the flow of the pump \\
\hline & 5 & The connectors should be cheaper than off-the-shelf ones \\
\hline & 6 & The connectors should withstand exposure to humidity \\
\hline & 7 & $\begin{array}{l}\text { The production of the connectors should be independent of Ma- } \\
\text { sanga's supply chain }\end{array}$ \\
\hline & 8 & The connectors should fit Masanga's cleaning procedure \\
\hline \multirow{8}{*}{$\begin{array}{c}\text { SAFETY } \\
\text { REQUIREMENTS }\end{array}$} & 9 & The connectors should prevent leaks of suctioned fluids \\
\hline & 10 & The connectors should prevent spills and disconnections \\
\hline & 11 & The connectors should withstand exposure to suction pressure \\
\hline & 12 & $\begin{array}{l}\text { The dimensions of the connectors should consider the inner diame- } \\
\text { ter of the tubing it is used with }\end{array}$ \\
\hline & 13 & $\begin{array}{l}\text { The connectors should be compatible with the media passing } \\
\text { through them }\end{array}$ \\
\hline & 14 & $\begin{array}{l}\text { The connectors should withstand the different temperature they } \\
\text { might be exposed to during application, cleaning or shipping }\end{array}$ \\
\hline & 15 & The connectors should fit the components that they are used with \\
\hline & 16 & $\begin{array}{l}\text { The mounting of the connectors should be defined by the compo- } \\
\text { nents it is mounted to }\end{array}$ \\
\hline
\end{tabular}

\section{Embodiment requirements}

The requirements were specified for every connection be designed with the assumption that they will come point due to the different dimensions of the tubes and in contact with biological fluids and that they will be the collection pot's outlets.

In their application not every one of the connectors is

intended to have contact with bodily fluids, or to be

thoroughly cleaned every time, but all connectors will exposed to cleaning agents.

This approach will ensure uniform quality along all connectors and use safety.

\section{CONNECTION POINT REQUIREMENTS}

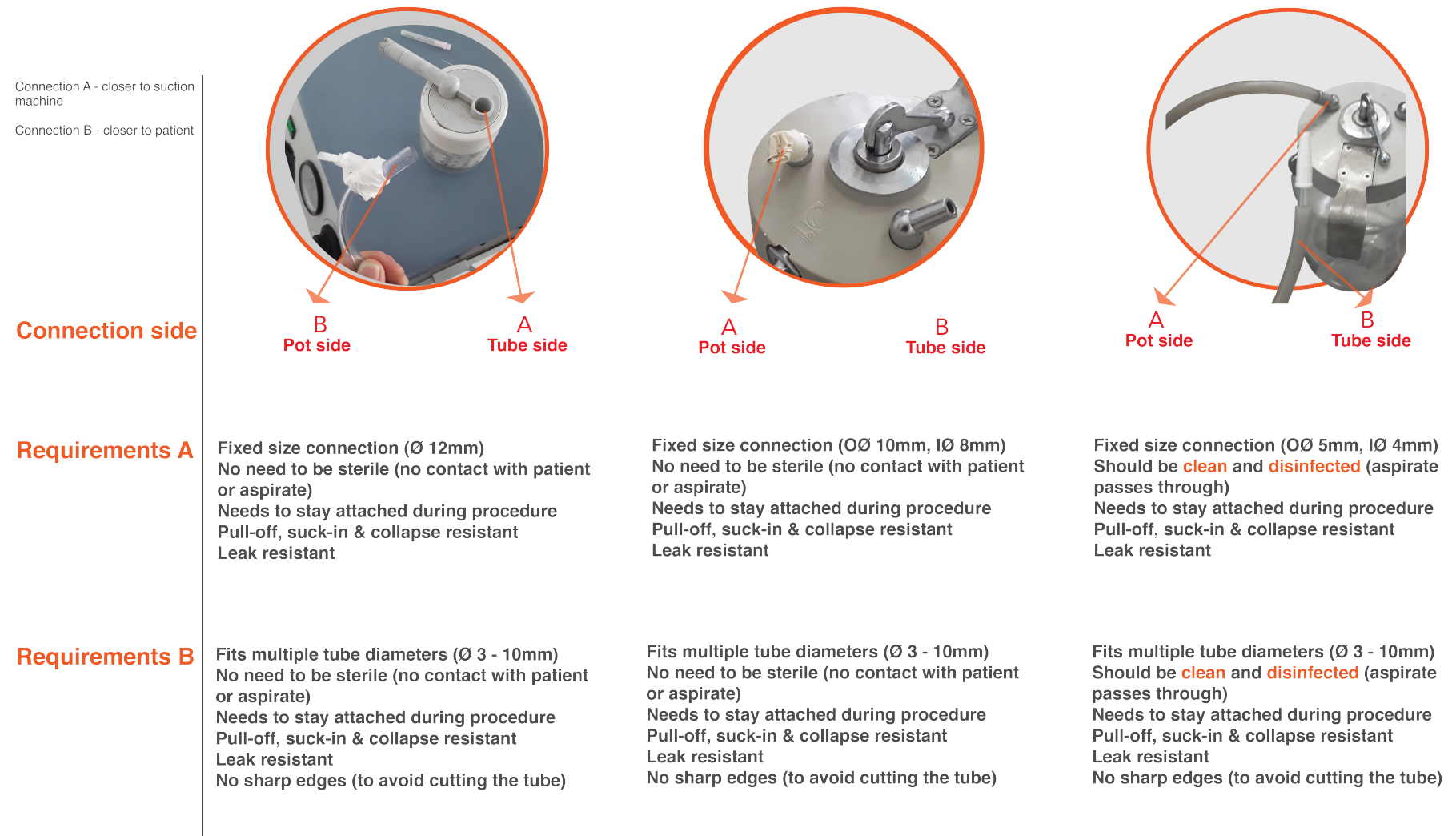

Figure 30: Embodiment requirements for System Connect 


\subsection{SYSTEM POWER}

List of requirements

The requirements for System Power were set following the

same principle as in System Connect

\begin{tabular}{|c|c|c|}
\hline Category & No. & Requirement \\
\hline \multirow{4}{*}{$\begin{array}{c}\text { SYSTEM } \\
\text { REQUIREMENTS }\end{array}$} & 1 & The system should provide back-up power for $\sim 2 \mathrm{~h}$ \\
\hline & 2 & $\begin{array}{l}\text { The system should pick up the power automatically after line power } \\
\text { failure }\end{array}$ \\
\hline & 3 & The system should be based on a $12 \mathrm{~V}$ car battery \\
\hline & 4 & The system should be protected from humidity \\
\hline \multirow{3}{*}{$\begin{array}{c}\text { SAFETY } \\
\text { REQUIREMENTS }\end{array}$} & 5 & The system should have built-in charge control \\
\hline & 6 & The system should be protected from short circuits \\
\hline & 7 & The system should invert DC voltage into AC voltage \\
\hline EMBODIMENT & 8 & The system should fit in a transportable box \\
\hline REQUIREMENTS & & \\
\hline
\end{tabular}

Table 2: System and Safety Requirements of System Power 


\section{Chapter 4}

\section{DESIGN FREEZE}

Before diving into the development of the final design solutions, some fundamental decisions need to be made.

For System Connect, decisions regarding the manufacturing process and the general embodiment of the connectors are made.

For System Power, the initial architecture of the system will be presented based on the system's required performance.

Finally, a Failure Mode Element Analysis (FMEA) will be presented, along with the testing that should be performed in the next phase of the project.

$\longrightarrow$ Cylindrical end dor pot connection

$\sim$ Potlid 


\subsection{SYSTEM CONNECT}

\section{Method}

The requirements set in Chapter 3.2 were used as a starting point towards defining the main design drivers of the system.

\section{Design Drivers}

\section{Design for reuse}

Taking into consideration Masanga's behaviour towards medical consumables, it is essential that the connectors are designed for reuse and the do not disrupt Masanga's working principles, but instead improve the use of the suction pump.

Design for reuse would mean that the designed connectors would be frequently exposed to biological, suctioned fluids and gases and frequent chemical cleaning. Therefore it is important to choose the right material that would allow for this treatment, while

\section{Design for local manufacturing}

From the insights gathered in chapter 2.5 it was concluded that manufacturing opportunities are very limited in Sierra Leone. The manufacturing process for the connectors would further influence the embodiment and the material choice for the connectors, which is directly connected to designing for reuse.
Taking into consideration the two main design drivers, the first step in this chapter is to decide on the chosen manufacturing method. The decision will be followed by an analysis of the suitable stiffness of the connectors, which is additionally influenced by the manufacturing method and the materials that the method supports. Lastly, the embodiment of the connectors will be defined based on the Embodiment Requirements stated in Chapter 3.2

\subsubsection{How do we manufacture them?}

The insights showed that manufacturing possibilities are limited in Sierra Leone. Possible scenarios and prototypes were developed, such as turning a connecto from steel, but unpredictable availability of material and the possible physical distance from the manufacturer were considered strong enough arguments to dismiss this idea. See Apendix 5 for full analysis on Manufacturing scenarios.

The possibility of 3D printing and Masanga's ongoing engagement in 3D printing prostheses for amputees were the scenario with the most promising outcome. The decision to proceed with 3D printing was validated with Savonen's General and Contextual triage for 3D printing of medical devices [67]. The triages cover questions related to risk, product usage, material selection, device properties, contextual appropriateness and the economics of the project. The connectors passed the triage, which gave scientific approval and validation to proceed with this method of manufacturing. The results from the triage can be found in Appendix 6.

Additionally, a more complete analysis was performed on Masanga's 3D printing facilities, which showed that their facilities are sufficient for the production of the connectors. The results can be sound in Appendix 7 .

Benefits of Local Manufacturing 3D printing (LM3D)

Literature research was done on the benefits of LM3D [68]. From the research the following benefits were learned:

\section{Improved healthcare service}

The reduced delivery times and obtainable supply chain could significantly improve the quality of healthcare services that Masanga offers. 3D printing tubing connectors could be the starting point for Masanga on the journey of developing an in-house manufacturing facility where they would be able to produce a variety of spare parts, not only for the suction pump but also other devices that could benefit from LM3D.

\section{Reduced cost}

As the cost of a 3D printing remains the same regardless of the geometric complexity of the part, the cost of a single component could be drastically reduced. The average cost of a single medical connector varies between $0.4 \$$ and $2.5 \$$, however most of these market-available connectors would not be suitable for $\mathrm{Ma}$ sanga due to dimensional challenges and they are rarely sold per piece, but in a batch of at least a 100 pieces. A rough calculation, including the cost and weight of one roll of filament and the weight of the connectors (Appendix 8) showed that the price of printing one connector would be approximately round up to $0.10 \$$ per connector (excluding electricity and human labour costs). Hence, a custom-designed, 3D printed connector would cost less than a connector from a medical manufacturer, making it a viable candidate for localized $3 \mathrm{D}$ printing.

\section{Independent supply chain}

A localized manufacturing approach could help the envisioned supply chain scenario for Masanga (Appendix 9) to become reality. Localized, in-house manufacturing does not mean solving the problem with the lack of consumables, as a vast array of stakeholders and circumstances influence that problem, but it could help the hospital gain more access and better use of their medical devices.

\section{Potential for distributed local manufacturing}

Aside from the ability to address their individual needs,

a localized manufacturing setup could also serve as a development strategy to improve the industrial capabilities of the local community. Part of Masanga's vision for the future of the project is to expand their local manufacturing of consumables by also providing consumables for other hospitals in the area who might have the same problem, or a different problem that could be addressed with 3D printing. That way, the availability of many specialized products could expand to cater the needs of multiple healthcare providers. 


\subsubsection{Stiff or flexible connectors?}

Chapter 2.2 showed that medical tubing connectors can be either stiff or flexible. The choice of whether to proceed with a stiff or flexible design of the connectors would influence:

-The embodiment of the connectors

-The production material \&

-The manufacturing complexity

Having the manufacturing method defined already, it was possible to make a comparitive analysis between $3 \mathrm{D}$ printing with stiff and with flexible materials. The first step was to make a comparative analysis between stiff and flexible 3D printing filamets.

Desktop research $[61,62,63,64,65]$ and literature research [66] was done on the following filaments:

- Stiff materials: PLA, PETG, TOUGH PLA and ABS - Flexible materials: TPU, TPA, TPC and Nylon

The materials were evaluated based on:

- Water resistance

- Chemical resistance

- Heat resistance

- Cost

- Printability

- Compatibility with available devices.

The research was followed by an expert validation with Tessa Essers [66], a 3D printing expert from the Applied Labs at the faculty.

Based on the research results and the expert consult it was concluded that producing the connectors with a stiff material would be the right decision. The rationalle is that flexible materials are not water tight nor resistant to chemicals, which makes them unsafe for use and could lead to safety hazards. Tessa also mentioned that flexible materials are extremely complex to print with and require a high level of skill in 3D printing, which cannot always be guaranteed at Masanga. Parts 3D printed with different grades of TPU were also inspected (Fig. 31) to determine whether they have the compatible elastic coefficient and most of them seemed too stiff.

Note: The materials both showed impeccable bending flexibility, but Tessa said that none of them would stretch as much as needed for the application.

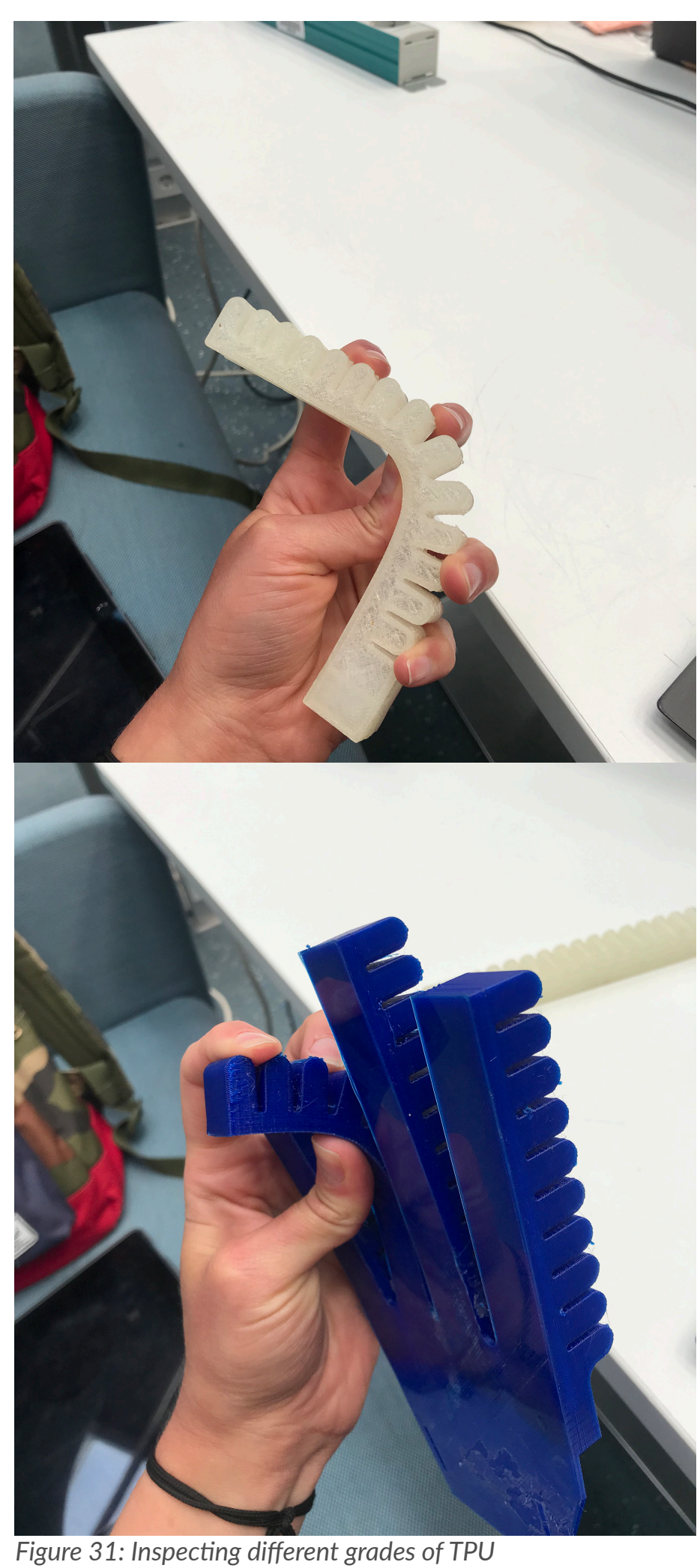

\subsubsection{Material choice considerations}

Savonen (2019) [72] suggests that when designing for LM3D, it is imperial to compare the mechanical properties of the filaments available in the context with the original materials used for the given product. The filament of choice should have mechanical properties as similar as possible to the original material.

On that note an analysis was made comparing:

- PLA, PETG and ABS - most common filaments available in context

- PC, Nylon, PP and PVDF - most common materials used for injection molding connectors.

What is common among the original materials is that they all have a high strength, are resistant to high temperatures and show good resistance to certain chemicals. The full analysis can be found in Appendix 10.

The analysis was followed by two expert consultations with:

- Julie Fleischer [73], Biomechanical Engineer, former TU Delft researcher

- Jan van Frankenhuyzen [74], Biomechanical Engineer at $3 \mathrm{mE}$, TU Delft

The expert consults lead to the decision to exclude PLA from the list of potential 3D printing materials due to its porosity, which immediately makes it unsafe for use.

The final decision was to further test the final design with PETG and ABS filament.

\section{Procurement of materia}

The material choice was discussed with the client as well, on the aspect of filament procurement and cost According to Jan Henk, the procurement process for the material would be the same as for the Tough PLA that they use for printing protheses, which is delivering the material from the Netherlands by plane, usually brought by a staff member or volunteer when they travel to Masanga. According to him, unless the price

of the chosen filament is drastically higher than the one of Tough PLA, there should be no problem to procure the filament. The price for Ultimaker's Tough PLA that they use is between 40 and 50 euro (depending on the seller), so a material in that price range is acceptable for the hospital. 


\subsubsection{Initial Embodiment Design}

\section{Method}

In this sub-chapter the embodiment of the two sides of the connector is defined. Desktop research [70,71] and several ideation (See Appendix 11) lead to the decision to proceed with a barbed connector on the tubing side and a cylindrical connector on the collection pot side. Following the design specifics are presented.

\section{Tube side: Barbed connector design}

A barb connector was deemed the ideal choice as it provides a leak-proof, tight fit. The use of barbs is most common in applications involving low pressure and fluid, gas or airflow control applications. The possibility of having incremental barbs means that the connectors can fit multiple tube sizes, which is extremely important as the hospital is working with any applicable tube that they have available, in a dimensional range from 3 to $10 \mathrm{~mm}$.
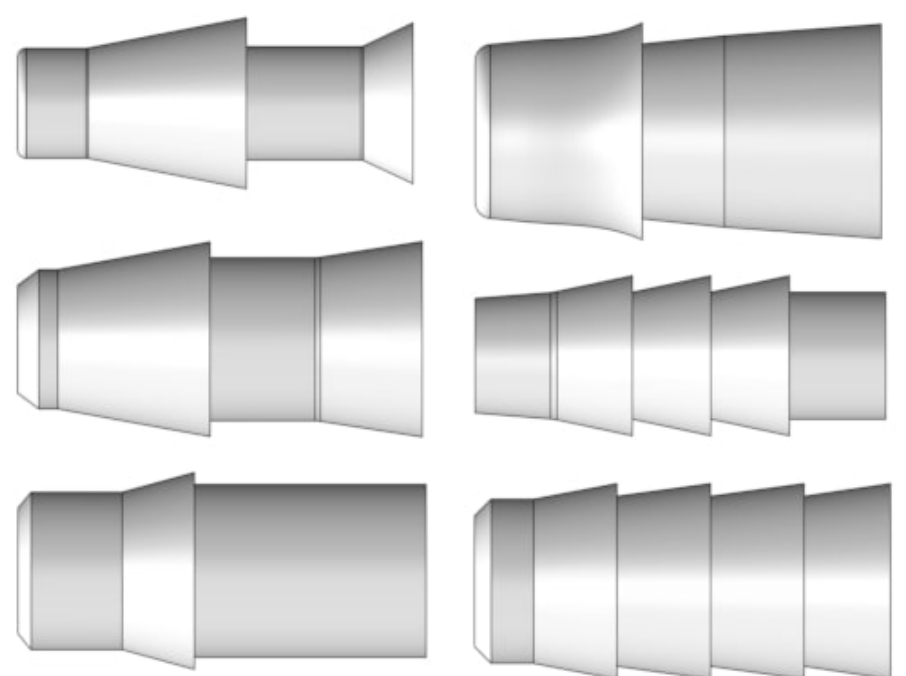

Figure 32: Different types of barb connectors

A barb connector is the part of a connector that is connected to a hose or tubing by being inserted into the hose or tubing. Another definition that describes barb connectors well is: "a connection made and held in place by one or more continuous radial serrations or ridges surrounding a hollow tube through which fluid and air flow can take place."
The use of barbs is most common in applications involving low pressure and fluid, gas or airflow control applications. The barb ridge grips the interior tubing wall and provides a sealing surface without causing any damage to the tubing wall.

The installation of a barb connector requires a tube to be pushed up the slope of the barb and past the barb's edge, past the barb's gripping edge and then over and along the shaft of the barb.

Barb connectors come in different configurations. For this application I have chosen to proceed with the small multi-barb design which does not have a molded parting line on the first barb which prevents the part from ing in to be connected.

\section{T.7T Small Multi-Barb}

Figure 33: Chosen type of barb connector

Designing a barb connector comes with a list of guidelines that need to be followed for optimal results.

The design of the barb profile determines how much a hose or a tube stretches when pushed over the barb. The tube stretching is indicated as the percentage of expansion of the tube's inner diameter. The higher the expansion the better the seal and hold under higher pressure.

Pulling the tube on a barbed connector actually causes the tube to contract and grab the barb even tighter meaning that it is very hard to remove a tube from a connector, but also ensures that it is not likely that a tube can be accidentally disconnected from the connector. The barb profile also determines how easy or difficult it is to install the hose.

The factors that influence the grip and seal quality of the barb are (Fig. 34):

\section{BARB CONNECTOR DESIGN FACTORS}

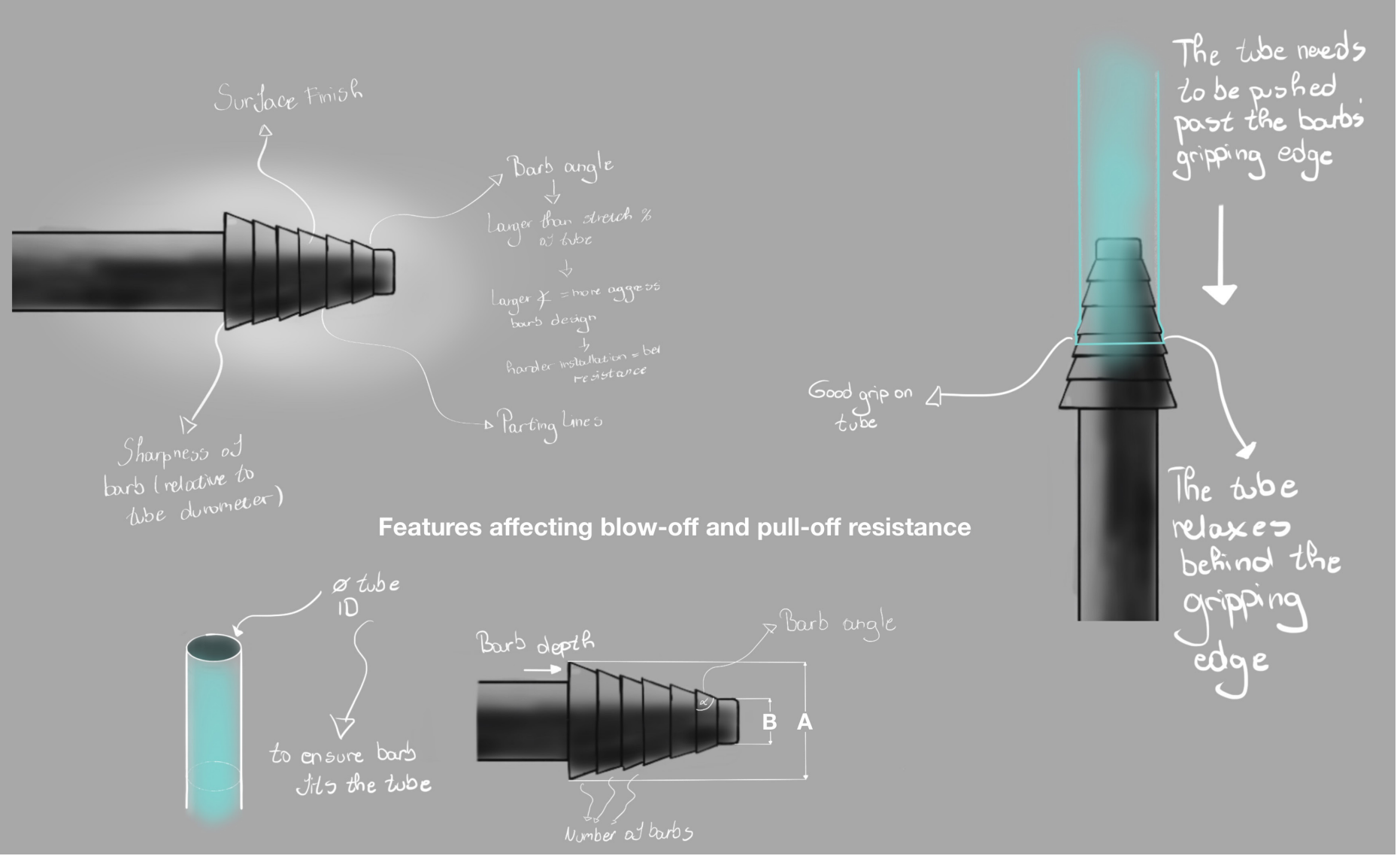

Figure 34: Barb connector design factors

- Barb angle - should be larger than the expansion \% of the tube - leading to a more aggressive barb design - harder installation but greater resistance

- Parting line

- Surface finish

- Sharpness of barb relative to durometer of tube

While factors that influence the blow-off and pull-off resistance are:

- Number of barbs

- Depth of barb

- Spacing of barb ridges

- Inner diameter of tube
In this case blow-off resistance is not taken into consideration as the purpose of the connectors is for suction, therefore blow-off could not possibly occur.

Tube internal diameter and durometer are among the key parameters in barb design. A durometer is a dihardness of materials such as elastomers and plastics to being penetrated or indented. For medical tubing, the hardness (durometer) influences how much and how easily the tube can be stretched when inserting a connector.

Barb Design

While tube diameters were easy to determine based on the availability at Masanga, finding out the durometer of the different tubes is hard as tubes are made from different materials, with different wall thicknesses and by different manufacturers, factors which all influence the durometer values. Finding the exact durometer of the tubing is not possible as tube availability changes. [75]. A material's hardness is the material's resistance 
Therefore, the decision for designing the barb profile was to use the same barb profile as the one on the connectors provided by LUMC (Chapter 2). This decision was made because it ensures that the barb profile will definitely work well with the tubing, as it is a type of barb profile already in use at a high end hospital.

Number of barbs adapted to tube size

Tubing diameters at Masanga range between $3 \mathrm{~mm}$ and $10 \mathrm{~mm}$. However, a decision was made to start at $5 \mathrm{~mm}$ with the first and smallest barb, instead of 3 , and finish with a $12 \mathrm{~mm}$ barb, which would allow a $10 \mathrm{~mm}$ tube to grip around it. This decision for the primary barb was made based on two factors: suction flow and method of manufacturing. If the outer diameter of the first barb would be $3 \mathrm{~mm}$, the internal diameter would have to be maximum $2 \mathrm{~mm}$ wide, which could cause particles of the aspirate to get stuck, which could then block the entire suction flow. Printing such small perimeters comes with the risk of print failure or reduced dimensional and detail accuracy. The decision was verified with Jan Henk, who agreed that this is a risk we should try to avoid to prevent hazardous situations or print failures.

\section{Barb sharpness and parting lines}

A sharper barb design allows for better grasping of the tubing. However, an overly sharp barb could cut the tube if installed or uninstalled harshly. On the other hand, a barb that is not sharp enough could lead to a more slippery connection with the risk of disconnecting.

With a manufacturing method such as 3D printing, the sharpness of the barb will be influenced by the printer properties, despite how it was modeled. Therefore, the barb sharpness will be further addressed in the next chapter.

\section{Collection pot side: Cilindrical design}

The side of the connector that attaches to the collection pot comes in five different sizes, depending on the collection pot outlets. The outlets on the pots are all cylindrical, therefore a decision was made to design the pot side of the connectors as cylindrical, uniform on all connectors, on each connector with the respective diameter size of the outlet it would connect to. pots.

\subsection{SYSTEM POWER}

\section{Method}

In Chapter 3.3, the requirements for System Power were defined as follows:

\section{The system should provide back-up power for $\sim 2 h$ \\ 2. The system should pick up the power auto- matically after line power failure}

3. The system should be based on a $12 \mathrm{~V}$ car battery

Early in the design process there was a concern that the connectors made for the bigger openings could accidentally fall or be sucked inside the collection pot, because even the widest barb diameter is the same size as the collection pot's opening. This worry was dismissed later when Jank Henk brought the lids of the collection pots to the Netherlands. Upon their inspection, it was concluded that inside every outlet, the collection pots have a stopper installed (fig. 36). These stoppers, together with the angled positioning of the outlets will prevent the connectors from getting sucked inside the

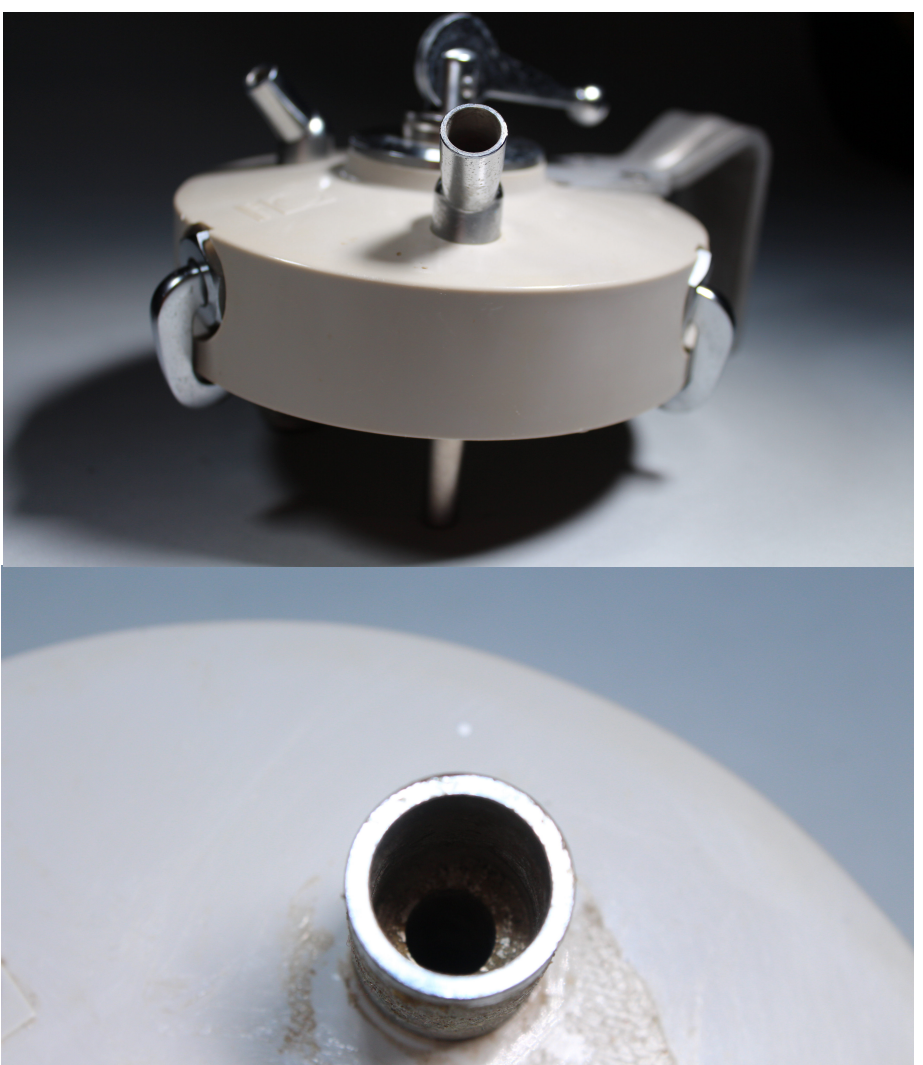

4. The

midity

5. The system should have built-in charge

6. The system should be protected from short circuits

7. The system should invert $D C$ voltage into

AC voltage

8. The system should fit in a transportable box

Based on consultations with experts $[56,57,58]$ desktop research $[59,60]$ and the list of requirements, the preliminary system architecture was developed (Fig. 37)

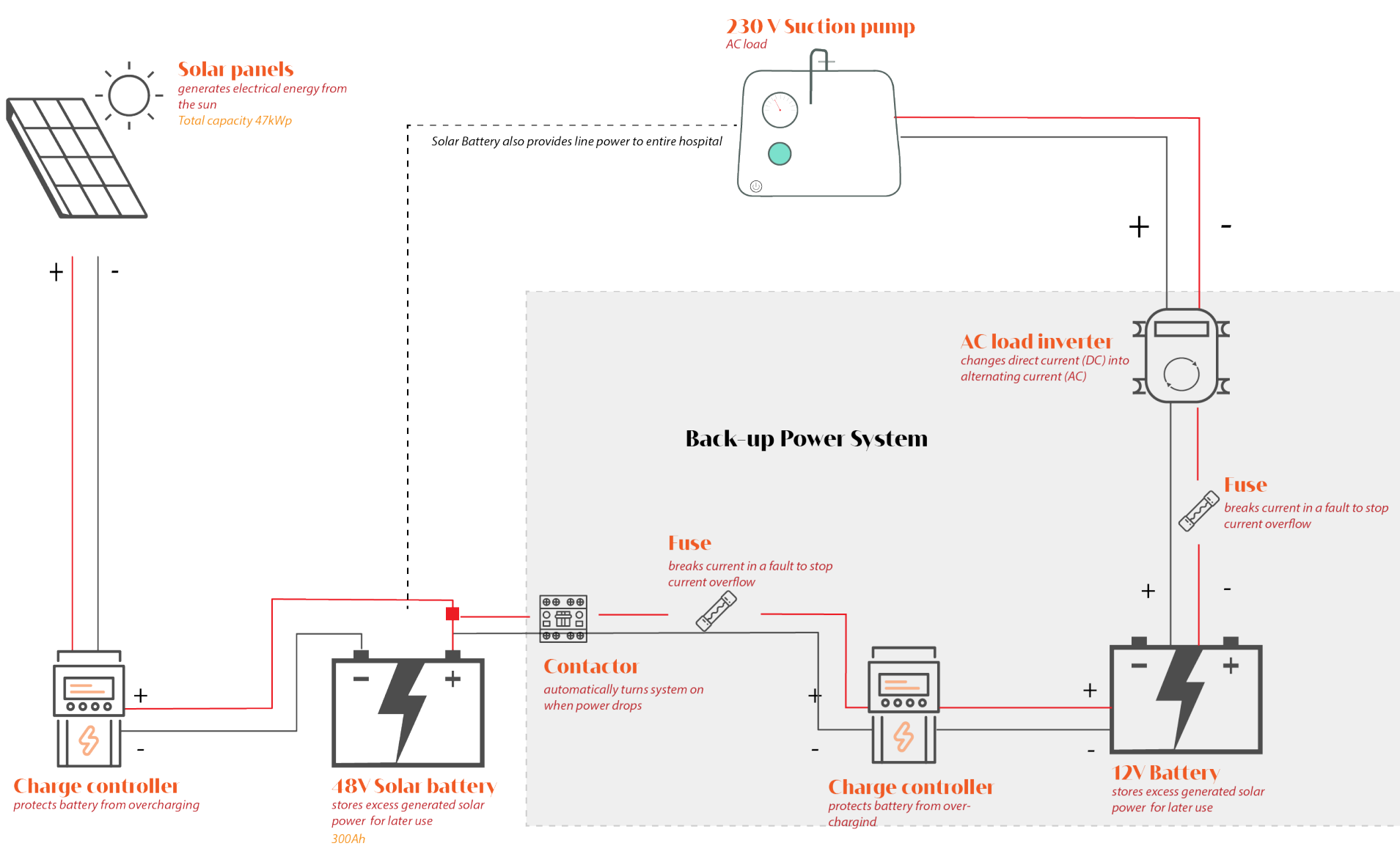

Figure 37: Preliminary architecture of System Power 
The main components that the system is required to have in order to satisfy the requirement are:

- Car battery: Power source

- Contactor: Automatic switch from line power to the system

- Inverter: to invert $12 \mathrm{~V} \mathrm{DC}$ into $230 \mathrm{~V} \mathrm{AC}$ power

- Charge controller: to protect the battery from overcharging

- Fuses: to prevent short circuits

In the following chapter the system architecture will be adapted based on the power consumption and

voltage of the suction pump.

The goal is to get a maximum power efficiency for the lowest price possible, without having to make changes on the pump itself.
Products introduced to cater to a vulnerable population The potential hazards with their probability and severshould not pose any safety threats that may harm the ity levels were identified and an action plan was made end user [69]. In chapter 2.5 the general safety needs and risks of the use of connectors were defined. When designing for additive manufacturing, issues can occur that would not regularly occur if the product was made with another method of manufacturing. Henceforth, before going into local manufacturing, it is important to foresee the potential hazards that arise from LM3D as a manufacturing method.

Therefore, the decision was to proceed with a full Failure Modes and Effect Analysis (FMEA). The FMEA took into consideration the potential hazards that could occur as a result of:

- Poor manufacturing quality

- Improper reuse

- Exposure to the elements

- User error on how to prevent these hazards from occurring. From the action plan for hazard prevention a test plan was developed for System Connect:

- Test on chemical compatibility of manufacturing material and changes in mechanical properties

- Usability

- Performance

- Environmental impact

- Exposure to biological fluids

For System Power, because the system is developed on a conceptual level, at this stage the risks were taken as precautions in the choice of components.

The full FMEA and test plan can be found in Appendix 12. ty levels were identified and an action plan was made 
Chapter 5

\section{DEVELOP}

During this phase the final design solution for the subsystem are developed.

For System Connect, design iterations and decisions are made in three phases: Embodiment Design, Design for Manufacturing and Material Choice.

For System Power, based on the preliminary system architecture and the power requirements of the suction pump, the suitable components for the system are chosen. 


\subsection{SYSTEM CONNECT}

\subsubsection{Method}

Before the start of the prototyping phase, it was important to make several decisions on what should be achieved with the final prototype produced.

Based on the List of requirements, fhe final goals for the connectors were defined:

\section{- Reusable}

- Water tight connectors that

- Would improve the use of the suction.

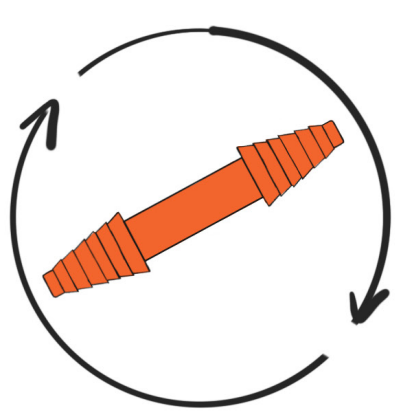

REUSABLE

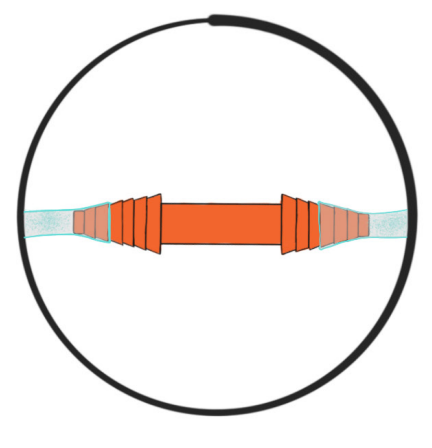

WATER TIGHT

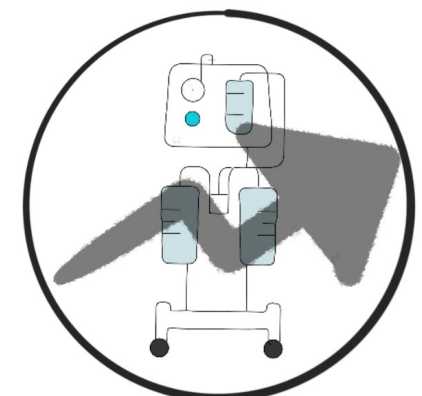

IMPROVES SUCTION
The improved use further relies on the connectors making for:

Phase 1: Embodiment design: achieving the set goals while preparing for manufacturing

- Safer connection points between the components

- Improved suction flow

- Faster preparation of the suction pump

and by that solving the initial challenges of the project, or pain points, presented in chapter 2.3 .

The goals were achieved in three phases, through:

Phase 3: Material choice: chosing the final testing phase of chosen materials

With this phase the connectors achieved a trl level 5 , meaning that by the end of this phase the connectors should be validated in their relevan environment of use.

\subsubsection{Phase 1: Embodiment design}

\section{Method}

The Embodiment Design is directly related to solving

the goal of improved use of the suction pump by

- Safer connection points between the components

- Improved suction flow

- Faster preparation of the suction pump

Through ideation, the challenge was to achieve an

- Improved internal geometry

- Improved external geometry

- Hole alignment

A part's geometry does not influence the price of the part that needs to be printed [72], but for optimal performance of the printing, certain adaptations in the part geometry should be taken into consideration.

\section{Improved external geometry}

In the external geometry of the part changes were made in the points where a combination of the part geometry and the manufacturing method could result in the formation of weak points prone to breaking, i.e. points where the part could break if exposed to tension (Fig. 39). These are the points where the cylindrical shape of the connector experiences transitions from a larger to a smaller diameter. In these points fillets were added to distribute the tension among multiple, rounded layers, instead of having the stress concentrated in one layer.
The angle of the barbs, which was adopted from the cesign of existing connectors, was measur The precise measurement of the angle was necessary to ensure that the angle could be printed as an overhang. $45^{\circ}$ is usually the maximum angle that most printers can print successfully, therefore this angle was not considered a risk in printing, which was confirmed

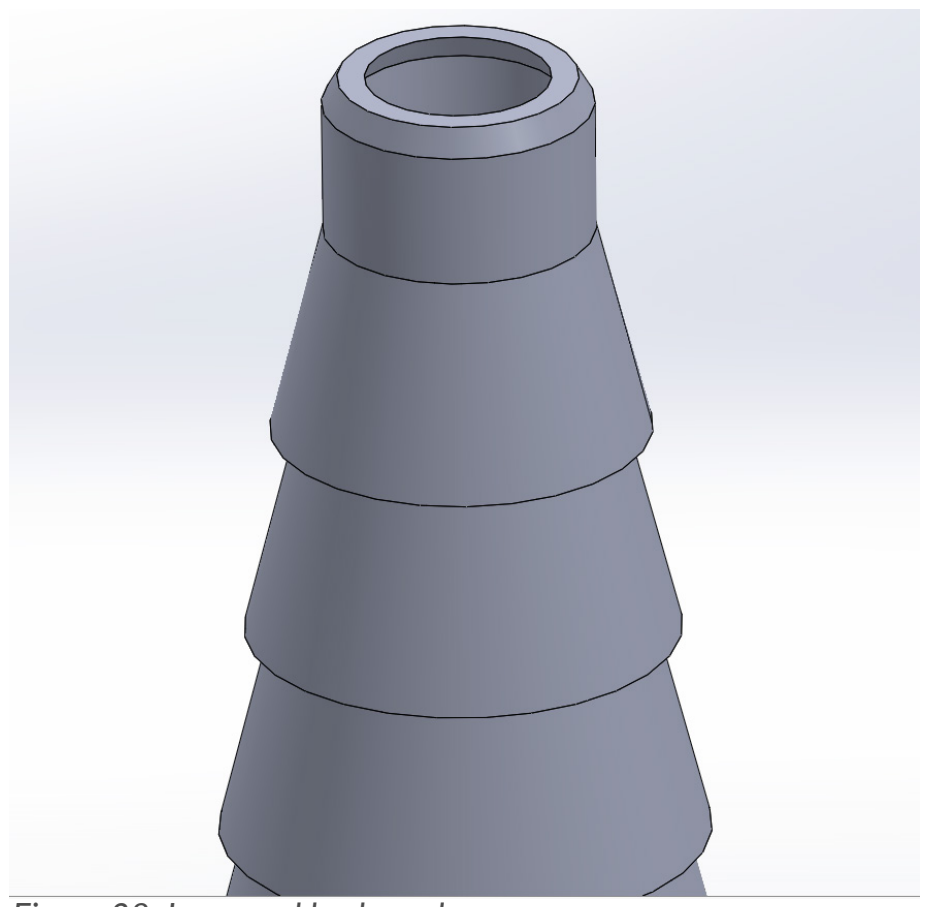

Figure 38: Improved barb angle

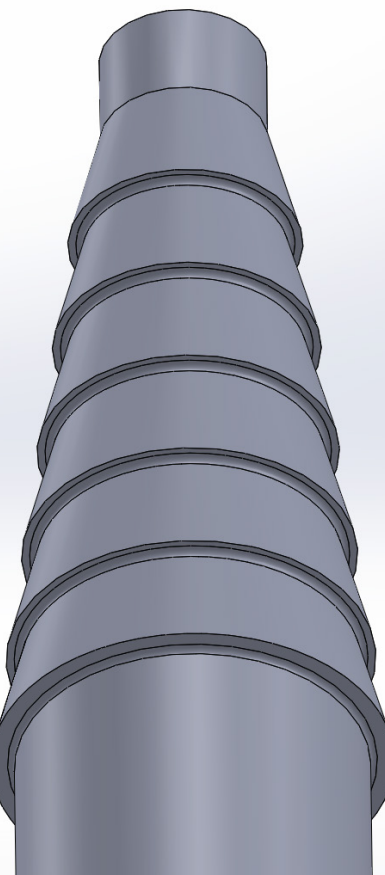

Figure 39: Fillets added for improved tensile properties

in the numerous printing iterations.

An overview of all design iterations can be found in Appendix 13, including a description of all the changes that have been made.

Filets were also added at the parting lines between the 
barbs. Although these changes are not directly visible in the finished design, the difference between the layer deposition can be witnessed in the slicer.

All potential bridges and inconsistencies in the internal walls were removed, leaving a smooth transition from the top to the bottom of the connector.

Internal geometry

In the part's internal geometry, multiple iterations were made to ensure an optimal printability and functionality performance.

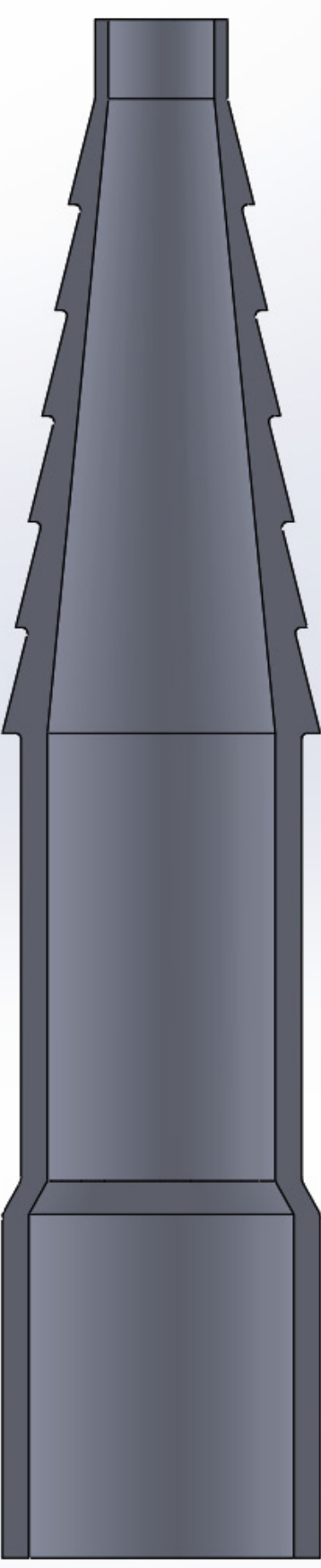

In the part's wall thickness it was ensured that there is no wall thinner than $0.5 \mathrm{~mm}$. Initially there was a concern that this diameter might be too thin, but prototyping showed good results every time.

\section{Hole alignment}

The first and most important step was to ensure hole alignment. Although the part has only one hole, due to the transitions in width (both internally and externally), it was necessary to provide a smooth transition that would not interfere with the printing process or weaken the part.

\subsubsection{Phase 2: Design for manufacturing}

Method

The starting point for this phase of product develop-

\section{DESIGN \\ GOALS}
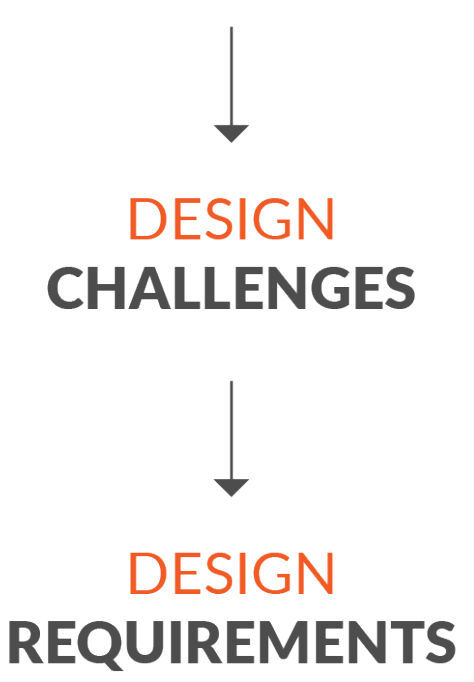

REQUIREMENTS

\section{D PRINTING}

FACTORS

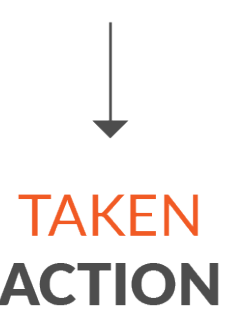

ment was having in mind the set goals for the connectors to be:

- Reusable

-Water-tight

-Improving the use of the suction pump and by that solving Masanga's current challenges of:

- Unsafe connections between components - Reduced suction flow

To achieve these goals and overcome Masanga's challenges, another set of Embodiment for Manufacturing requirements were set for the connectors. The 3D printed connectors should:

- Have smooth inner walls - for uninterrupted suction flow

- Should have smooth outer walls - to avoid damaging the tubing

- Should have no holes or cracks - to prevent leaks or spills

- Should have sharp barb edges - for a good grip on the tube

Having these embodiment requirements defined, the $3 \mathrm{D}$ printing factors that would contribute to achieving these requirements were defined as following:

- Proper layer adhesion - to prevent formation of holes or cracks

- Good overhang settings - for optimal barb edge sharpness

- A well calibrated printer - for guaranteed quality in layer adhesion

- Suitable printing temperature and cooling adapted for printing small perimeters

Having in mind the embodiment of the connectors and the final design requirements, Desktop research was also done on the most common 3D printing errors that could influence the quality of the final connector de- 
sign.

The most common failures that could influence the quality of the final connector and their results are:

- Printing with an incorrect temperature

- Under or over extrusion of materia

- Mechanical issues with the printer

- Incorrect printing speed

- Incorrect fan speed

- Positioning on the printer

Following in the chapter the taken actions to improve the manufacturing of the connectors will be explained. The list of actions taken includes both actions that were applied in the 3D printing slicer and settings applied to the hardware of the printer. Approximately 70 connectors were printed in the process. For the complete 3D printing records see Appendix 13.

Recommended material temperatures for optimal results

Each 3D printing filament has its own temperature at which it should be molten and extruded to achieve optimal printing results. To avoid any failures, the decision made was to print the connectors with the recommended extrusion temperature, as well as the recommended print bed temperature. The temperature settings for PETG and ABS can be found in Table 3.

\begin{tabular}{|l|l|l|}
\hline Material & PETG & ABS \\
\hline Extruder temperature & $255^{\circ} \mathrm{C}$ & $240^{\circ} \mathrm{C}$ \\
\hline Print bed temperature & $100^{\circ} \mathrm{C}$ & $60^{\circ} \mathrm{C}$ \\
\hline
\end{tabular}

Table 3: Extruder and print bed temperatures of PETG and ABS

Reduced printing speed for improved layer adhesion and surface smoothness

Printing small parts requires a lower printing speed to ensure that each layer has time to cool down before a new layer is deposited on top. Multiple iterations were done with various printing speeds. The optimal speed for printing a single connector was found to be $40 \mathrm{~mm} / \mathrm{s}$. This printing speed was tested on PLA, ABS and PETG and gave impeccable results with all three materials

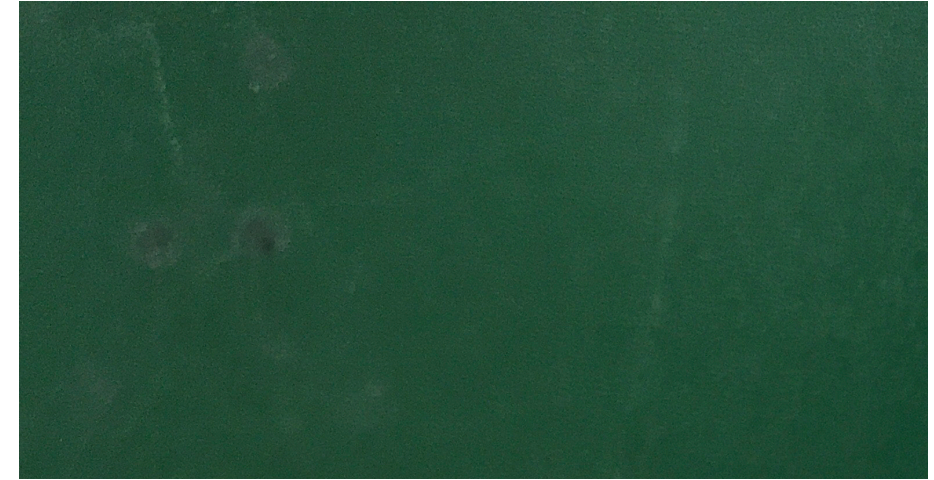

Layer height: $0.1 \mathrm{~mm}$ vs $0.5 \mathrm{~mm}$

Desktop research on 3D printing [76] suggest that best layer adhesion and surface smoothness can be achieved by having a lower layer height. The optimal minimal layer height achievable by a $0.4 \mathrm{~mm}$ nozzle (such as the one on Ultimaker printers) is around $0.1 \mathrm{~mm}$ and $0.2 \mathrm{~mm}$, while the minimum should not exceed $0.05 \mathrm{~mm}$. A test was done by printing one connector with $0.05 \mathrm{~mm}$ layer height and $0.1 \mathrm{~mm}$ layer height. Upon microscope inspection no visible difference in
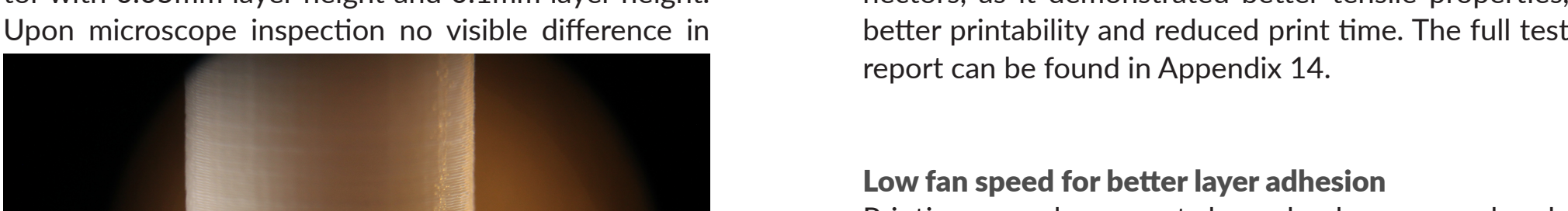

Printing a new layer must always be done on an already solidified layer, otherwise the new deposited layer will move and distort the already deposited layers.

Iterations were done with fan speeds varying from $100 \%$ to $15 \%$. For sequential printing (one connector at a time), the optimal fan speed was discovered to be $15 \%$, both during the initial layers and the rest of the print.

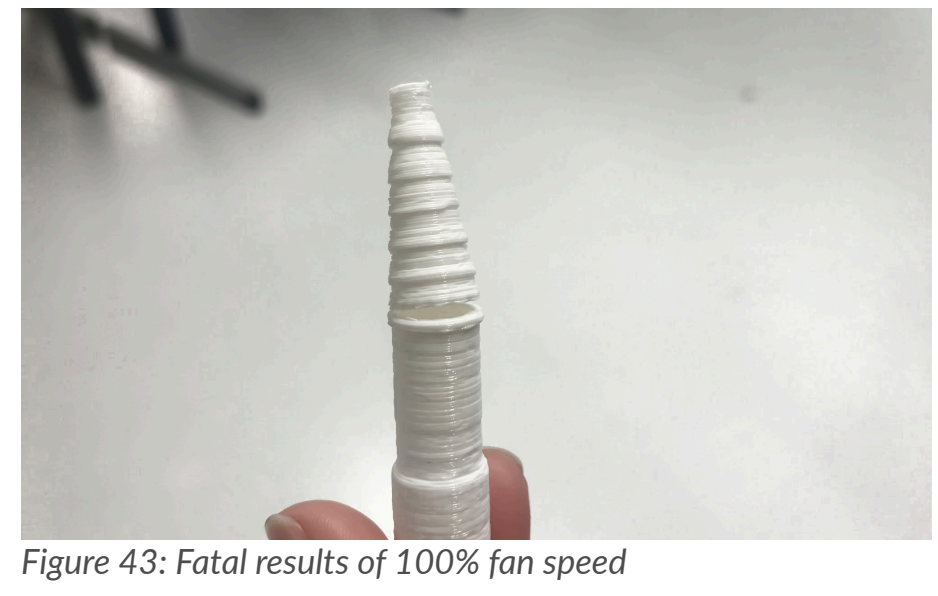

No support to avoid blobs on ths surface

The changes in printing orientation ensured that there is no need for printing support. The main reason why it

layer adhesion was witnessed (Fig. 41). The connector printed with $0.05 \mathrm{~mm}$ demonstrated lowered printabili- was decided to avoid support is because the removal of support always leaves small bumps on the printed part. In the case of the connectors, a smooth surface is necessary, therefore they were continuously printed without support.

$100 \%$ Infill for complete water tightness and stiffness The connectors are hollow on the inside, with a varying wall thickness between $0.5 \mathrm{~mm}$ and $1 \mathrm{~mm}$ throughout their length. To ensure a stiff and non-porous structure, the infill was set to $100 \%$ from the start.

Flipped printing orientation for optimal barb sharpness

The cylindrical shape of the connectors requires that they are printed in vertical orientation. Printing them horizontally would require adding support to the parts that float. The removal of the support would consethat float. The removal of the support

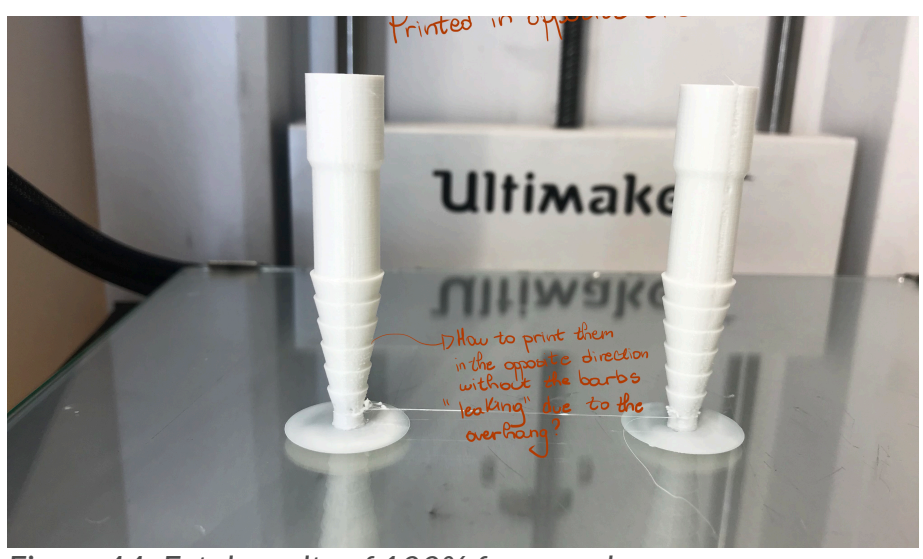

Figure 44: Fatal results of $100 \%$ fan speed

What was noticed in the given print orientation is that due to the presence of overhangs in the barb design, the barb started "leaking" downwards and their sharpness decreased. A test on printing the connector turned around for $180^{\circ}$ showed incredible results in the barb sharpness. An initial concern was that the narrow initial barb would not be able to support the rest of the barb, but multiple iterations showed that with well printed initial layers, the structure can hold the rest of the print.

Part positioning on print bed

Expert consult [77] suggested that to avoid ambient temperature and surrounding conditions to affect the prints, that they should be printed at the centre of the build plate.

Although it might not have been a result of ambient conditions, the prints showed better layer adhesion, especially among the first layers, when they were posi- 
Frequent build plate leveling for even layer adhesion A properly leveled build plate ensures even extrusion of the material on the build plate surface. Signs that the build plate requires leveling are: varying gap between the lines of filament across the surface of the print, warps, inconsistent build plate adhesion or varying layer height and width. The Ultimaker S5 used at Masanga has the option of automatic build plate leveling, which makes it convenient for novice users, as the interface guides the user in the steps that need to be taken (Appendix X)

\section{Gear adjustments}

Extruder gear tension is a commonly overlooked hardware adjustment in $3 \mathrm{D}$ printing. If the tension is too low, the extruder fails to feed material, and if the tension is too high it can result in the formation of wavy structures or blobs across the print. Performing manual gear adjustment to the printer resulted in impeccable changes in the layer adhesion, without any gaps or lamination occurring between the material layers.

\section{Filament quality}

3D printing filaments are hygroscopic, meaning that they have a tendency of absorbing moisture if exposed to humidity from the environment. The moisture makes the filament swell, leading to poor build plate adhesion, delayed extrusion, bubbles on the surface of the print, soft and easily breakable parts or even complete failure of the print. An easy method to determine whether the filament has absorbed moisture is to take a piece and try to snap it in half. If it snaps easily, the filament has most probably absorbed moisture from the environment.

Recommendation:

An easy way to preserve the filament is to keep it stored in an airtight, plastic container with silica gel beads. Silica gel beads are an ideal and affordable solution to maintain the humidity level of the filament, because of their low price and high availability.

\section{Extrusion flow}

Improper extrusion can be a result of many factors, caused by hardware, software or the material fed in the extruder. What was noticed during the prototyping was that on some printers the extrusion flow had to be reduced to $0.9 \%$ in the slicer settings, as printing with an extrusion flow of $100 \%$ often resulted in lines

forming on the side of the print or a blob at the bottom of the print.

\subsubsection{Phase 3: Material Choice}

Method

The goal of this phase and the testing is to determine whether PETG or ABS is a more suitable candidate for $3 \mathrm{D}$ printing reusable medical tubing connectors. Based on the goals and requirements set, the production material for the connectors should be:

\section{- Be water-tight}

- Chemically resistant

- Resistant to environmental effects

- Compatible with biological fluids

From these points a test plan was made. The decision was to test the materials for:

- Environmental effects for storage by being placed in a humidity chamber for 14 days (arbitrary estimated storage time)

- Infection getting stuck in between materi-

al layers by infecting them with artificial test soils (ATS)

- Compatibility with the cleaning method of masanga by exposing to a chlorine bath - Compatibility with Hydrochloric acid present in gastric juices (suctioned media) by soaking in hydrochloric acid

The chemical compatibility tests were the final deciding factor in the choice of production material for the connectors.

In this chapter the tests will be explained on their Method, Hypothesis and Results.
Humidity Test

Method

The goal of the humidity test was to see whether storage of the connectors at Masanga, where humidity levels are high would result in the material absorbing moisture from the environment. The test was performed by placing an ABS and a PETG connector in a humidity chamber (Fig. 45 ) at $32^{\circ} \mathrm{C}$ and $80 \% \mathrm{RH}$, compatible with heat and humidity levels at Sierra Leone, or 14 consecutive days, an arbitrary estimated storage time for the connectors. The weight and surface quality of the connectors were recorded before and after humidity exposure to detect changes.

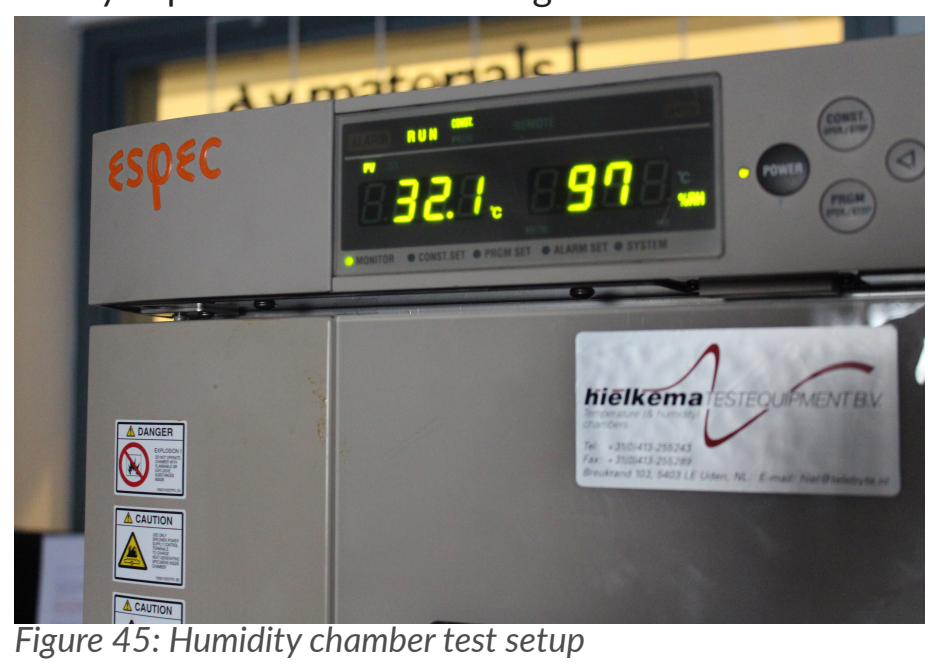

Hypothesis

The hypothesis for the test was that the PETG connec tor would behave better under humidity exposure than the ABS connector

Results

Both connector demonstrated no change in weight or surface finish, upon which it was concluded that both materials are safe for storage at Masanga Hsopital.

The full test report and testing protocol can be found in Appendix 15.

\section{Infection Test}

Method

The goal of this test was to determine whether the embodiment of the connectors and the material choice and its printability would influence the ease of cleaning of the 3D printed connectors. The test was performed by artificially infecting an ABS and PETG connector with Artificial Test Soil (ATS), made with egg white and food colouring (Fig 46) and left to dry out completely for two hours. The connectors were then cleaned with Masanga's standard method of cleaning by soaking in a $0.5 \%$ chlorine bath (Fig. 47). The weight of the connectors was recorded before and after the test to determine the presence of residual contamination post cleaning. The connectors were also inspected under UV light before and after the test to check for residual contamination.

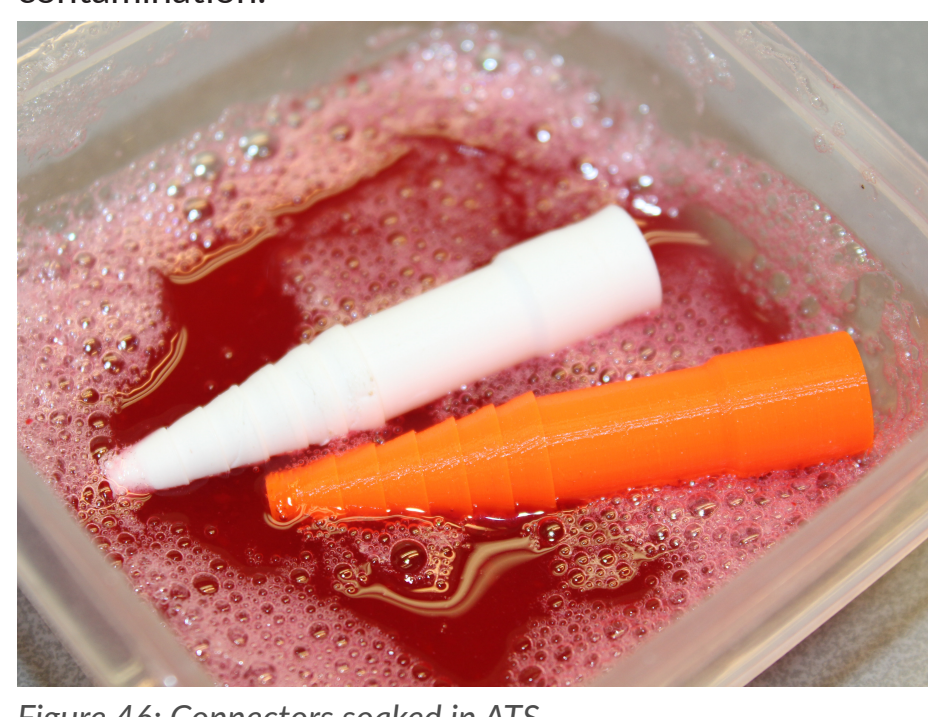

Figure 46: Connectors soaked in ATS

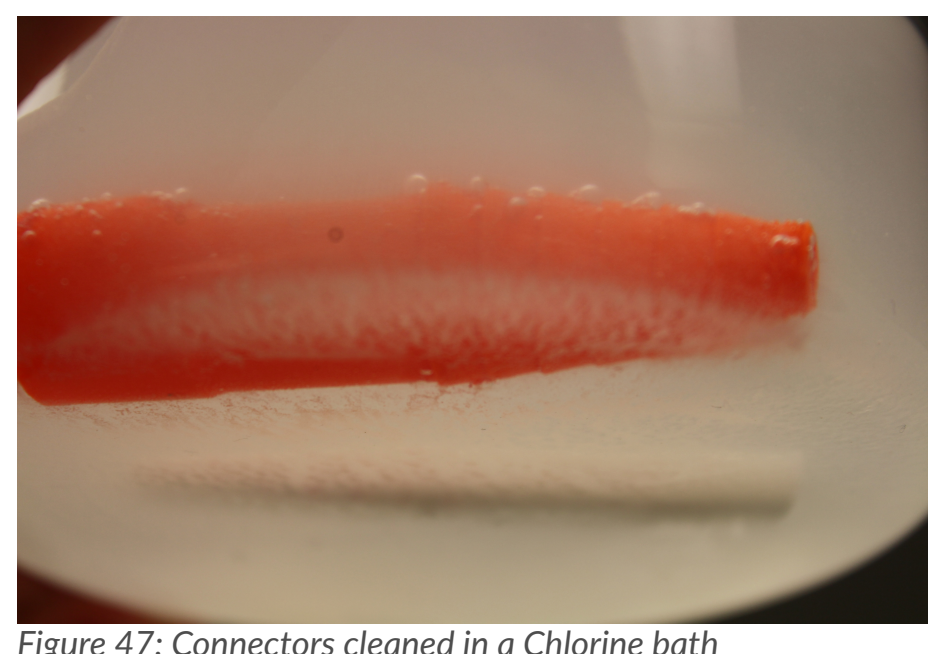

Hypothesis

Contamination would get stuck in the corners between the barbs of the connectors.

Results

The results showed that no residual contamination is left on the connectors when applying Masanga's standard cleaning method. This test was the first step towards validating that the connectors would be suitable 
for use at Masanga Hospital.

The full test report and test protocol can be found in Appendix 16.

Chemical Compatibility Test

\section{Method}

The goal of this test was to inspect how the chemical treatment of PETG and ABS connector would influence changes in their mechanical, in particular the ultimate changes in their mechanical, in particular the ultimate
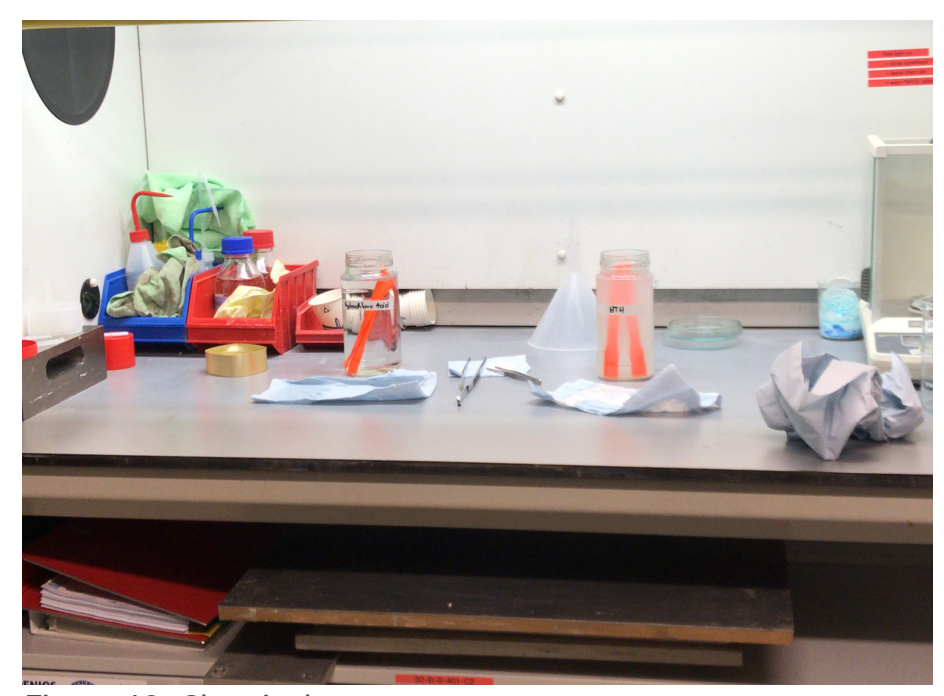

Figure 48: Chemical test setup

tensile strength, material degradation and surface quality. The testing was performed on PETG and ABS tensile dog bone samples printed by soaking them in 25 cycles in a 0.5 Chlorine bath and $0.1 \mathrm{M}$ Hydrochloric acid solution for 10 minutes. The weight and surface finish of the samples was recorded before and after the tests to detect changes. After the 25 soaking cycles, the tensile test was performed on the samples to see whether the chemical treatment had any influence on the mechanical properties of the samples. The results were verified against control samples that were left untreated.

Hypothesis

Parts 3D printed with PETG will have better chemical compatibility compared to parts printed with ABS

Results

The results of the chemical testing showed that ABS connectors demonstrate overall better tensile properties compared to PETG. However, due to ABS absorption of fluids during the testing, a decision was made

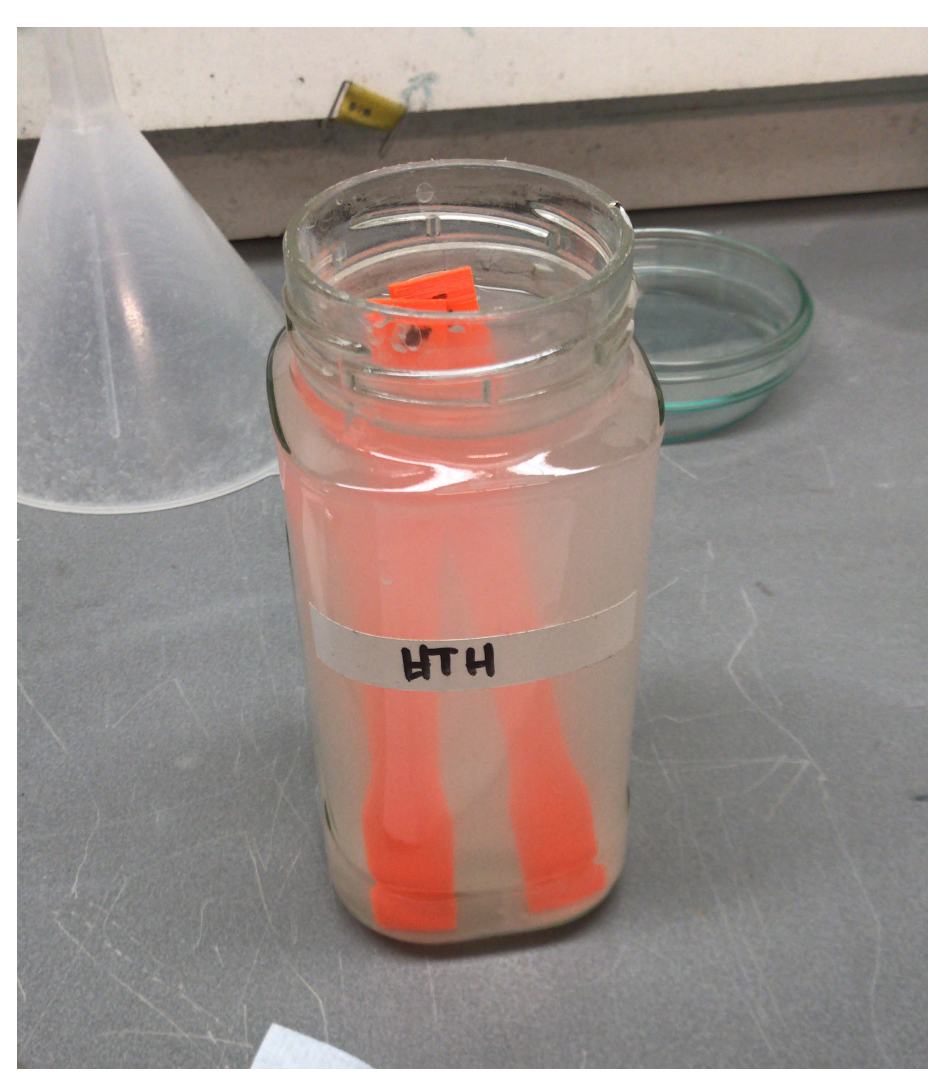

Figure 49: Samples soaked in a chlorine bath

to proceed printing the medical tubing connectors with PETG as it demonstrates good chemical resistance and does not absorb the fluids it is soaked in, which makes

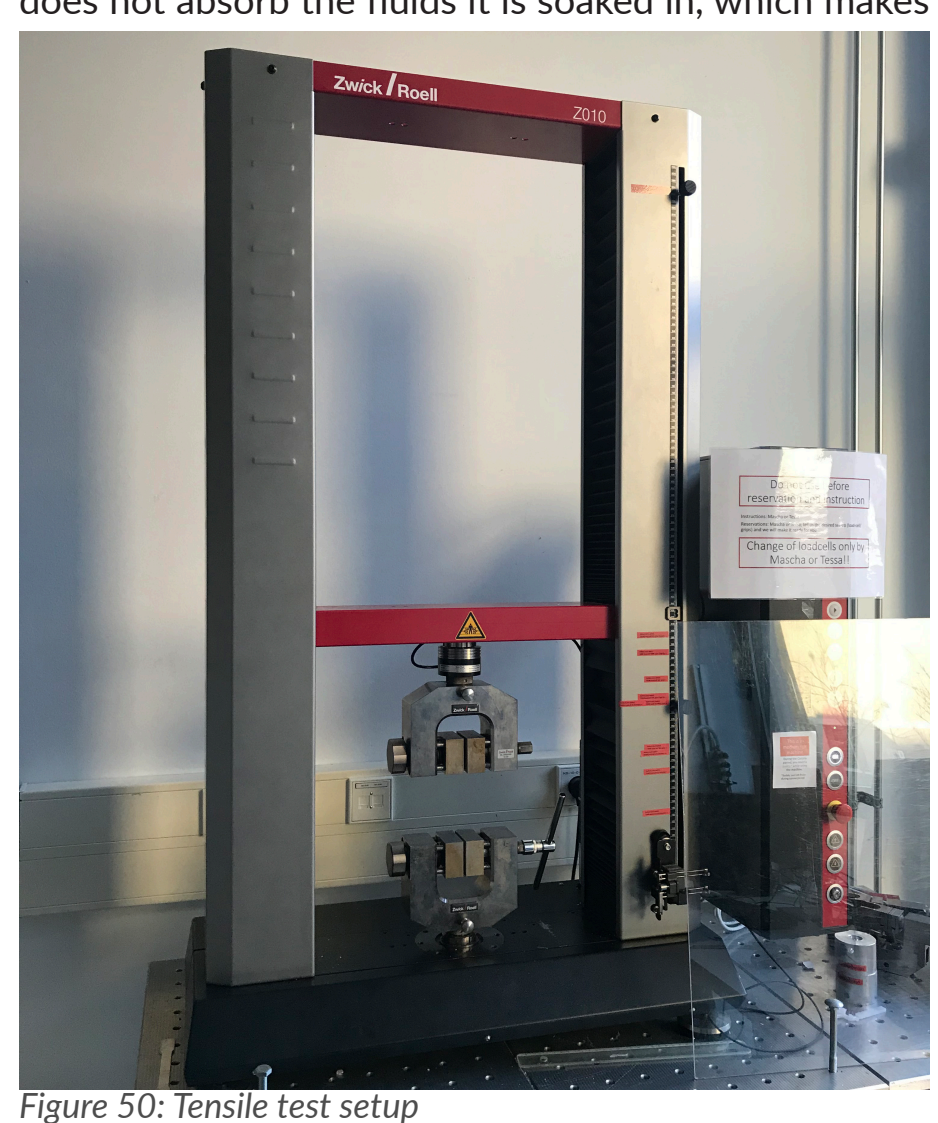

it a perfect candidate for a reusable product.

The full test report and testing protocol can be found in Appendix 17.

Conclusion

The performed tests showed that connectors printed with PETG would be suitable and safe for use at $\mathrm{Ma}$ -

sanga Hospital, in regard to:

- Compatibility with humidity exposure during storage

- Ability to successfully clean after use to avoid cross contamination and

- Fitting Masanga's behaviour towards reusing medical consumables. 


\subsection{SYSTEM POWER}

Method:

In the previous chapter the main components required for the power pack were determined. In this chapter through desktop research $[77,78,79,80,81]$ and expert consultations the specific types of each component were picked to satisfy the power consumption of the suction pump.

As shown in Chapter 2.3, the suction pump at Masanga Hospital has:

-A power consumption of 110 Watts

And requires

-A power supply of 230 Volts AC

The decisions were validated with an electrical engineer [82]. The availability of the components in the context was confirmed with two of the locals:

Sheku [83]: Logistics officer at Masanga Hospital

Titouan [84]: Employee at Easy Solar (the company that installed Masanga's solar power grid)

The research lead to the choice of the following components:

Battery charger with built in charge controller

Titouan suggested an $A C$ to $D C$ charger with built-in charge control from the company Victron (Fig. 51), that also comes with built in short-circuit protection in case of any power fluctuations in Masanga's power line therefore eliminating the need for an additional fuse in the system. The charger is designed to be compatible with $6 \mathrm{~V}$ and $12 \mathrm{~V}$ car batteries of any type which allows flexibility in the choice of car battery. The charger comes together with jump cables that connect to the battery, making it easier to source all the components. It includes an integrated thermal sensor to eliminate over charging in hot climates, making it perfect for use at Masanga. It has the ability of charging dead batteries, allowing for reuse of existing and available batteries that are obsolete at Masanga, and can automatically detect battery sulfation or acid stratification to restore lost battery performance. Its advanced maintenance properties prevent overcharge, even if left for longer than intended.

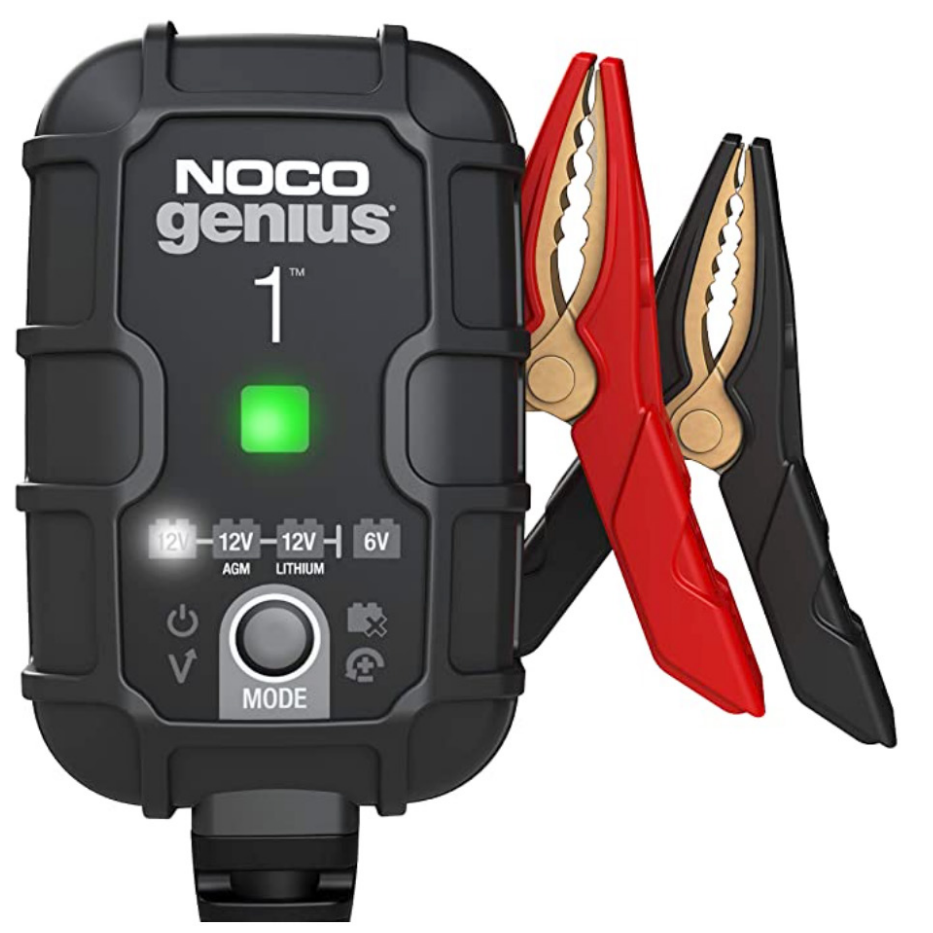

Figure 51: Battery charger suggested by Titouan

Procurement of these types of chargers in Sierra Leone can be done via any e-commerce company. Easy Solar offered to order one for us through their official vendor from the Netherlands.

Battery box for portability, humidity, heat and impact protection

As mentioned in the previous chapter, the alternative power system is intended for use inside the OR, where it comes in contact with other medical devices and the medical staff. To prevent the system from posing a threat to the safety of the staff and the overall organization within the OR, it was concluded that there should not be any cables laying around and that the car battery should be protected from accidentally being kicked or pushed. Placing the entire system in a battery box (Fig.. 52) would allow the system to be portable as one unit. The boxes come with dividers, which allow for division of the space inside the box into separate compartme one side all of the power inlet components, such as the battery charger and the cables are placed, the battery is placed in the middle and on the other side the power outlet components can be placed, such as the fuse and the load inverter. The boxes are made of plastic and

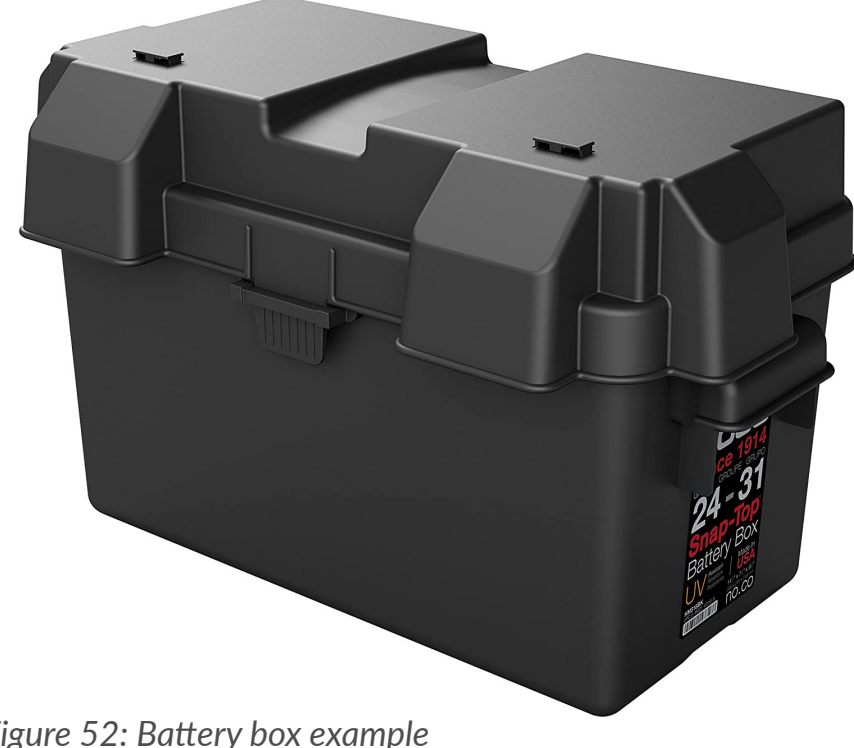

Figure 52: Battery box example

they can easily be drilled to install a power outlet that would serve for direct plugging of the suction pump to the power system. By enclosing the system in a box it is protected from environmental influences, such as exposure to humidity. The box allows the whole system to be transported from one location to another without any component getting lost.

A 12V, Deep cycle battery to withstand regular discharging

Deep Cycle batteries were found to be the most suitable choice for this application as they are meant to be regularly deeply discharged and recharged. Additional

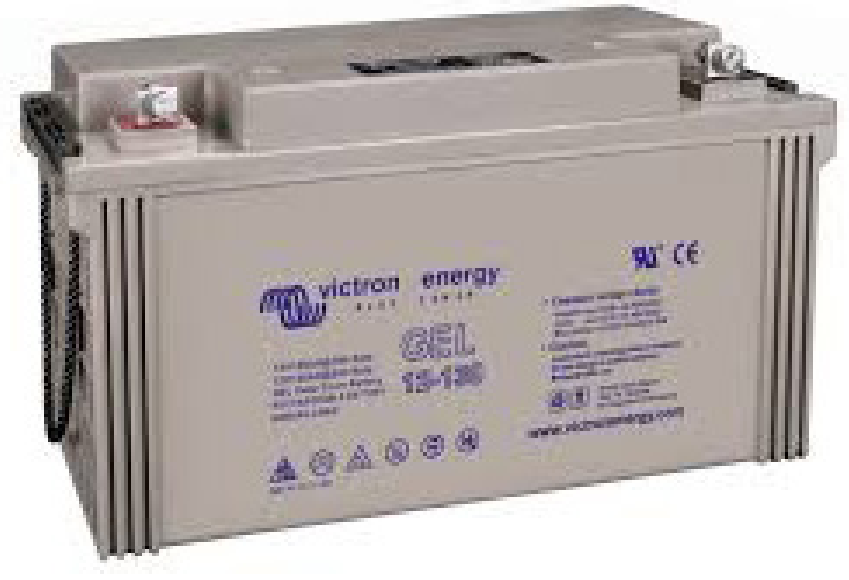

Figure 53: Deep Cycle car battery

calculations were done to choose a battery with the correct capacity, indicated in ampere hours. The calculations showed that any battery with a capacity of 35 ampere hours or higher would be sufficient to power the pump for approximately 2 hours. The complete calculation can be found in Appendix 18.

Fuses to protect the system from short circuits The fuse has two main purposes in the system:

- To protect the device and users from risks of fire and electric shock \&

- To isolate a subsystem from the main system, in this case System Power from the suction pump system.

The right amperage of fuse is defined by the amperage of the car battery. Therefore, the system would require a fuse with a minimum amperage of 35 amps or higher, as higher amperage fuses are recommended for use in areas with high heat.

From DC to AC with a sine wave inverter

The suction pump works on a single phase electrical motor, for which Sine Load Inverters are the optimal choice.

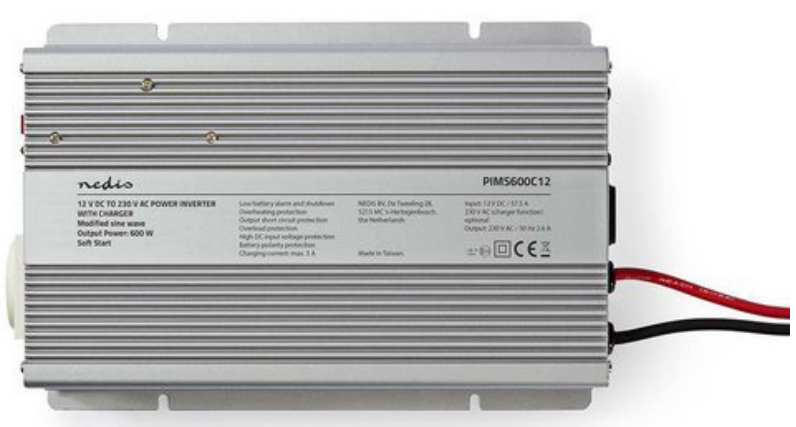

Figure 54: Sine wave load inverter

A load inverter is an electronic power device that changes direct current (DC) into alternating current (AC). Choosing the right load inverter for a given application depends on the total draw of the device that will be used. For use with the suction pump an inverter at $110 \mathrm{~W}$ would be sufficient. 
A contactor to automatically take the power over

Having the system immediately turn on after a power

drop can be done by installing a contactor. In situations

where the system would be plugged into the hospital's

line power and charging

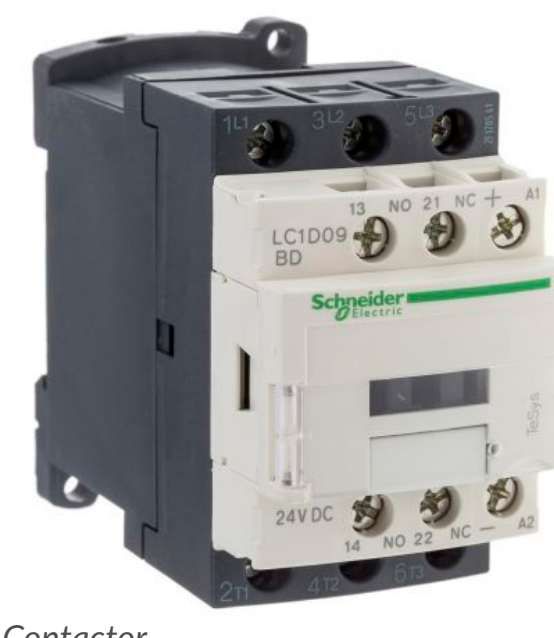

Figure 55: Contactor
Domestic cables between pump and load inverter

electrical installations, different cable thicknesses

are chosen based on the current flowing through the

system. For this application, regular domestic cables

would be enough to transfer the power from the in-

verter to the device. Their availability in various lenghts

makes it easy to pick a long cable and position the de-

vice further from the operation table to avoid tripping over the power pack.

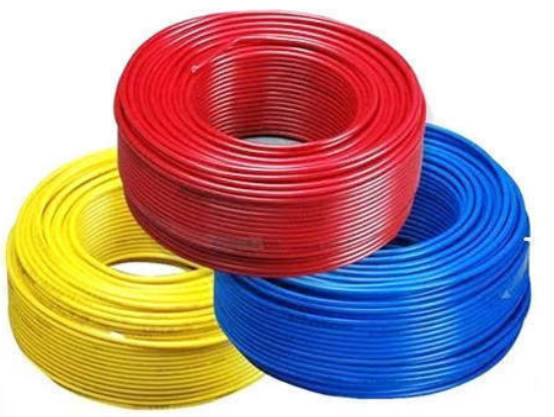

Figure 56: Domestic cables 


\section{Chapter 6 DELIVER \\ In the Deliver Phase the final design solutions will be presented.}

For System Connect, the final design decisions for the 3D printed medical tubing connectors will be presented, followed by the final evaluation of the design solution in the relevant context (TRL level 6)

For System Power, the final concept for the portable power pack will be presented. 


\subsection{SYSTEM CONNECT}

The final design solution for System Connect are locally $3 \mathrm{D}$ printed medical tubing connectors, produced with PETG filament.

Following in this chapter the final 3D printing parame- Finally, the results of the final evaluation of the conters for the connectors will be presented, followed by nectors at Masanga will be presented.

the main distinguishing features of the connectors.

\begin{tabular}{|l|l|}
\hline $\begin{array}{l}\text { Slicer Parameters for FDM 3D Printing of Medical Tubing } \\
\text { Connectors }\end{array}$ \\
\hline Device & Ultimaker S5 and Ultimaker S3 \\
\hline
\end{tabular}

\begin{tabular}{|l|l|c|}
\hline \multirow{4}{*}{ Material properties } & Type & PETG \\
\cline { 2 - 3 } & Extrusion temperature & $\mathbf{2 4 0} \mathbf{C}$ \\
\cline { 2 - 3 } & Print bed temperature & $60^{\circ} \mathbf{C}$ \\
\cline { 2 - 3 } & Flow & $100 \%$ \\
\hline
\end{tabular}

\begin{tabular}{|l|l|c|}
\hline \multirow{4}{*}{ Print Quality } & Layer height & $0.1 \mathrm{~mm}$ \\
\cline { 2 - 3 } & Initial layer height & $0.2 \mathrm{~mm}$ \\
\cline { 2 - 3 } & Line width & $0.25 \mathrm{~mm}$ \\
\cline { 2 - 3 } & Initial layer line width & $100 \%$ \\
\hline
\end{tabular}

\begin{tabular}{|l|l|c|}
\hline \multirow{2}{*}{ Infill } & Infill density & $100 \%$ \\
\cline { 2 - 3 } & Infill pattern & N/A \\
\hline
\end{tabular}

\begin{tabular}{|c|l|c|}
\hline Print bed adhesion & Brim & $\mathbf{8 m m}$ \\
\hline
\end{tabular}

\begin{tabular}{|c|l|c|}
\hline \multicolumn{2}{|c|}{ N/A } \\
\hline Support & \multicolumn{2}{|c|}{} \\
\hline \multirow{2}{*}{ Speed } & Print speed & $40 \mathrm{~mm} / \mathrm{s}$ \\
\cline { 2 - 3 } & Number of slower layers & 4 \\
\hline \multicolumn{2}{|l|}{} \\
\hline Cooling & Fan speed & $15 \%$ \\
\hline
\end{tabular}

\subsubsection{Connector features}

\section{Customizable dimensions}

Having the 3D printing settings established already, in case a new piece of equipment with different dimensions is introduced to the hospital, a connector could easily be printed just by recording the outlet dimensions (As done in chapter 3.2) and changing the dimensions of the model. That way, Masanga hospital could reproduce connectors depending on their momentary demand, without having to depend on any supply chain or having to look for an existing connector with the required dimensions.

\section{Safe to reuse for up to 25 cycles}

The chemical testing showed that the mechanical properties of the connectors change almost insignificantly after 25 cycles of chemical exposure, making them safe to use up to 25 times, or 25 surgical procedures. However, more reuses than that are not recommended before additionally testing the connectors for more cycles.

\section{Easily reproducible}

In case a connector gets lost or breaks, the staff could easily reprint a new one in less than two hours. The gcodes for the files will be provided to them, therefore a new connector would be just a few clicks away at any

time.
4. Reduced assembly time for nursing staff

By having a suitable connector for every connection point the staff would save time on trying to find a way to secure every connection. As they are already understaffed and overworked, reducing the assembly time of the suction pump could give them more time for other tasks around the hospital.

5. Total set manufactured in $\sim 8$ hours (printing a sequence)

The possibility of 3D printing the whole set of connectors as one sequence on the 3D printer was tested and showed that a set of 5 connectors (excluding the connector with two tube sides) can be printed in approximately 5 hours. The connector with both barb sides needs to be printed separately as it is slightly higher than the rest of them and not compatible for printing in a batch. 
6.1.2 Final Design Evaluation: Usability and performance test

During Jan Henk's visit to the Netherlands, a meeting was organized where the design was analyzed and validated. Finally, Jan Henk went back to Masanga with a number of samples of connectors, two of which were dimensioned to fit the small collection pot of the hospital. Having the connectors at Masanga made it possible to do a final evaluation of the design on the suction pump itself, with the engagement of the local staff

\section{Method}

The test was divided in two parts:

- The connectors during the preparation for use of the suction pump

- The connectors in the use of the suction pump

Durign part one, the test was performed on the:

- Usability of the connectors by the local staff

During part two, two test were performed on the:

- Performance of the connectors when exposed to negative pressure from the suction pump

- The performance of the connectors during suction
Usability Test

\section{Method}

The goal of this test was to examine the usability of the connectors with a real user and understand what kind of problems or confusion the user experiences during the use of the connectors.

The user was asked to connect the suction system by using the connectors, as if they are preparing the pump for a surgery.

Results

The results of the test showed that the users had no problem with understanding how to use the connectors. Without any prior explanation about the embodiment the nursing staff was able to demonstrate how they would connect the system if they had the connectors ready to use.

During the test the connector with the smallest diameter on the collection pot side broke (Fig. 57), which showed that the printing settings for that connector should be revisited and that special methods may need to be applied to improve the quality and durability of the part.

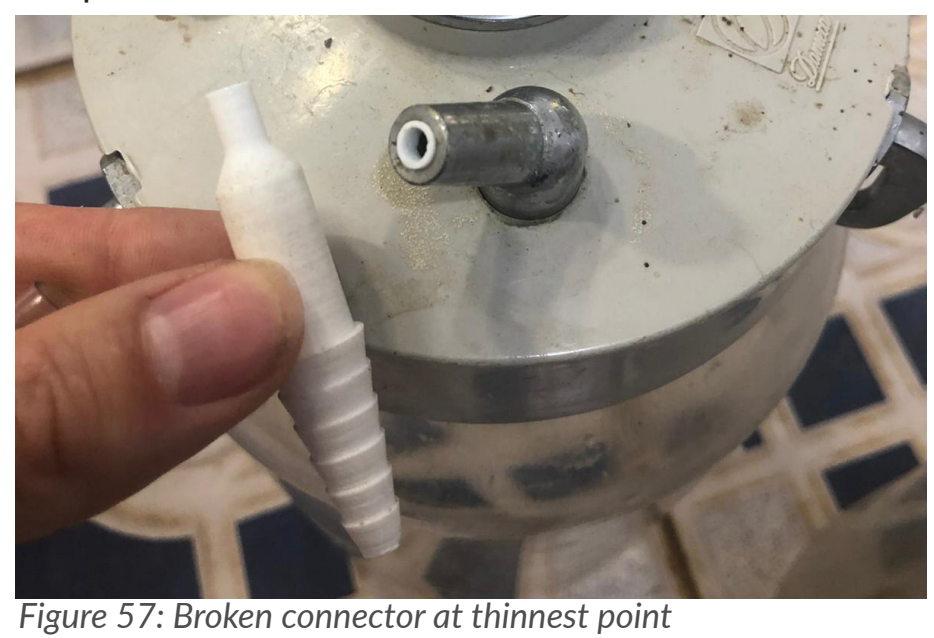

A request from the staff was that the connectors should be made flexible. The idea of printing the connectors from a flexible material was already looked and was determined to be unsuitable. However in the fut idea can be revisited and further testing can be done to see whether there is a possibility of 3D printing the connectors flexible.

An interesting observation was that one member of the nursing staff was able to find another purpose for the connectors that was not previously intended. The conclusion was that the collection pot side designed to fit the smallest outlet on the small collection pot can also be used to connect to a catheter, which has a smaller diameter than the tubing and is less flexible.

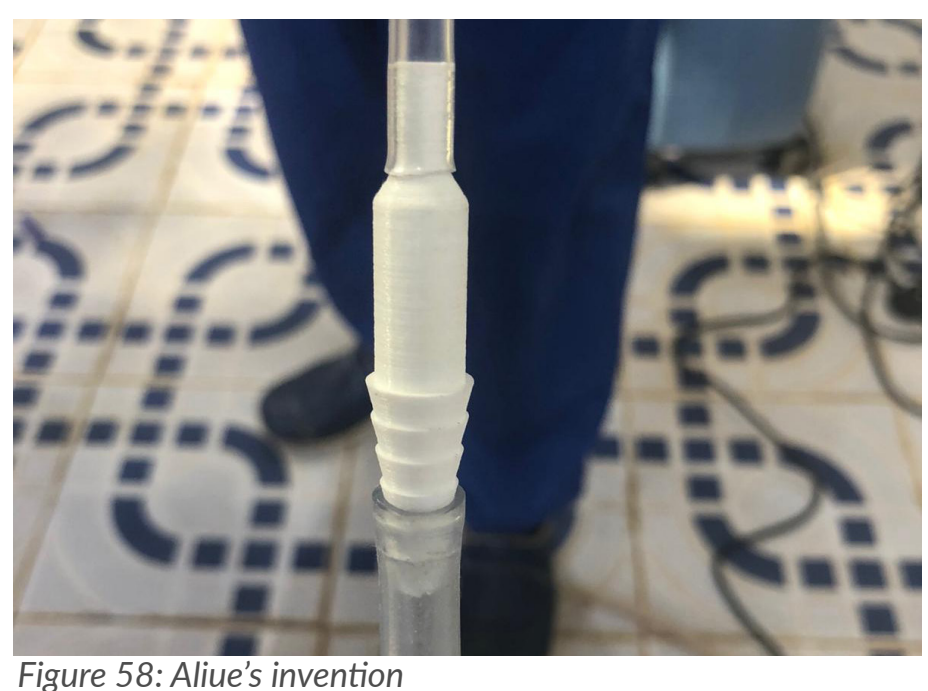
Figure 58: Aliue's invention

Note: The connectors used in the test were printed with PLA, as they were sent to Sierra Leone before the decision to print with PETG was made. Connectors printed with PETG are more resistant to stress and pressure,

Conclusion

The design of the tubing connectors is understandable and easy to use for the local staff. The most important conclusion however is that the nursing staff should be engaged even more in the design process. As end users of the product, they have the best understanding of what they need from the product and they have a lot of practical knowledge that can be useful for the designer.

\section{Performance Test}

\section{Method}

The goal of the test was to determine whether the connectors can withstand exposure to suction pressure and whether the flow of the suction pump would be improved with the connectors. The test was performed by first exposing them to suction pressure only. Afterward the suction flow was inspected by suctioning 1 liter of clean water, by using the connectors to connect the system.

Results

The connectors performed excellent during the test! No issues were detected, the connection points remained stable and there were no leaks on interruptions in the process.

\section{Conclusion}

The connector performed up to all expectations during the test. While in the previous chapter the material testing determined that printing the connectors with PETG makes them safe for reuse, this test proved that the connectors provide a safe, leak proof use of the pump, by overall improving the use of the suction pump.

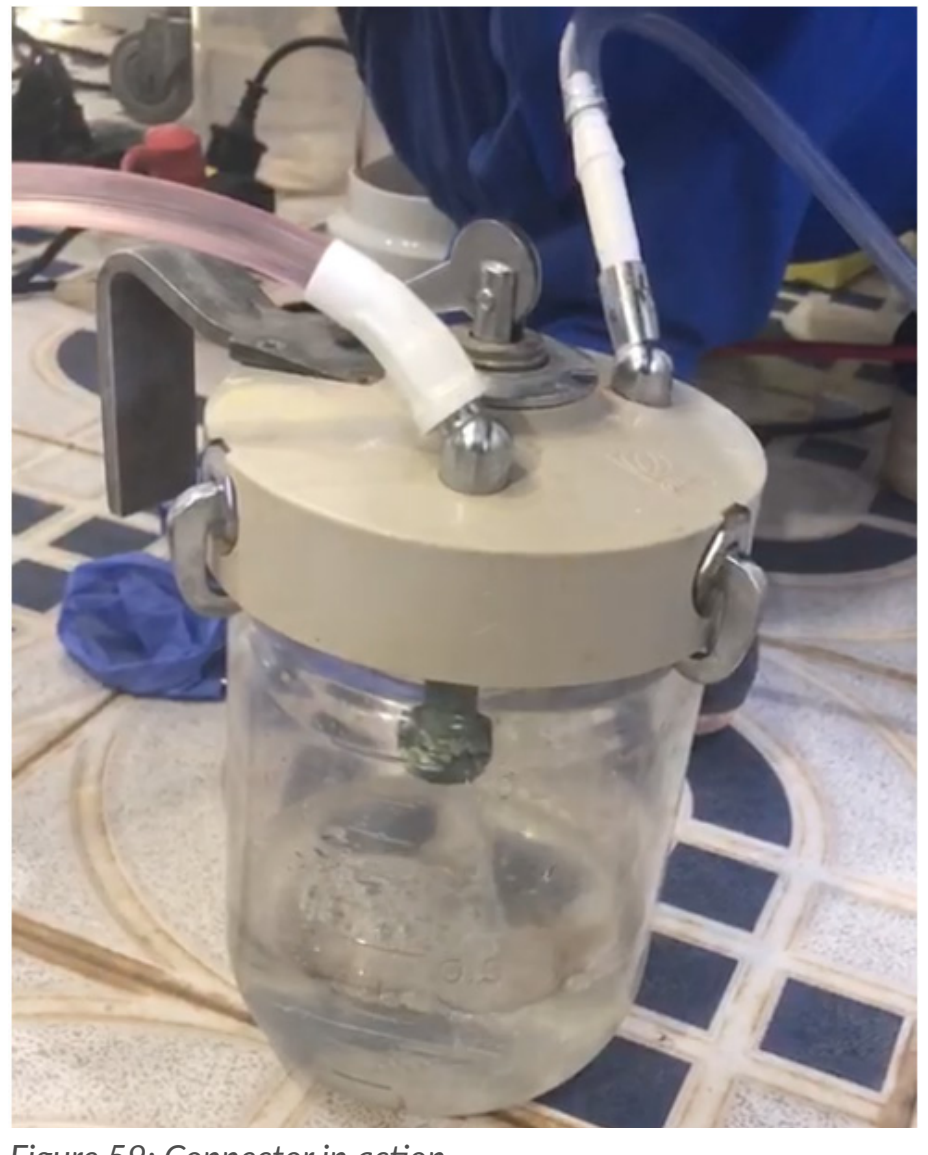

Figure 59: Connector in action 


\subsection{SYSTEM POWER}

The final design solution for System Power is a concept for a portable, rechargeable power-pack, based on a $12 \mathrm{~V}$, locally sourced car battery as the main power source (Fig. 60).

\section{PORTABLE POWER SYSTEM}

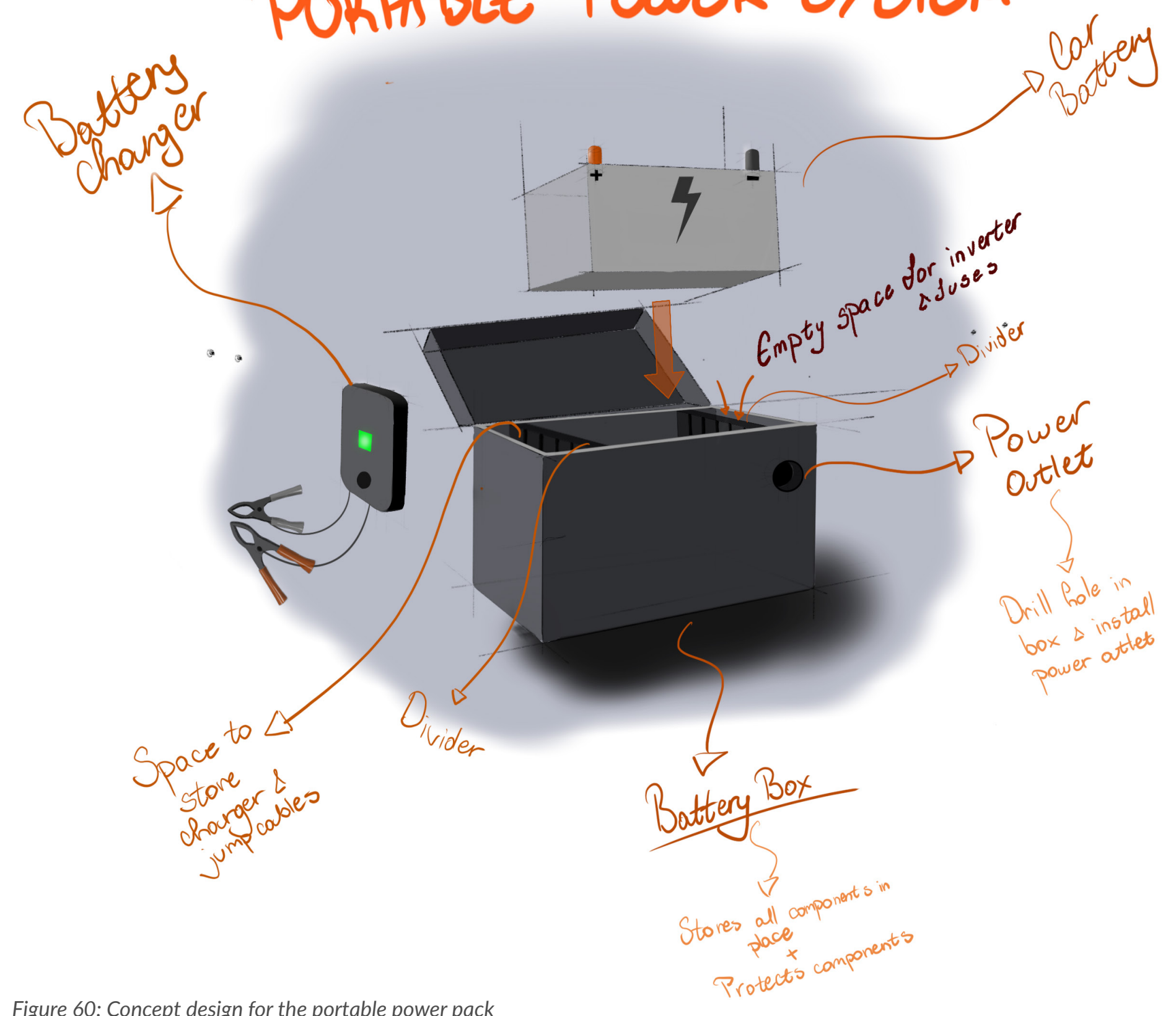

\section{System Features}

\section{Locally sourced components}

Every component in the system can be found at local hardware or automotive shores. In case of any sort of failure in the system, the components can easily be replaced by new ones or the expertise of the local repairmen can be used to repair components instead of pairmen can be
replacing them.

\section{Power for up to 2 hours}

The possibility of having a back up power source that can power a device for 2 hours gives a sense of security to the staff that no matter the conditions, in situations of power shortages, the surgery can continue safely without risking the health of the patient and the success rate of the surgical procedure.

\section{Automatic power pick up}

The presence of a contactor in the system allows it to detect when the line power drop so it can immediately start powering the device.

\section{Portable and protected from impact}

By putting the whole system in a box, the staff would be able to transport the power pack wherever they need around the hospital. The box would protect the system from environmental factors and impact. 



\section{(1) concuson}

\subsection{CONCLUSION}

With regard to the challenges of lack of consumables and frequent power cuts, the use of Masanaga's surgical suction pump can be improved with:

- Local, on-the-ground FDM 3D printing of PETG medical tubing connectors to connect mismatching consumables and

- Installing a portable, back-up battery power pack, built with a locally sourced $12 \mathrm{~V}$ car battery + locally sourced gadgets.

The staff of Masanga was thrilled for this possibility to improve the use of the suction pump.

"The nurses are very excited about the possibility of improving the suction"

- Emily, expat nurse at Masanga Hospital

The practice of 3D printing tubing connectors could lead Masanga towards a possibility of locally producing various other reusable medical consumables that they are in need of and that are fit for improvement through LM3D. This practice would however require the engagement of a designer or a BMET to aid them in discovering the possibilities for improving the use of other medical devices as well.

If this practice is proven to be successful, the staff of Masanga has the intention of expanding their produc tion and turning towards a Decentralized Local manufacturing approach. This means that in the future the team of Masanga could be able to produce consumables for other regionathospitals as well who have similar problems with a lack of consumables. To achieve this the staff of Masanga would need to perform:

\section{- Field research}

- Problem mapping

\subsection{PROJECT EVALUATION}

This chapter provides an evaluation on the extend to which the crucial steps in the project were satisfied.

- Solution framing

- Manufacturing

of relevant reusable medical consumables for other local hospitals in need.

As for System Connect, if the solution is proven successful, the same principle of powering could also be applied to the other surgical devices. A possibility to look into making a single system that would be able to provide power to multiple devices could also be interesting but it was deemed out of the scope of the project, but still worth looking into.

What about the future?

A decision has been made together with Masanga hospital that the project would continue after the graduation and as soon as the covid crisis settles down. The goal is to continue the project on the ground, with a field trip of around three months, a period during which the manufacturing of the connectors would be tested locally and the performance of the connectors could be brought to a TRL level 7, which means that the system Operational Environment. During this field trip the goal is to also train the staff on how to independently manufacture the tubing connectors without the need of an expat expert.

The field trip would also make it possible to locally source the components and build System Power togethe with the locals and map out how and where components can be fixed or replaced in case of a failure.
Method

The evaluation of the project and the word completed was done on several factors that were crucial during the project:

\section{- Contextual Analysis}

- Stakeholder Engagement

- Application of principles of Frugal Innovation

- Problem Definition and Framing

- Design Development Phase

- Final Design

\section{Contextual Analysis}

A grave disadvantage from the beginning of the project was the inability to perform contextual research through a field trip. Luckily, Jan Henk and Peter were there to validate every finding and to provide first hand insights that might not be possible to learn solely through desktop and literature research. However, in the end everything turned out well. The troubles and the stressing about getting the right pieces of information were worth it, as the project was able to satisfy al of the requirements set by the contextual analysis.

\section{Stakeholder Engagement}

The project had a ton of stakeholders involved from start to finish. Having a good relationship with the stakeholders resulted in getting priceless pieces of information that otherwise could not be gathered. Listening to their needs and recommendations was important as to avoid delivering a misguided solution for the defined challenges. What could have been beneficial during the design framing and development phases would have been the more serious engagement of the local nursing staff in the project. For convenience how ever it was easier to have one central contact at the hospital throughout the project.

Application of principles of Frugal Innovation During this project I discovered that Frugal Innovations, especially in the medical field are my passion in life. The years I have spent in humanitarian and philanthropic work have thought me the importance of giving the user a tool that they could use long term to improve their well being with personal engagement and with resources that are available to them, instead of just giving them a complete product that might not be functional in their context after a certain period of time. The principles and challenges of Frugal Innovation helped me stay focused and make logical and confident decisions on how to proceed further in the project.

\section{Problem Definition and Framing}

The inconsistency in gathering information that was caused by the pandemic made it really hard to structure and explain the decision making process at the end of the project. But with a little bit of luck (in terms of all 
$f$ the information arriving sooner or later) and a lot of hard work, it was possible to structure the process and come up with successful results.

\section{Design Development Phase}

Approaching the development through three different phases made me realize that in Design for 3D printing, all factors and actions depend on each other. Having the requirements and risks defined and redefined every step of the way helped me make sure to never miss out on any product defining factor.

The testing phase was intended to be even more advanced in the initial test plan, but the pandemic made organization quite complex. Therefore, in the future stages of the project it would be beneficial if extra test are done to improve the design solution even more.

\section{Final Design}

The final design solutions satisfied all of the requirements set for the project. However, changes and experiments can still be done to improve the printing quality of the connectors, especially the one with the smallest perimeters. Overall, the design solutions were a success and most importantly, warmly accepted by the client.

\subsection{RECOMMENDATIONS}

This chapter provides several recommendations that could further improve the final outcome of the project.

\section{System Connect}

1. Testing of possibility to print with flexible materials

The nursing staff at Masanga showed a very strong interest in having the connectors be flexible. Research showed that flexible materials are not suitable for the application, however the idea should be further inspected as there might be a way to print the connec-

tors flexible and still maintain the desired properties.

\section{Improved slicer settings for connector with small diameter \\ Changes in the slicer settings could result in improved} printing and layer adhesion of the small perimeters.

\section{Power of 3D printe}

Although never mentioned by the staff as a disadvantage, the reliability of power regarding the 3D printing process should be further examined. Print failure because of lack of power could be a problem for the manufacturing process

\section{Chemical testing with more samples}

The chemical test were performed with only a few samples, which does not give results that are as reliable as they should be. Repeating the tests with more samples could result in stronger design validation

\section{Active engagement of nursing staff}

As mentioned multiple times during the project, active engagement of the local nursing stuff can give amazing results for a project designed in such a context.

\section{System Power}

6. Building and testing of power system on the suction pump

Although the system is a proven concept that works, testing it in the context, with locally sourced components, on the suction pump, can only show whether the results would be as expected

\section{Recommendations for Masanga}

\section{Hiring a full time BMET}

A BMET that is always present at the hospital could be in charge of mapping the need for locally manufactured, 3D printed consumables and could be in charge of preparing the models for production. Together with the 3D printing staff, they could start the envisioned practice of locally producing reusable medical consumables. 


\section{REFLECTION}

$90 \%$ of the defining elements of my graduation happened by chance. On the same day that I arranged my mentor while photocopying, an accidentally overheard conversation got me to contact my client. What made no sense in the beginning became one the best experiences of my life.

My passion toward Design for Low Resource Settings began during the course Advanced Embodiment Design, but it was through this project that I realized that it is my passion and it is the field that I want to work in (at least for the time being).

As a Rotaractor and humanitarian, helping other people has always been my dream. Makes me think of that saying "Pick a job you like and you'll never have to work a day in your life".

I am a very impatient person by nature and always expect things to go exactly the way that I had imagined them. This project taught me that things sometimes do not work out as planned, but if you are brave and patient enough to stick around for the entire ride, fantastic things are waiting at the finish line. Naturally, the words "Trust the process" were heard during every coach meeting. I am glad that by the end of the project Mlearned how to enjoy the process and enjoy the little victories along the way.

On a similar note, my urge to strive for perfection and to reach where no man has reached before led me to being unaware of the real results that were happening around me. I am extremely thankful that my supervisors were always there to help me get back on track and focus on the present and tangible moment. Staying focused was definitely one of the hardest lessons that I learned at TU Delft, but it is a lesson that

The most beautiful part of this experience was my realization of how determined I can be when I have clear goals and a strong vision. Many experts and stakeholders were smothered with phone calls, emails and whatsapp messages during the process. I have a habit of getting emotionally at- tached to projects, but those are the projects that always end up being the best. Working with passion helped me take the project even further than I had initially imagined.

The initial goal that I had for my graduation project and the actual outcome ended up having almost nothing in common, but thanks to these little inconveniences, I got the chance to learn some amazing skills. I am glad that this project helped me develop in:

Performing remote contextual research Engagement and management of stakeholders Risk analysis and testing

$3 \mathrm{D}$ printing for medical devices.

With these skills (and many more to gather in the future), my intention as a Master in Industrial Design I intend to make healthcare and wellbeing available to everyone, one step at a time. And hopefully, with a great team around me. 


\section{REFERENCES} 1. Malkin, A. (2007), Design of Health Care Technolo-
gies for the Developing World, 9:567-87

2. Howitt, P., Darzi, A., Yang, G. et al., Technologies for global health., Lancet. 2012; 380: 507-535

3. Oosting, R. M., Wauben, L. S. G. L., Groen, R. S., Dankelman, J., 2018, Equipment for essential surgical care needs for novel design, Health and Technology (2019) 9:269-27

4. Malkin, A. (2007), Design of Health Care Technologies for the Developing World, 9:567-87

5. Aranda-Jan, C. B., Jagtap, S., Moultrie, J., (2016). Towards a Framework for Holistic Contextual Design for Lown 10(3) $43-63$ tings. International Journal of De-

6. Malkin, A. (2007), Design of Health Care Technologies for the Developing World, 9:567-87

7. Malkin, A. (2007), Design of Health Care Technologies for the Developing World, 9:567-87

8 .Dr. Jonathan vas Nunes, (2020, April), Personal interview

9. What is the framework for innovation? Design October), Available from: https://www.designcouncil. org.uk/news-opinion/what-framework-innovation-design-councils-evolved-double-diamond

10. Masanga Hospital: History, (Accessed 2020, revisited May-Oct.), Available from: https://www.masangahospital.org/about-masanga/history/

11. About the Masanga project: Masanga Hospital Rehabilitation P roject - MHRP, (Accessed 2020, revisited May-Oct.), Available from: https://www.masanga.dk/ om-os/

12. Achtergrondfilmpje 3D printing Lab in Masanga Hospital Sierra Leone, Available from: https://vimeo. able from:https://www.youtube.com/watch?v=U5Z7FND1zXI\&list=PLkEb876Cg3r-YWtJDt5uzWtxv3 Up $5 \mathrm{sMh} \&$ index $=26 \& \mathrm{t}=10 \mathrm{~s}$

14. Update Masanga Hospital Sierra Leone, (June, 2019) AFAS Netherlands, Available from https://www. 876Cg3r-YWtJDt5uzWtxv3 Up5sMh\&index=25
15. Masanga stories The Ministry of Health and Sanitation (Dec., 2018), Masanga Hospital, Available from: https.//WWw.youtube.com/watch?V=B2DloOQixag\&list=PLkEb876Cg3r-YWtJDt5uzWtxv3_Up5sM-
h\&index $=27 \& t=3 \mathrm{~s}$

16. vas Nunes, J. (April 2020) Personal Interview

17. van Raaij, F., (June 2020), Personal Interview

18. Jorgensen, P. B., (June 2020), Personal Interview

19. Dubbink, J. H., (June 2020), Personal Interview

20. Winter, J., (May 2020), Personal Interview

21. van Gaalen, M., (5-9 June, 2020), Email question-

22. van der Stelt, M., (5-9 June 2020), Email question23. Savonen, B., (2019), A Methodology for Triaging Printing in Low-Resource Environments, The PennsylPrite Engineering

24. European Commision, (2017), The European Medical Device Regulation, Accessed during internship (2019) at Crescent Tech B.V.

25. Aranda-Jan, C. B., Jagtap, S., Moultrie, J., (2016). Towards a Framework for Holistic Contextual Design for Low-Resource Settings. International Journal of Design, 10(3), 43-63

26. Agbana, T. et.al., (2019), Schistoscope: Towards a locally producible smart diagnostic device for SchisHumanitarian Technology Conference, Seattle, DOl: 10.1109/GHTC46095.2019.9033049 27. Malkin, A. (2007), Design of Health Care Technologies for the Developing World, 9:567-87

28. Oosting, R. M., Wauben, L. S. G. L., Groen, R. S., Dankelman, J., 2018, Equipment for essential surgical care in 9 countries across Africa: avallability, barriers (2019) 9.269-27

29. Bianchi, C., Bianco, M., Ardanche, M., Schenck, M., . Healthcare frugal innovation: A solving problem 30. Tran, V., Ravaud, P., Frugal innovation in medicine for low resource settings, Tran and Ravaud BMC Med- icine (2016) 14:102, DOI 10.1186/s12916-016-0651-

1. Arora, M, Girgas, Y (2018), Importance of Supply Chain Management in Healthcare in Third World Countries, International JOurnal of Supply and Operation Management, February 2018, Volume 5, Issue 1, pp.

32. Dr. Jonathan vas Nunes, (2020, April), Personal interview

33. World Heath Organization, (2011), Surgical Devic es: Apirator, Available at: http://www.who.int/medical devices/en/index.htm

34. Lamb, B., et. al, (2017) The Principles of Vacuum Clinical Application in the Hospital Environment, Ohio Medical, Fourth Edition

35. Mega Medical TV (March 25th, 2012), Operating a Portable Suction Pump - Demonstration, (Accessed 202, June), Available from: https://www youtube com watch?v=pqrT_abh-EM\&list=PLkEb876Cg3r-YWtJ Dt5uzWtxv3_Up5sMh\&index=1

36. Airway suction (Accessed 2020, revisited MayJune), Available from: https://www.sscor.com/ems suction_products

37. Surgical and airway suction (Accessed 2020, re visited May-June), Available from: https://www.me delahealthcare.com/en/solutions/professional-vacu-

38. Surgical suction and electrosurgery (PDF), Inspital, Available from: https://pdf.medicalexpo.com/pdf/ inspital-medical-technos:/pdfmedicalexpo-com/pdf/ surgical-2019/127077-215831.htm

39. Setting up Basic Suction Equipment for Suction ing a Patient, (August 28th, 2017) (Accessed 2020 May) Available from: https://www.youtube.com/ watch? $v=m q G g b b x N b x E \& l i s t=P L k E b 876 \mathrm{Cg} 3 r-Y W t$

40. Dr. Diederich Cornelisse, (2020, June), Video call interview

41. Dr. Elske Sitsen, (2020, June), Video call interview

42. Dr. Jan Henk Dubbink, (2020, September) Whatsapp messaging

43. What Are the Most Common Complications of Suc- tioning? (2020, June), Available from: https://blog.sscor. com/what-are-the-most-common-complications-ofsuctioning

44. World Health Organization, (2010), as cited by Aranda-Jan et. al (2016)

45. Pushak N., Foster V. (March 2011). Africa Infrastructure Country Diagnostics. Country report. Sierra Ine's Infrastructure: A Continental perspective, The World Bank, Washington DC

46. Malkin, A. (2007), Design of Health Care Technologies for the Developing World, 9:567-87

47. Robinson C. (2019). Primary health care and famiy medicine in Sierra Leone. African journal of primary health care \& family medicine, 11(1), e1-e3. https://doi. org/10.4102/phcfm.v11i1.2051

48. World Health Organization, (2020), Sierra Leone, (Accessed 2020, June) Available at: https://www.afro. who.int/countries/sierra-leone

49. World Data, The climate in Sierra Leone, (Accessed 2020, June) Available at: https://www.worlddata.info/ africa/sierra-leone/climate.php

50. Wikipedia, Healthcare in Sierra Leone, (Accessed 2020, June), Available from: https://en.wikipedia.org/ wiki/Healthcare_in_Sierra_Leone

51. Energypedia, Sierra Leone Energy Situation, (Accessed 2020, June), Available from: Sierra Leone Energy Situation

52. Google Maps, Distance from Masanga to Freetown (Accessed 2020, July)

53. Titoun, Easy Solar, Sierra Leone (2020, September), Personal communication

54. Design World (2013), Critical Steps in Selecting Fluid Connectors for Medical Applications (Accessed 2020, July), Available at: https://www.designworldonline. com/critical-steps-selecting-fluid-connectors-medi- 
Engineering

cal-applications/

55. Industrial Specialties Mfg. \& IS MED Specialties (2019), Barb connectors in depth - design and function, (Accessed 2020, July), Available from: https:// www.industrialspec.com/about-us/blog/detail/barbconnectors-in-depth-design-and-function

56. Jesper Winter, (2020, May), Personal Interview

57. Martin Verwaal, (2020, August), Personal Interview

58. Wim de Wilt, (2020, September), Personal Interview

59. DIY Tryin, (May 26th 2014), Turn a Car Battery Into an Emergency Power Charger, (Accessed 2020 August), Available from: https://www.youtube.com/ watch? $v=$ Lc3rtn5ducY\&list $=$ PLkEb876Cg3r-YWt $J$ Dt5uzWtxv3_Up5sMh\&index=21

60. Designed by Instinct, (July 3rd, 2011), Build a portable power pack for $\$ 25$, (Accessed 2020, August), Available from: https://www.youtube.com/watch?v=7Tf3fngKA-c

61. All3DP, (2020), Flexible Filament for 3D Printing Simply Explained, (Accessed 2020, August), Available from:https://all3dp.com/2/flexible-3d-printing-filament-which-should-you-chose/

62. All3DP, (2020), TPE Filament: The Basics \& Best Brands 2020, (Accessed 2020, August), Available from: https://all3dp.com/2/tpe-filament-explained-and-compared/

63. All3DP, (2020), TPU Filament: The Basics \& Best Brands 2020, (Accessed 2020, August), Available from: https://all3dp.com/2/tpu-filament-explained-and-compared

64. All3DP, (2020), Best Printing Temperatures for PLA, PETG, TPU and Nylon, (Accessed 2020, August), Available from: https://all3dp.com/2/the-best-printing-temperature-for-different-filaments/\#: :tex-
$\mathrm{t}=\mathrm{PLA} \% 20$ prints\%20best\%20at\%20around,20\%20 and $\% 2060 \% 20 \%$ C2\%BOC.\&text $=$ PLA $\% 20$ produc es\%20the\%20best\%20results\%20with\%20proper\%20 cooling.

65. Ultimaker Tough PLA Sheet, Available from: https:// ultimaker.com/download/74971/UM180821\%20 TDS\%20Tough\%20PLA\%20RB\%20V11.pdf

66. Xiao, J., Gao, Y. The manufacture of 3D printing of medical grade TPU. Prog Addit Manuf 2, 117-123 (2017). https://doi.org/10.1007/s40964-017-0023-1

67. Savonen, B., (2019), A Methodology for Triaging Product Needs for Localized Manufacturing With 3D vania State University, The Graduate School, College of Engineering

68. Savonen, B., (2019), A Methodology for Triaging 68. Savonen, B., (2019), A Methodology for Triaging Printing in Low-Resource Environments, The Pennsylvania State University, The Graduate School, College of Engineering 69. Savonen, B., (2019), A Methodology for Triaging
Product Needs for Localized Manufacturing With 3D Printing in Low-Resource Environments, The Pennsylvania State University, The Graduate School, College of Engineering

70. Industrial Specialties Mfg. \& IS MED Specialties (2019), Barb connectors in depth - design and function, (Accessed 2020, July), Available from: https:// www.industrialspec.com/about-us/blog/detail/barbconnectors-in-depth-design-and-function

71. Design World (2013), Critical Steps in Selecting Fluid Connectors for Medical Applications (Accessed 2020, July), Available at: https://www.designworldonline. com/critical-steps-selecting-fluid-connectors-medical-applications/

72. Savonen, B., (2019), A Methodology for Triaging Printing in vania State University, The Graduate School, College of
73. Julie Fleischer, (2020, August), Personal Interview

bGImaWVyPUFHOEFYRkFQVZZXQIMmZW5jcnwdGVkSWQ9QTAYNTA4MTgXMIAOVVVMMUW0OUhOJmVUY35 CHRIZEFSWQ9QTAZMik4MzlxRUtKUOsXVEZEMEpGJndpZGdldE5hbWU9c3BfYX74. Jan van Frankenhuyzen, (2020, August), Personal RmJmFjdGlvbj1jbGlja1JIZGlyZWNOJmRvTm90TG9nInterview

75. Industrial Specialties Mfg. \& IS MED Specialties, 82. Wim de Wilt, (2020, September), Personal InterWHAT IS DUROMETER? - ELASTOMER AND PLASTIC HARDNESS, (Accessed 2020, September) Available from: https://www.industrialspec.com/about-us/ $\mathrm{blog} /$ detail/what-is-durometer-elastomer-and-plastic-hardness

76. All3DP, 2018, 3D Printing Layer Height: How Much Does It Matter?, https://all3dp.com/2/3d-printer-layerheight-how-much-does-it-matter/

77. Auto Batteries.com, Compare Car Battery Technologies: Which Battery Technology is Right for Your Vehicle, (Accessed 2020, November), Available from: https://www.autobatteries.com/en-us/battery-technology-types/overview

78. Power Electronics (2010), Selecting Fuses: Simple Procedures to Get the Right Overcurrent Protection for DC-DC Converters (Accessed 2020, November), Availabe from: https://www.powerelectronics.com/technologies/passive-components/ article/21863300/selecting-fuses-simple-procedures-to-get-the-right-overcurrent-protection-for-dcdc-converters

79. Circuit Digest (2018), Introduction to Different Types of Inverters, (Accessed 2020, November), Available from: https://circuitdigest.com/tutorial/different-types-of-inverters

80. Power Stream, (2019), How to calculate battery run-time, (Accessed 2020, November), Available from: https://www.powerstream.com/battery-capacity-calculations.htm

81. Battery Charger, Available from: https:// www.amazon.com/NOCO-GENIUS1-Fully-Automatic-Temperature-Compensation/ dp/B07W46BX31/ref=sr_1_1_sspa?_encoding $=U T F 8 \& \mathrm{c}=\mathrm{ts} \& \mathrm{dchild}=1 \&$ key words $=$ Bat tery+Chargers $\&$ qid $=1600434462 \& s r=8-1$-spons $\&$ ts

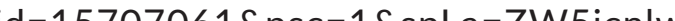


92 Improving the use of surgical suction pumps in Sierra Leone 